OECDpublishing

\title{
THE OPERATORS AND THEIR FUTURE
}

THE STATE OF PLAY AND EMERGING BUSINESS MODELS

OECD DIGITAL ECONOMY PAPERS

September 2019 No. 287 


\section{Foreword}

This report, "The Operators and their Future: The State of Play and Emerging Business Models", was prepared by the Working Party on Communication Infrastructure and Services Policy (WPCISP). It explores how communication operators may develop in the future. The report takes a five to ten year perspective and examines trends in the industry around different operator models.

The paper was approved and declassified by written procedure by the Committee on Digital Economy Policy on 3 May 2019 and prepared for publication by the OECD Secretariat. It was drafted by Bengt Mölleryd (PTS Sweden), Verena Weber and Sam Paltridge from the OECD Secretariat. The authors received contributions from Maximilian Reisch from the OECD Secretariat and WPCISP delegates regarding their country experiences. It was prepared under the supervision of Sam Paltridge and Verena Weber.

It contributes to the OECD Going Digital project, which aims to provide policy makers with the tools they need to help their economies and societies prosper in an increasingly digital and data-driven world. For more information, visit www.oecd.org/going-digital. \#GoingDigital

Note to Delegations:

This document is also available on O.N.E. under the reference code:

DSTI/CDEP/CISP(2017)5/FINAL

This document, as well as any data and any map included herein, are without prejudice to the status of or sovereignty over any territory, to the delimitation of international frontiers and boundaries and to the name of any territory, city or area. The statistical data for Israel are supplied by and under the responsibility of the relevant Israeli authorities. The use of such data by the OECD is without prejudice to the status of the Golan Heights, East Jerusalem and Israeli settlements in the West Bank under the terms of international law.

(C) OECD 2019

You can copy, download or print OECD content for your own use, and you can include excerpts from OECD publications, databases and multimedia products in your own documents, presentations, blogs, websites and teaching materials, provided that suitable acknowledgement of OECD as source and copyright owner is given. All requests for commercial use and translation rights should be submitted to rights@oecd.org 


\section{Table of contents}

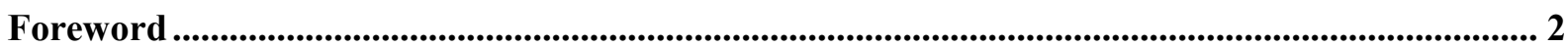

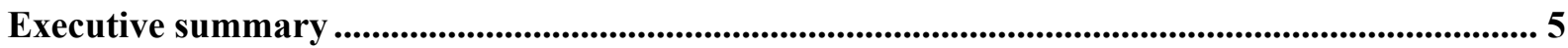

The Operators and their Future: The State of Play and Emerging Business Models....................... 8

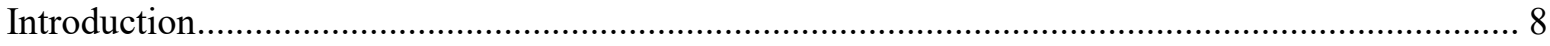

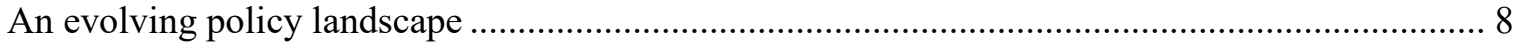

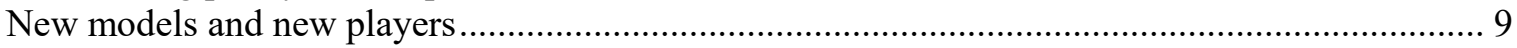

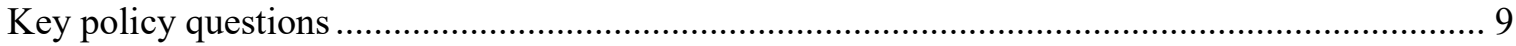

Broad trends in the financial performance of the communication industry ................................. 10

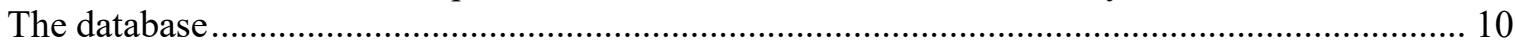

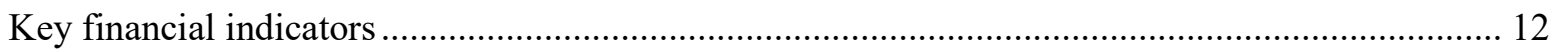

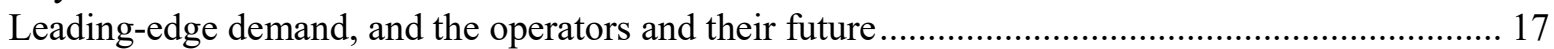

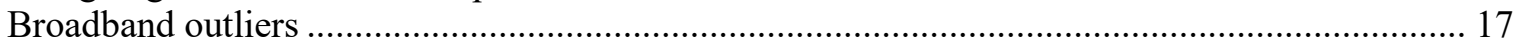

Average speeds in the OECD viewed through the metric of online video games........................... 20

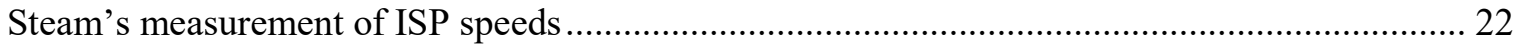

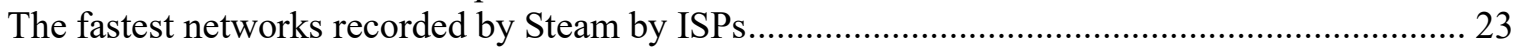

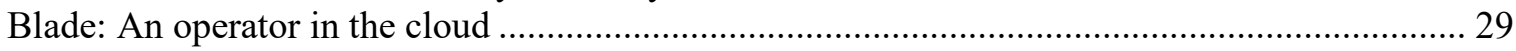

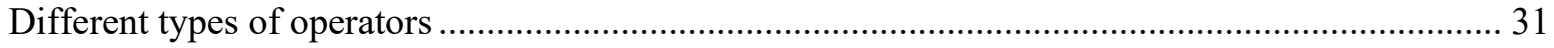

Traditional (vertically integrated) mobile and fixed broadband providers..................................... 31

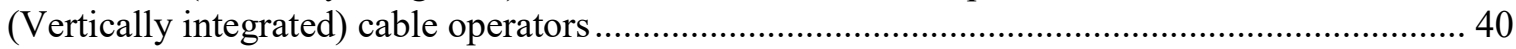

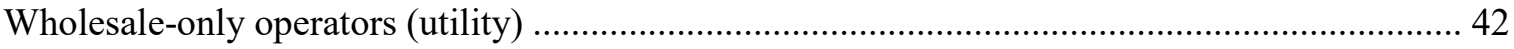

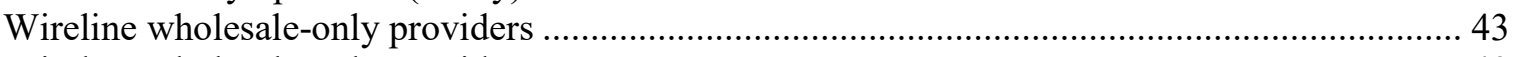

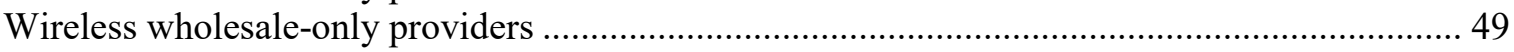

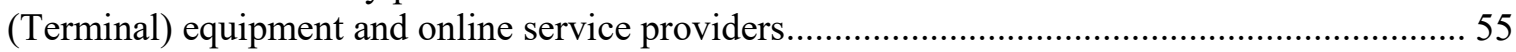

Examples of technologies that may influence the operators and providers ..................................... 58

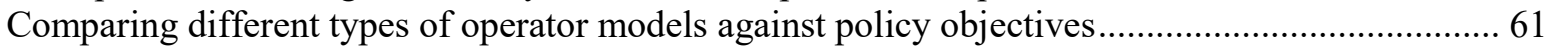

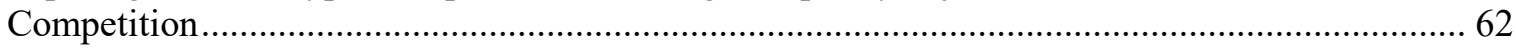

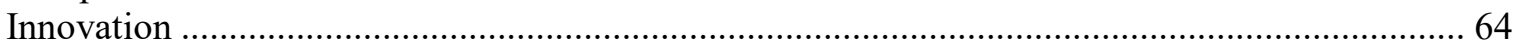

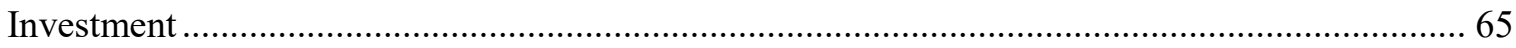

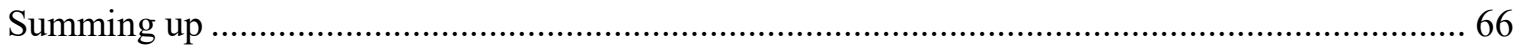

Annex I.A. Selected wholesale-only wireless tower and distributed antenna systems (DAS)

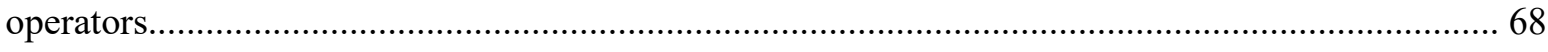

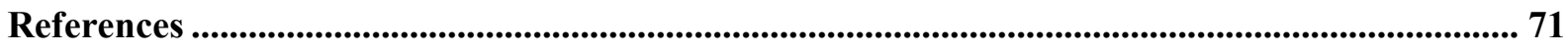

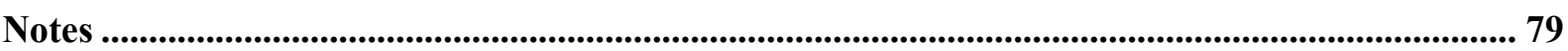

\section{Tables}

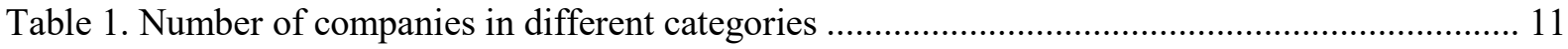

Table 2. The fastest 25 networks recorded by Steam for ISPs in OECD member countries* ............. 25

Table 3. Cumulative total return for American Tower (AMT) versus other indexes ............................52

Table 4. Overview of Google's investment in submarine fibre cables................................................ 57

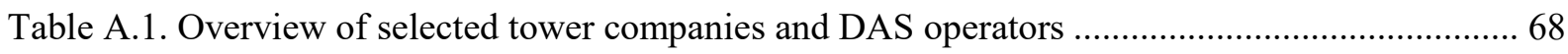




\section{Figures}

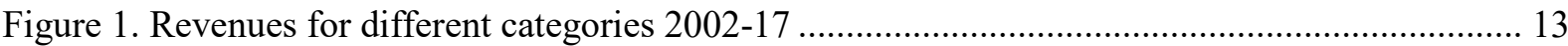

Figure 2. Average EBITDA and EBIT margins for the operators 2002-17 ...................................... 13

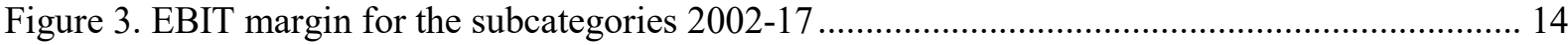

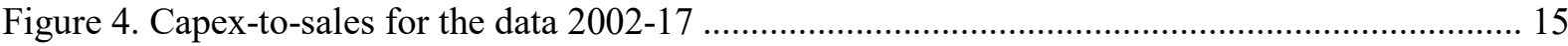

Figure 5. Capex-to-sales: Challengers vs. Incumbents................................................................. 16

Figure 6. Return on invested capital for telecommunication carriers, and cable \& satellite as total

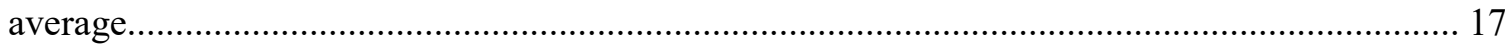

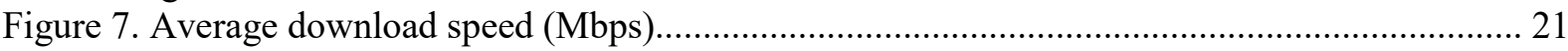

Figure 8. Average download speeds recorded by Steam and Akamai ............................................... 22

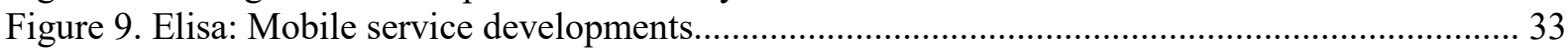

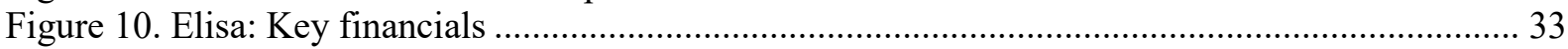

\section{Boxes}

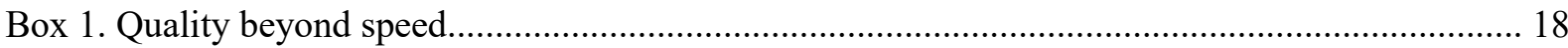

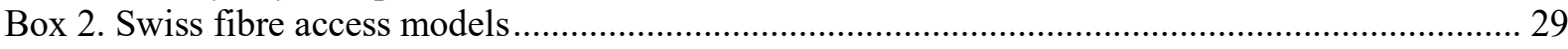

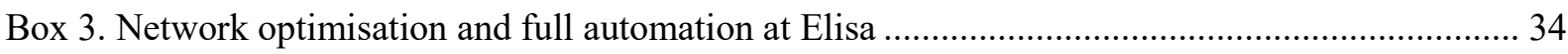

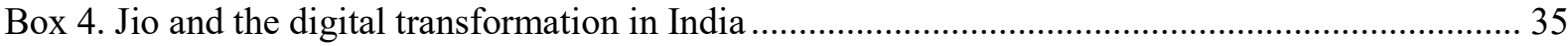

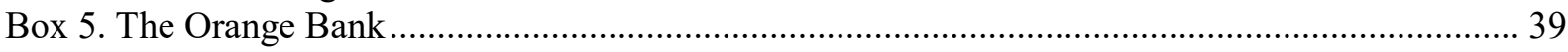

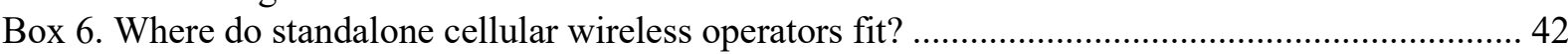

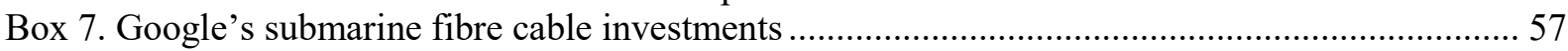




\section{Executive summary}

In OECD member countries, no longer a single entity provides all communication infrastructures and services. Rather, different models have emerged for providing connectivity and services. How will operators provide connectivity and services in the future? Will they be viable drivers of digital economies?

This report examines the financial performance of the industry and business models over a five-ten year period. It looks at leading-edge demand (which is expected to become mainstream over the period). At the same time, it recognises that such demand is only one prism through which to view the future of operators. ${ }^{1}$ The approach has been chosen as we believe leading edge demand and speed to be outstanding indicators for the future landscape of operators. However, there are different analytical approaches that can be considered.

Special attention is paid to gamers, one of the most demanding high-speed user communities of the Internet. The report subsequently assesses different types of operators that provide access to communication services. Finally, it explores issues and challenges that may affect the balance between infrastructure competition and shared use.

The report highlights three overall trends, which influence the dynamics of the market.

i) A broader variety of services from telecommunication operators. Operators are acquiring media companies and Internet firms. They are also moving into new industries such as advertising, banking, health services, home monitoring systems, insurance and sports franchises.

ii) Increased specialisation rather than diversification. This development, partially illustrated by the move of wholesale-only operators to share infrastructure, covers both fixed and wireless networks. Proponents say that financial, organisational, regulatory and market factors are driving the trend. The shift indicates the development towards what they see as a utility-like business model.

iii) Expanded role of terminal equipment and online service providers that now serve end users. These providers are aided by applications with a global reach and propelled by their leadership in research and development (R\&D).

\section{Key findings}

- Revenues for the communication industry more than doubled between 2002 and 2017. Growth has, however, been flatter in the second half of this period compared to the steep rise in the first half.

- Vertically integrated operators: Traditional vertically integrated telecommunication operators have faced pressure in recent years. Growth rates for some access products have declined, while new business lines have sometimes had lower margins. In response, they are striving to drive costs down and increase profitability. At the same time, they are changing their business and operating models to increase revenues. Some are moving into other parts of their value chains with new services or leveraging their data for analytical services (i.e. big data). Others are moving into novel industries for communication operators such as banks or digital health services. 
- Cable broadband operators have invested in infrastructure via upgrades using the Data Over Cable Service Interface Specification (DOCSIS) over their coaxial networks. Like traditional telecommunication operators, cable operators are being challenged by content owners using the Internet to deliver content directly to end users. Increasingly, content owners are joining with other players to offer "skinny bundles" or à la carte services. These players range from fixed telecommunication providers and mobile operators to over-the-tops (OTTs). Overall, however, vertically integrated operators are still robust players as infrastructure operators and holding their own in terms of Internet access. This is especially the case where users do not have multiple alternative infrastructure or service providers and vertically integrated operators are adept at using new technologies to provide services. At the same time, new content delivery platforms and services may emerge from the use of new technologies (e.g. blockchain).

- Wholesale (vertically separated) operators have grown in importance over recent years. They range from backbone wholesalers in the fixed market, to tower companies in the mobile market, to integrated wholesale networks in both the fixed and mobile communication market. This category of operators may significantly change the dynamics of communication markets. It could be a more cost-effective model for investment in broadband networks if these operators can generate attractive propositions for others to use their infrastructure. For operators in the future, the various wholesale-only models could help save costs, increase use of networks and perhaps minimise risk compared to retail businesses. At the same time, wholesale-only players need many service providers to use a network. The key features required for successful wholesale-only businesses are stable financial performance, long investment horizons, strong free cash flows and an incentive to provide upgraded infrastructure as demand arises by retail providers.

- (Terminal) equipment and online service providers had become the largest enterprises in the world as measured by market capitalisation by 2017. In addition, they are the leaders in R\&D expenditure. Aside from the devices and online services for which they are best known, these companies have been expanding their own communication infrastructures. They are now among the largest providers of backbone fibre networks, including undersea cables. Equipment and online service providers have also entered voice and chat markets dominated by the traditional vertically integrated operators. They are increasingly invested in video content production, which some leverage for their advertising businesses. In addition, they have launched subscription services, with integrated linear television and on-demand shows. In the area of the Internet of Things and artificial intelligence, online service providers have become leading players for voice assistance systems. These companies will be key players in the evolution of communication infrastructure and services. To date, however, they have largely not become Internet Service Providers. This suggests that while they are extremely effective competitors for OTT services, traditional and new access operators maintain advantages in this field.

The different types of operators have transformed their business models, portfolios of offered services and technologies, as well as entered each other's markets. Voice and video are still important, but are often no longer the core businesses of telecommunication and cable providers. In response to changing demand, a combination of access and data transmission has replaced voice and video. 
Some technologies on the horizon such as blockchain, personal cells (pCells), artificial intelligence, virtual reality may further augment or disrupt the future approaches of operators. A range of intelligent communication devices and assistants is now available for "smart homes", automobiles and so forth. Meanwhile, augmented and virtual reality may define how people interact with communication services. While smartphones have become the interfaces most used for communication services, companies such as Microsoft and Magic Leap are working on ways to place interactive images before viewers. Such a future era of spatial computing will likely create new directions for all players.

What might all this mean for policy making and regulation? First, it is important that all the different operator models are able to meet policy objectives. In some cases, this may require regulation. Policy makers should fully assess the impact of the different models on competition, innovation and investment based on a careful market analysis. This should include the number of competitors, the potential co-existence of different operator models and historical developments in a market. Finally, the report provides some general insights as to what kinds of issues and challenges may be more inherent to some models than others, which may likely be at the forefront of considerations around the balance between infrastructure competition and shared use. 


\section{The Operators and their Future: The State of Play and Emerging Business Models}

\section{Introduction}

Today's communication infrastructures reach further into every aspect of economic and social life than ever before. This is nowhere more evident than in the growing integration of communication infrastructures. Such integration is designed to increase efficiency in earlier transformative technologies such as highways (e.g. connected cars/traffic lights/streetlights) and electricity (e.g. more efficient production, distribution and monitoring).

The increasing use of digital infrastructures across economies and societies paves the way for new services, products and applications. This, in turn, potentially transforms how people live and work. How are these services best provided? What can be learned from different models applied across the OECD?

Looking into the future is never easy. As its starting point, this report analyses the evolution of the industry's financial performance. It then describes how the industry itself is evolving, looking at potential models for providing access to high-speed communication services. To that end, it analyses leading-edge demand as this may become mainstream over the next five to ten years. Furthermore, it examines the type of companies that serve this demand.

The report then clusters and compares different categories of operators. It outlines the most important developments in these categories before signalling emerging technologies that may influence operators in the future. It concludes by comparing different types of operators against policy objectives.

\section{An evolving policy landscape}

OECD member countries recognise that access to communication infrastructures is essential for several reasons. First, it prevents "digital divides". Second, it creates opportunities to address policy priorities. Key policy areas include health, education, transportation, public administration, civic engagement and, more broadly, economic development and competitiveness.

Policy and regulatory approaches may have like-minded objectives to extend high-speed connectivity, including in rural and remote areas. However, they often differ on how to achieve this goal across the OECD. The reasons for the different approaches depend on a myriad of factors. These include inherited networks and their capabilities, the experience and outcomes of market liberalisation, and population densities.

Historically, OECD member countries had different models of service provision. Ownership of operators, for example, could be public, private or co-operative. Operators could also be integrated suppliers by service or geography (e.g. splits between local, regional, national and international). For most of the 20th century, until liberalisation opened markets for new players, these operators had a monopoly in infrastructure and services. 
Different types of companies emerged to deploy fixed and wireless communication infrastructures or some form of communication services using a particular or unspecified network infrastructure. These range from the traditional fixed and mobile telecommunication providers to cable operators. In other cases, new operators initially had their main business or activities in other areas. Municipalities, for example, added communication services to other utilities they traditionally provided such as water and energy. In addition, providers of over-the-top (OTT) services started to deploy their own network infrastructure.

\section{New models and new players}

Today, perhaps the one element shared across all markets is the lack of a single entity that provides all infrastructure and services. Rather, there are different models for connectivity. In some locations this is due to splits between infrastructure and services along the lines of wholesale and retail. In other locations, there are simply different networks (e.g. fixed, wireless or multiple operators of these infrastructures).

While markets share the lack of a single entity, they have other key differences. Even with models that are more integrated, different companies may provide their own elements of infrastructure. For example, some companies specialise in providing towers for wireless connectivity that are different from the mobile service providers that use these facilities. Others may share infrastructure such as towers or backhaul/backbones. Finally, integrated players no longer provide a single set of services (e.g. telephony or cable television). Rather, they often provide a bundle of communication services. In addition, they are often active in areas that were once unrelated beyond basic connectivity (e.g. money transfer, security, advertising, data analytics and many more).

In recent decades, the liberalisation of telecommunication markets has opened to new entrants. Players with a range of different business models, levels of infrastructure and service provision have also emerged. While an incumbent in one country may be a new entrant in another, it is possible to broadly assess how traditional players have performed financially against challengers.

Cable broadband providers, for example, are an identifiable category. While they are often incumbents in cable television, they are new entrants in the provision of telecommunication services. At the same time, a number of new players only offer wholesale infrastructure and some only offer retail services.

\section{Key policy questions}

Given the important role communication services play, policy makers should be informed about the development of the communication industry, about the different operator types that provide access to communication services and about how the industry might evolve.

Understanding these developments will help policy makers find answers to a set of policy questions. For example, how do the different models provide the incentives for the investment required in areas such as the next generation of wireless networks $(5 \mathrm{G})$ or deeper deployment of fixed infrastructures, such as fibre optics? Will different models provide the coverage, quality of service and, most importantly, the competitive choice to meet the increasing demands of digital economies and societies?

These are fundamental policy questions for the future of high-speed broadband connectivity. Policy makers must strike a balance between promoting end-to-end 
infrastructure competition, the shared use of networks through models such as wholesale retail separation, or some combination of both.

It is, of course, unlikely that one size fits all cases. All models have advantages and disadvantages. They also have substantial implications for the future of regulation. Specifically, they determine the level to which markets can influence infrastructure and service provision. This, in turn, has consequences for private and public investment, ensuring effective competition and so forth.

\section{Broad trends in the financial performance of the communication industry}

This section sets out financial data from just after the turn of the century until the present. This provides a broad indication of industry trends in areas such as revenue, investment and profitability. By categorising providers of services, the report aims to see how traditional telecommunication operators have performed next to challengers, how larger operators have performed against smaller players and so forth. This level of performance is important because scale is often used to justify mergers, though global trends are only one consideration in any particular case.

Over the past several decades, few sectors have undergone more change than the communication industry. In large part, the increasing demand for the services that underpin transitions to digital economies and societies has driven the change. This has gone handin-hand with substantial growth in subscriptions for new fixed and mobile access, as well as with a shift in demand from services such as traditional telephony to data. Meanwhile, some key metrics, such as the sector's total revenue, have grown only modestly in recent years. This has led operators to upgrade networks and offer new services, invest substantially and seek to increase efficiency and reduce costs.

The transition to Internet Protocol (IP) networks has facilitated a wider range of new service providers to compete with traditional telecommunication operators. All these players are Autonomous Systems (i.e. they have their own networks). However, some networks are more extensive than others. To limit the scope of Autonomous Systems, all of which invest in digital infrastructure, the report focuses largely on those providing access infrastructure or broadband access services. It also examines the financial performance of the largest broadband access and service providers.

This approach excludes companies such as Apple, Amazon, Facebook and Microsoft, although they have extensive fibre networks. It also means excluding Alphabet, one of the largest global investors in undersea cables and backbone networks. In the case of Google Fibre, Alphabet is also a local access unit. However, Alphabet is not primarily a provider of local access infrastructure.

Conversely, the analysis includes cable broadband networks. Originally, these players offered only cable television services. However, they upgraded their facilities to offer a full range of telecommunication services. Meanwhile, other players have entered the market, including firms previously categorised as real estate, construction or wholesale infrastructure providers. These firms provide elements of telecommunication infrastructure (e.g. the towers used for wireless communications) as their main focus or were created to provide standalone wholesale access facilities.

\section{The database}

The report compiles financial information for 179 telecommunication operators from all parts of the world for 2002-17 based on data from Bloomberg. ${ }^{2}$ These companies have a 
combined market capitalisation of USD 3.0 trillion and employ 5.1 million people. In the following, the report uses the Bloomberg Industry Classification System to discuss financial metrics over time. Bloomberg divides the companies into four categories: i) telecommunication carrier; ii) cable \& satellite; iii) infrastructure construction; and iv) consumer electronics. Moreover, the companies are either defined as incumbent or new entrant based on their origin (Table 1).

Overall, the data indicate that profit margins are relatively stable for the identified sectors and that investment levels are around $15-17 \%$ in relation to sales. A comparison between the different categories shows a couple of notable points:

- Telecommunication carriers continue to invest at around $16 \%$ of sales. This means that the actual investment depends on how revenues are developing.

- Cable \& satellite players generate higher earnings before interest and taxes (EBIT) margins than telecommunication carriers, underscoring the profitability in their operations. Telecommunication carriers generate higher levels of return on capital investment (ROIC) compared to the other categories. Return levels were trending down in 2016 before turning upwards in 2017.

- Incumbents are maintaining a strong position. Compared to challengers, incumbents invest more and deliver higher EBIT margins, as well as higher ROIC levels. Incumbents are competitive compared to challengers. This means they will continue to be a force in the market and certainly also strive to be among the future operators.

The ability of the incumbents to remain competitive will depend on, among other things, their flexibility to adapt to technological innovation, consumer preference, and demand and supply conditions.

Table 1. Number of companies in different categories

\begin{tabular}{rrrr}
\hline & Challenger & Incumbent & \multicolumn{2}{c}{ Total } \\
\hline Cable \& satellite & 36 & 0 & 36 \\
Consumer electronics & 3 & 0 & 3 \\
Infrastructure construction & 11 & 0 & 11 \\
Telecommunication carrier & 74 & 55 & 129 \\
Total & 124 & 55 & 179 \\
\hline
\end{tabular}

The database does not list all operators and differs slightly from categories discussed later in the document. However, it captures the leading players around the world. This means that the output provides the best available broad indicators of some key financial metrics for communication operators.

As a first step, the report included all players with a market capitalisation of over USD 1 billion providing telecommunication or cable services. At a second stage, the authors added some further cable and satellite companies and infrastructure construction companies, as well as non-listed companies. This means the data set includes a few smaller players; they were considered relevant for assessing some elements of infrastructure developments such as investment trends (e.g. publicly funded wholesale networks).

In addition, Sony is included as Sony Networks is one of the largest Internet Service Providers (ISPs) in Japan. ${ }^{3}$ More companies could certainly have been added, driven by the inclusion of adjacent sectors. However, to keep the data set manageable, the report 
applies sector definitions used by Bloomberg, as well as the minimum level of market capitalisation.

The operators come from 55 countries; financial data have been reported in 46 currencies and converted to USD. The exchange rate is based on a yearly average with one data point per month. The data cover the period 2002-17. In the case of Bloomberg data, company data for new entrants are included from the time of public listing. This means that data are not available for all companies for the entire period. However, the analysis aims to capture general trends in the sector as a whole and in the different categories. As a result, the approach likely provides reasonable indications of developments over the period.

\section{Key financial indicators}

Data have been collected for five parameters:

i) Revenue (i.e. sales). This is the amount of money that a company actually receives during a specific period, in this case per annum.

ii) Earnings before interest, taxes, depreciation and amortisation (EBITDA). This is an indicator of a company's financial performance for operations. However, it does not consider the cost of debt and depreciation, which are substantial for capital-intensive operators. EBITDA, commonly used in relation to revenues or sales, is referred to as the EBITDA margin. This gives a sense of how the operations of a business are performing.

iii) EBIT margin. This represents operating earnings over operating sales. By considering depreciation and amortisation, it aims to show how a business is doing.

iv) ROIC. This aims to indicate how effectively a company uses the sources of capital (equity and debt) invested in its operations. It is calculated as net operating profit after tax/total invested capital. Net operating profit is EBIT multiplied by one minus the tax rate. Total invested capital measures the total amount of money that has been endowed into a company by the shareholders, bondholders and all other interested parties.

v) Capital expenditure (capex) in relation to sales. Capex represents the funds used by a company to acquire, upgrade and maintain physical assets. These assets include property, plant or equipment, such as infrastructure for networks.

The parameters are presented and examined in more detail in the following.

The total revenue for all of the operators in the database is USD 1.94 trillion for 2017 and USD 1.88 trillion 2016 (Figure 1). This represented a 3.2\% growth over this period. In 2017 , telecommunication carriers made up $83 \%$, and cable \& satellite made up $12 \%$. These were followed by selected companies categorised by Bloomberg under consumer electronics (4\%) and infrastructure construction (1\%). 
Figure 1. Revenues for different categories 2002-17

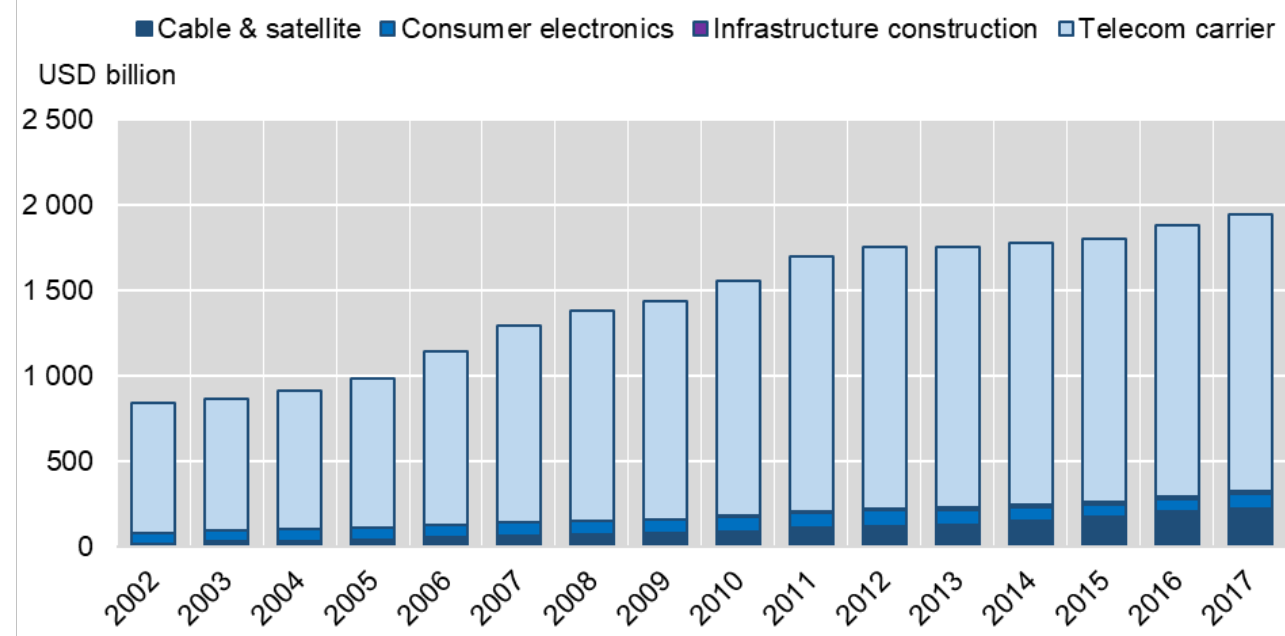

Source: Bloomberg Financial dataset (2018).

The EBITDA indicator aims to measure a company's cash flow. It does not consider any financial cost, depreciation or amortisation. Rather, it attempts to indicate how the operating business is performing. In 2017, the average EBITDA margin for all operators was $30.9 \%$ compared to $30.5 \%$ in 2016 . However, the EBITDA margin has declined over the previous decade. The operating profit margin (EBIT margin) considers depreciation and amortisation. The EBIT margin has hovered around $14-15 \%$ over the period under consideration (Figure 2).

Figure 2. Average EBITDA and EBIT margins for the operators 2002-17

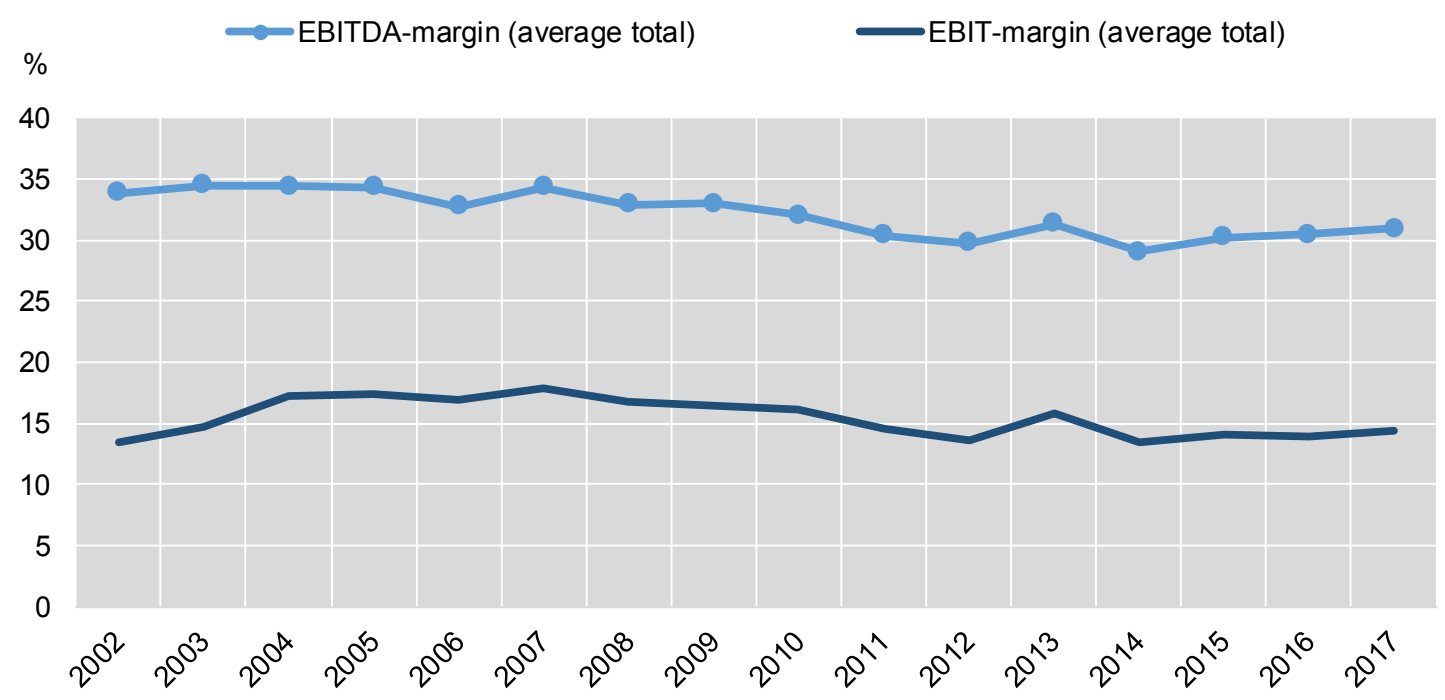

Cable \& satellite operators have consistently generated higher EBIT margins compared to telecommunication carriers between 2010 and 2016. However, they were aligned in 2017 (Figure 3). Notably, the operators listed under infrastructure construction have seen the 
highest EBIT margins. Such margins are required to generate return on their investment levels, which are consistently higher compared to the other categories.

Figure 3. EBIT margin for the subcategories 2002-17

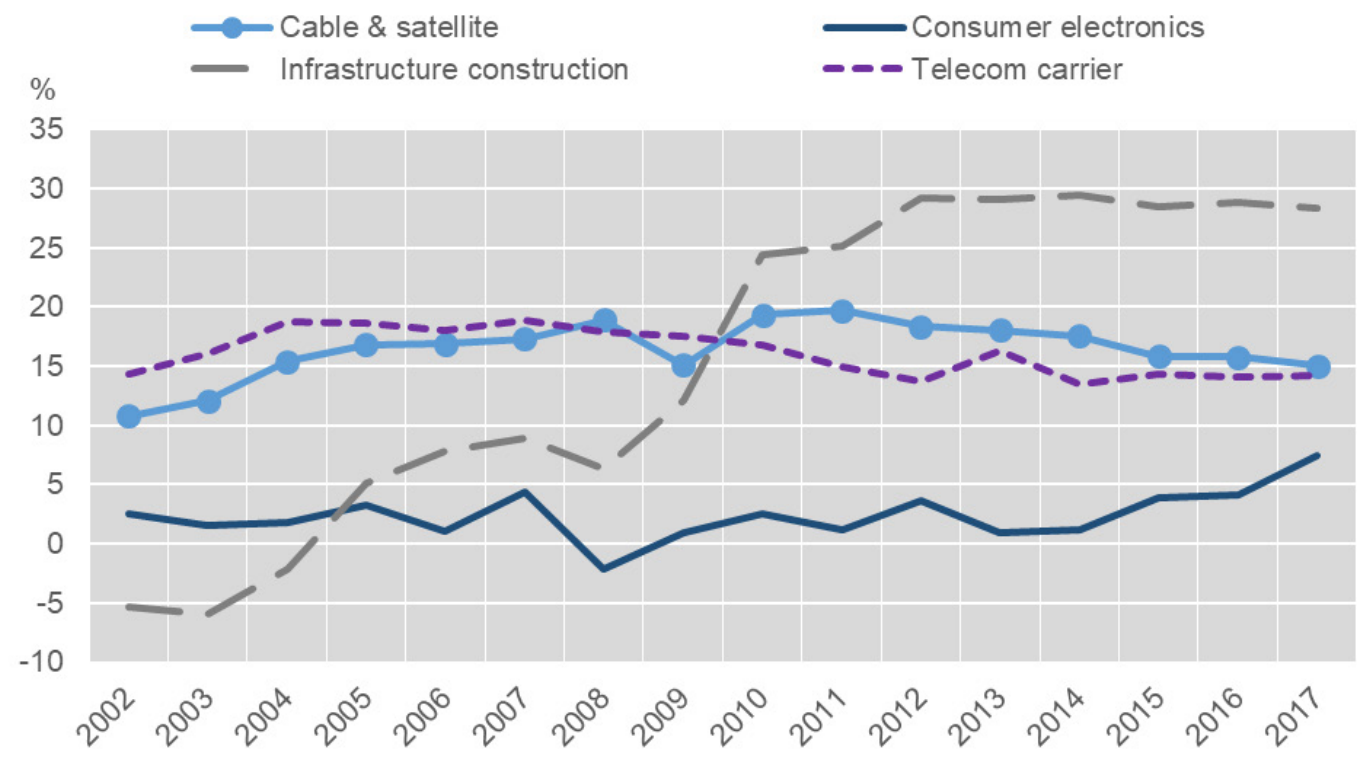

Infrastructure is a prerequisite for communication network operators. This means the sector is capital-intensive and requires continuous capital expenditure. In 2016, the average capex-to-sales ratio for all the companies was $15.8 \%$, a slight increase from $15.7 \%$ in 2017 (Figure 4). Meanwhile, the average capex over the last 15 years has been $15.5 \%$. Telecommunication carriers appear to invest consistently more than cable \& satellite, whose investment during the last ten years has been below the industry average. This may also reflect that telecommunication operators own more wireless networks than cable companies. This means such operators have associated expenditure on successive generations of technology (i.e. $3 \mathrm{G}$ to $4 \mathrm{G}$ and so forth), as well as upgrades of fixed infrastructure. 
Figure 4. Capex-to-sales for the data 2002-17

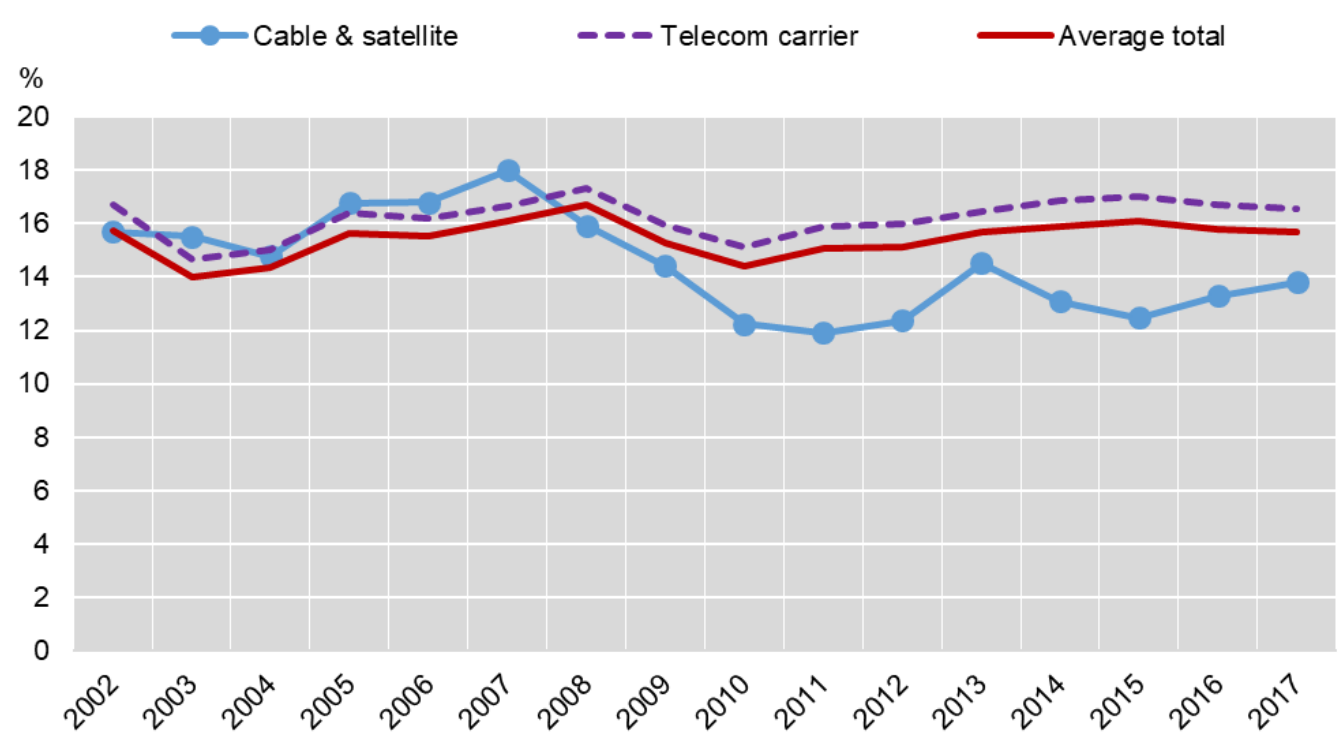

Aside from classification as one of the four groups, the players have been defined as either incumbents or challengers to facilitate analysis. Incumbents may be new entrants (challengers) or incumbents outside their traditional markets, due to acquisitions. However, the groups can also be distinguished as historical operators versus new entrants.

Given that incumbents are generally vertically integrated operators, infrastructure is an intrinsic part of their business. As a result, incumbents invest continuously in infrastructure, while challengers have varying levels of investment. The level of capex-tosales has consistently been higher for incumbents compared to challengers up to 2017 (Figure 5). However, challengers, including cable \& satellite operators, increased their level of investment during 2017 compared to the year before. 
Figure 5. Capex-to-sales: Challengers vs. Incumbents

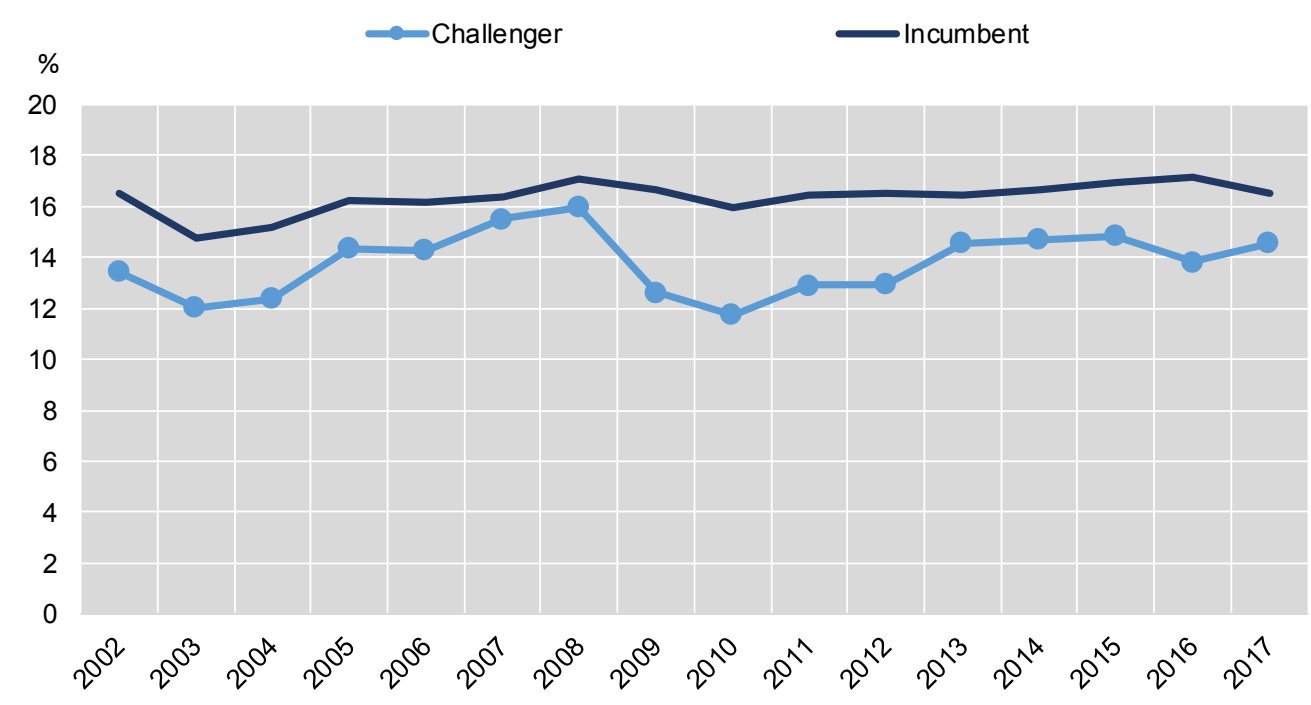

Given the capital-intensive nature of the communication industry, profit margins must be sufficiently high to generate a reasonable return on investment. The level of depreciation and investments should, over time, be aligned. This means that with a capex-to-sales ratio of around $15-16 \%$, figure 5 indicates the level of depreciation in relation to revenues that will be deducted going from EBITDA to EBIT.

Ultimately, the operating profit in relation to the invested capital determines the ROIC. While the ROIC for the different categories varies over time, the return rate trended downwards in 2016 before turning upwards in 2017. Although cable \& satellite players generated higher EBIT-margins, telecommunication carriers outperformed them with consistently higher returns on invested capital (Figure 6). 
Figure 6. Return on invested capital for telecommunication carriers, and cable \& satellite as total average

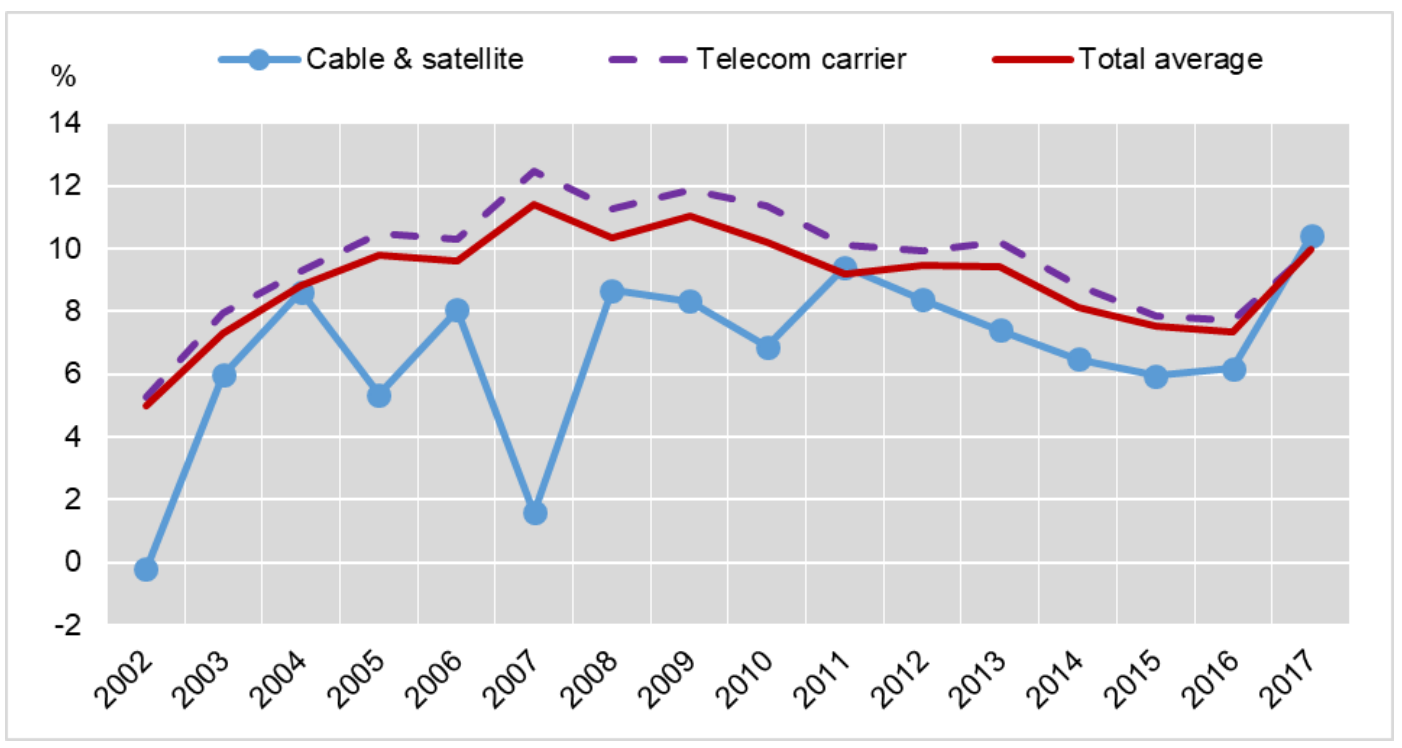

\section{Leading-edge demand, and the operators and their future}

This section examines how operators are responding to the leading-edge demand. This, in turn, may shed light on how the sector could look in the future. In considering models that communication operators may adopt, the report examines the most demanding high-speed users of the Internet. This could indicate what services will look like for a broader user group. Network operators undoubtedly provide infrastructure to cater to the higher demands of business users. For example, they support closely related mobile services and so forth. However, they regularly highlight online video streaming and gaming as areas of investment to attract customers.

The report uses metrics available for different categories of users for two reasons. First, data are not generally publicly available for business users. Second, data from firms such as Akamai cover demands from all types of users. Statistics from a company like Netflix, for example, could provide a metric such as average speeds experienced in servicing video content to its users. This is relevant because such services are reported to be among the largest generators of online traffic.

\section{Broadband outliers}

William Gibson said the future is already here, though not evenly distributed (NPR, $2018_{[1]}$. In the case of broadband access, there have always been outliers in terms of penetration, prices paid and the quality of services offered. Outliers may also provide indicators for more general industry trends, as they are often at the forefront of broader change.

Several quality measures exist (Box 1), including speeds offered to users. Today, in the OECD area, the leading advertised download speed is 10 Gbps. Only a small number of consumer offers are available at that level in limited locations, such as Japan and Switzerland (OECD, 2017 $\left.{ }_{[2]}\right)$. Meanwhile, in the United Kingdom, BT has trialled a 
business offer using fibre optic cables at $100 \mathrm{Gbps}$ and conducted laboratory trials up to 400 Gbps (Hardy, 2017 ${ }_{[3]}$ ).

\section{Box 1. Quality beyond speed}

While bandwidth speed is one metric to gauge overall performance, other measures of quality will become increasingly important for operators in the future. Many of these are in place today. However, as economies progress towards a world of "Connected Everything", operators and verticals will need to demonstrate improved service levels across a range of key performance indicators.

The need for improved response times ${ }^{4}$ between devices and compute nodes will grow, supporting many vertical use cases. Vehicles, industry and eHealth will measure success in time. 5G technology is promising one millisecond of delay for the radio element; the move towards full fibre will support this increasing need. Operators are increasingly looking to drive compute power to the edge of their services to improve and support these time-critical and fledgling services.

Operators will also increasingly be measured by assurance of delivery across their networks. For instance, critical services will need fewer errors ${ }^{5}$ and delays than today for quality key performance indicators to make a difference. As consumers and service consumption patterns evolve towards higher levels of online activities, greater "error free delivery" will be required and expected.

The need for operators to protect themselves and their customers in the future is growing. Reported levels of hacking of Internet of Things devices and home routers to access personal data have elevated security considerations in the minds of both consumers and policy makers. As such, trust will become a key quality metric by which to measure operators and verticals.

With the continued march towards a Connected Everything, industry and policy makers will need to constantly adapt approaches to defining and measuring service quality.

Experience shows it might take a decade or more before such high speeds are widely available in all countries. Just after the turn of the century, for example, operators in Korea advertised broadband access at $10 \mathrm{Mbps}$, which at the time was a pacesetter. Meanwhile, somewhat strikingly, Korea had a broadband access penetration of more than twice the next best performer in the OECD (Canada) and nearly 14 times the OECD average (OECD, $\left.2001_{[4]}\right)$. Today, those levels of speeds and penetration are very much baselines across the OECD, something that nonetheless took nearly two decades to accomplish.

Two factors drove the increase in broadband access speeds in countries like Korea and Japan: competitive markets, and the desire to meet demonstrated demand in environments with a high population density. These factors hastened the deployment of fibre optic technology. This, in turn, enables operators to offer higher speed services to businesses and consumers.

No single business model ensures operators will be among those offering the fastest commercial speeds to consumers. In the countries mentioned, together with New Zealand, Sweden, the United States and others, 1 Gbps offers to consumers are increasingly common, with different market structures. Even in these countries, it will take time for these offers to be more widely accessible based on the geographical availability of next 
generation access (e.g. Fibre to the Premises [FTTP], DOCSIS 3.1). It will also take time for this to be reflected in national average speeds observed from different perspectives.

The download speeds advertised by communication operators are, of course, different than the average speeds experienced at the national level by most consumers and small businesses. Countries with broader deployments of fibre, or other next generation access technologies, have on average much higher speeds than those that rely more on earlier generations.

Larger business users tend to be much more demanding than consumers. However, it is often impossible to break out the average broadband speeds they receive from leased lines or other forms of broadband access from national averages. At the same time, the indicators of the actual speeds experienced by users from firms such as Akamai ${ }^{6}$ encompass a crosssection of all types of users.

Netflix recommends users to have the following connection speeds to stream video: $3 \mathrm{Mbps}$ for Standard Definition; $5 \mathrm{Mbps}$ for High Definition; and $25 \mathrm{Mbps}$ for Ultra High Definition (Netflix, 2018 $8_{[5]}$ ). On average, across OECD member countries, the company generally reports speeds from $2 \mathrm{Mbps}$ to $5 \mathrm{Mbps}$ across the networks of different operators to reach their customers (Netflix, 2018 $\left.{ }_{[6]}\right)$. A household with multiple users watching different Netflix screens at Ultra HD requires a suitable Internet connection. However, the speeds noted will not test the leading broadband offers let alone today's outliers.

Players of online video games, who are among the most demanding users of high-speed Internet access, can be considered an alternative group of users. As with companies such as Akamai and Netflix, service providers of these games have the scale to generate useful indicators of the performance of different networks spread around the world. This includes data on individual networks and also aggregated statistics at the national level.

To put individual game platforms in perspective, Microsoft's Xbox Live had 53 million active users per month around the world by mid-2017 (Microsoft, 2017 $\left[7^{7]}\right)$. At the same time, Sony's Play Station Network had 70 million active users per month, while Steam, a digital distribution platform, had 67 million active users (Sony, 2017 ${ }_{[8]}$ ).

Netflix had 117.5 million subscriptions by the end of 2017 (Netflix, 2017 ${ }_{[9]}$ ). Like Netflix, platforms such as Steam, by their very nature, have many millions of users online at the same time. In mid-2017, Steam had 33 million users online each day and peaks of 1 million concurrently. Such networks are also growing rapidly. Steam's active users, for example, were growing by 1.5 million each month as of mid-2017 (Geek Wire, 2017 ${ }_{[10]}$ ).

In recent years, broadband access has enabled the industry to transform the market for games. In the past, users purchased physical packages with games. Now their games are digitally distributed. Depending on the business model, users subscribe or pay for games as services.

High-speed access is critical for downloading large files and keeping them updated. It is also vital for users of games, where latency can be critical to their experience. Today, online games can have many hundreds of thousands of users playing the same games. This means that services need to be delivered over networks for the same users to share the experience. This model will likely become even more prevalent as technologies such as augmented or virtual reality become a larger part of the industry's products. 


\section{Average speeds in the OECD viewed through the metric of online video games}

Since quality of service is so important to all parts of its value chain, the online video game industry provides a unique category of Internet use. The providers of the equipment and services used for games and much of the user population strive to extract the maximum performance of those elements they can influence. The same is true for many of the ISPs providing final access services to their customers. In fact, sometimes ISPs develop offers especially for avid game players. Examining the experience of platforms for game distribution and usage in terms of network performance is therefore a relevant indicator both to compare different countries and ISPs. Furthermore, it could provide insights into how operators might develop in the future.

Steam is one of the largest platforms for video game users around the world. It also provides an extensive set of statistics on the experience accessible from an online global traffic map. Published metrics include the total bytes downloaded in a country, the proportion of downloads within Steam's global total traffic and average download rates on a national basis. For the United States, some of these data are also available state by state.

Towards the close of 2017, Steam users across the OECD experienced average speeds of 29 Mbps. Remarkably, Korean users were accessing Steam at three times that rate and around twice the average rate recorded for the next two fastest countries - Sweden and Japan (Figure 7). Such a large difference between one country and others has not been observed across the OECD since the early days of the broadband era.

Two approaches can be used to examine why users in some countries experience higher speeds than others. One looks at indicators available nationally, such as the types of technologies in use. The other examines the performance of individual networks. The latter attempts to determine why Steam users on some specific networks experience higher speeds than others.

With respect to national indicators, the determining factor is likely the proportion of access technologies that are sometimes described as next generation in relation to total broadband access lines. The three countries with the highest speeds recorded by Steam are Korea, Japan and Sweden. These are also three of the four countries with the highest penetration of FTTP. The fourth, Latvia, sits just above the OECD average for download speeds for Steam.

The other countries above the OECD average, including Latvia, tend to have higher proportions of cable broadband networks in their technology mix. In addition, these countries, such as the Netherlands, Belgium, the United States and Canada, all position among countries with the most widespread cable broadband coverage. This suggests these networks have been upgraded to offer higher speeds with technologies such as DOCSIS 3.1. Hence, they rank above average for the OECD area. 
Figure 7. Average download speed (Mbps)

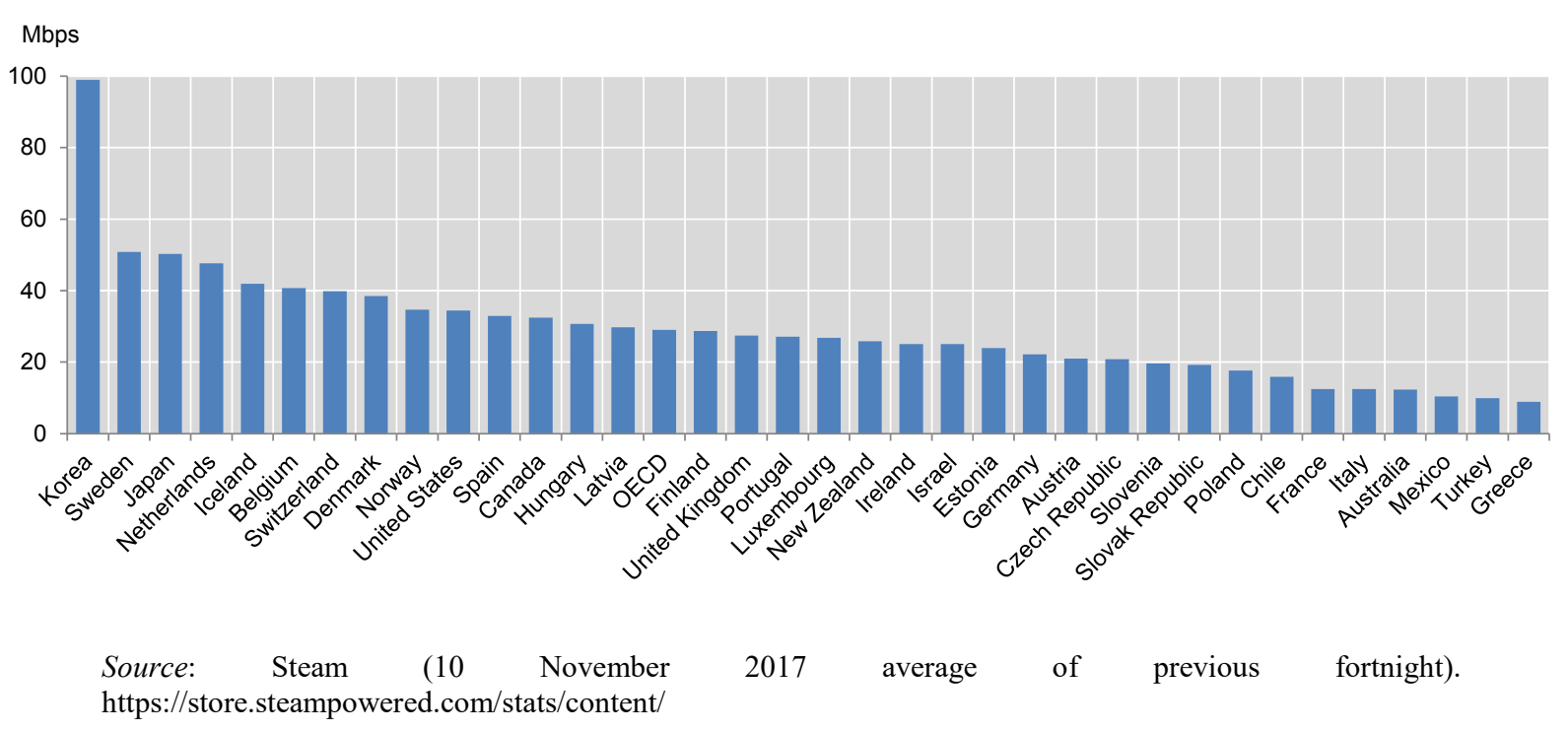

The Steam methodology is just one way to look at speeds on the Internet. While Steam only reports speeds for gamers, its data are consistent with data provided by Akamai. Specifically, the highest-performing countries according to Steam are also among those with the highest average speeds recorded by Akamai (Figure 8). The differences between both vantage points highlight the speeds recorded to gamers using Steam compared to the much broader spectrum of Internet use reflected by Akamai's data.

A large proportion of fibre, or some other next generation access technology, appears relevant to the experience of Steam users on a national basis. However, if this were the only consideration, then Sweden and Japan would likely record similar results to Korea. Nonetheless, those countries with high proportions of next generation networks have likely laid an important foundation. The most demanding communities can leverage the benefits of these networks. This explains the larger gaps for some countries than others between the results for Steam and Akamai. 
Figure 8. Average download speeds recorded by Steam and Akamai

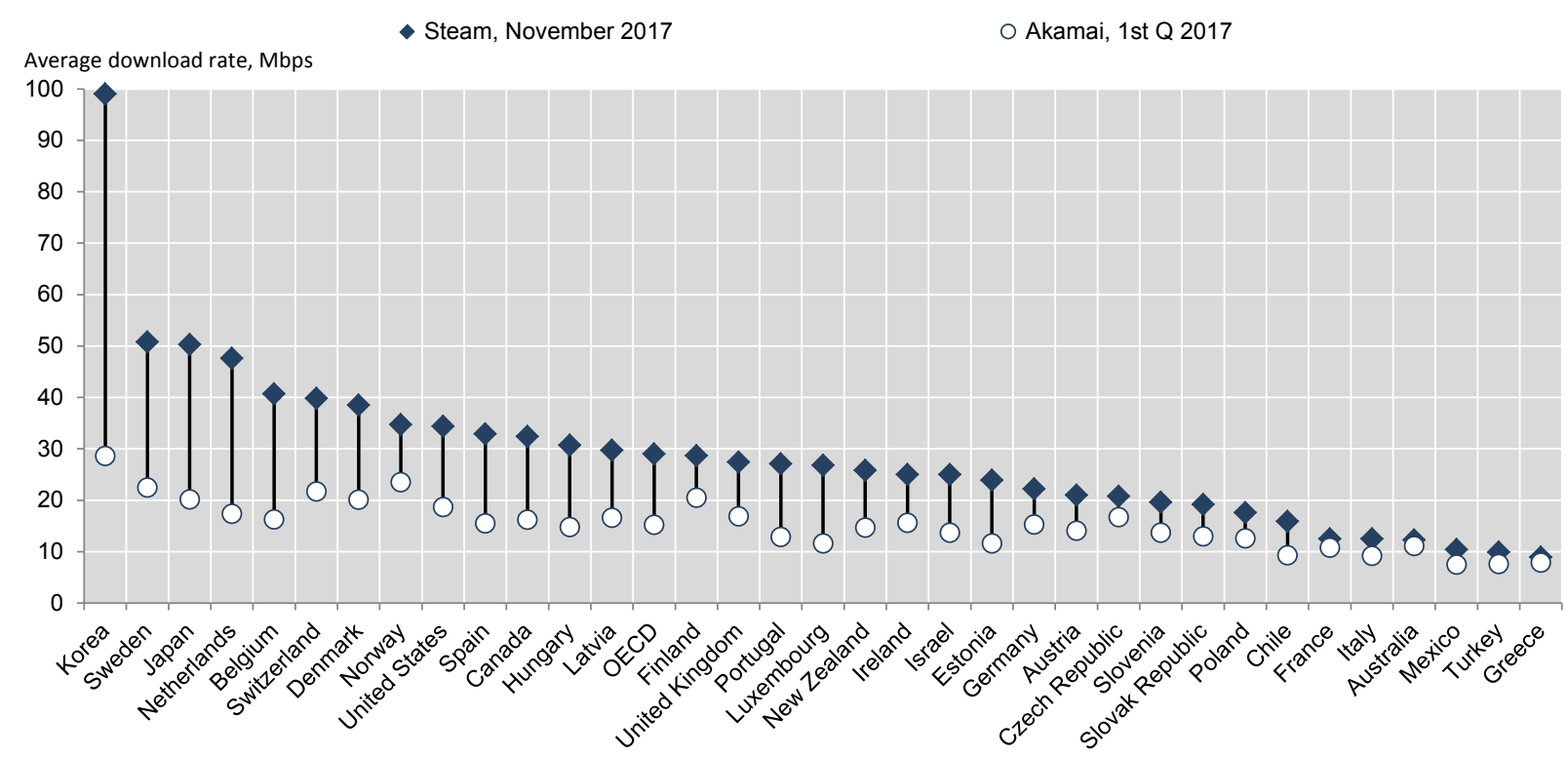

Note: Akamai data were not available for Iceland.

Source: Steam (10 November 2017 average of previous fortnight); Akamai, 1st Q 2017. https://store.steampowered.com/stats/content/

Different parts of the gaming ecosystem and users may be equally motivated to achieve the highest levels of performance. If this is true, then the experience observed with different networks needs to be examined. Such an analysis may help identify today's outliers among network operators. It can explain how providers with the highest speeds have used the available next generation platforms as springboards to enhance performance.

This analysis has one caveat. The Akamai data excludes, to the extent possible, identifiable mobile networks. In contrast, Steam includes access speeds for gamers on both fixed and mobile networks in the national statistics. Steam shows these networks separately if it can identify the relevant operator. In November 2017, for example, Orange is shown as a single entry in the top ten providers in France whereas Iliad Free appears twice. In other words, the performance of Iliad's fixed and mobile networks is shown separately.

\section{Steam's measurement of ISP speeds}

Steam's data record the performance experience by its community across countries. They also record the operators it detects as providing Internet access for these users. For each country of the world, the data set contains the ten most popular operators. They are recorded as providing access for Steam users and ranked by the number of bytes delivered to them. The data also record the average speeds experienced.

The ranking of ISPs correlates closely with their market share by subscriptions, although it does not always coincide. In Finland, for example, the regulator publishes the top four ISPs by subscriptions and groups smaller ISPs under other providers. In June 2017, the Finnish ISPs providing fixed line broadband ranked by size were Elisa $(35 \%)$, Telia Finland (29\%), DNA (26\%), the Finnet Group (8\%) and others (2\%) (Traficom, 2018 $8_{[11]}$ ). For Steam, in November 2017, the top five ranked ISPs were Elisa, Telia Finland, DNA and Elisa Mobile followed by Kaisanet (part of the Finnet Group). 
Unlike the Finnish regulator, Steam includes Elisa Mobile in its data. As of June 2017, Elisa was the largest mobile network operator (MNO) in Finland. It had 38\% of the market compared to Telia Finland (34\%) and DNA (27\%). The mobile market in Finland has the largest average use of mobile data per subscription compared to other countries (OECD, $\left.2017_{[2]}\right)$. In part, this is encouraged by companies such as Elisa charging by access speed rather than metred data usage for its mobile users. This is why players such as Elisa in Finland or Iliad Free Mobile in France appear in the top ten operators in their country for Steam. These companies are separately identifiable and have unlimited data access or large caps (i.e. Free Mobile has 50 GB for its $4 \mathrm{G}$ network).

Users with operators that offer unlimited data (Elisa) or high data caps (Iliad) do not necessarily experience higher or lower average speeds on a particular technology. For November 2017, Iliad's fixed network had an average of 9.1 Mbps for Steam. Conversely, its mobile network recorded $15.9 \mathrm{Mbps}$. For Elisa, it was the reverse order. The fixed network recorded 24.8 Mbps and the mobile network 17.3 Mbps.

For networks not identifiable as purely fixed or mobile, the inclusion of both technologies may increase or decrease their average. In France, for example, Orange is the largest player. It does not have a separate entry for fixed and mobile and the average speed was $13 \mathrm{Mbps}$. This was roughly the equivalent speed for Iliad based on a simple average of their fixed and mobile network. Meanwhile, Bouygues Telecom (Fixed) and Bouygues Mobile recorded speeds of 11.6 Mbps and 11.3 Mbps, respectively. For countries with higher mobile speeds and generous or unlimited mobile data offers, the proportion of gamers on mobile networks is likely larger, as in France and Finland.

Steam data may provide a leading indicator of market share. Placing aside the caveat of technology, in the sense that regulators generally treat fixed and mobile services as distinct markets, the Steam data provide a continuous indicator of the rankings of broadband access networks. This is measured in terms of size of data transfers for a large community of users. While this does not replace traditional approaches, it may be a complementary indicator due to its timely availability.

\section{The fastest networks recorded by Steam by ISPS}

In terms of the outlook for operators, the report examines the six fastest providers in OECD countries (Blade, Init7, Korea Telecom [KT], SK Telenor and Sony Networks). It also looks at MyRepublic in Singapore, as it is also the fastest ISP in Australia, New Zealand and Indonesia.

The selected operators have a range of different business models. They all have autonomous system numbers and their own networks, but the amount and type of physical infrastructure vary enormously. At one end, historical incumbents like KT provide their own end-to-end infrastructure. At the other end, a company like Blade has its own network, servers and so forth. In some ways, Blade can be considered the entity most reliant on the cloud. Given that users can access the service from any device on any network, it is less reliant on any specific network. In between these two approaches are ISPs that have regulated and commercially negotiated access to "last mile" access networks, which they combine with their own facilities.

In general, factors that seem key in the performance of the leading ISPs are the following:

- All the ISPs among the top 25 recorded by Steam use next generation access networks (e.g. FTTP, DOCSIS 3.1); the group that uses FTTP had the fastest speeds. 
- No single market structure guarantees an ISP will be among the leaders; both endto-end providers and regulated access providers are among the leaders.

- The ISPs with the highest speeds took measures to ensure superior performance through routing or other factors under their control (e.g. peering).

- The ISPs note, or imply through their business model, that it's critical for them to maintain as much control as possible over services offered to customers. This enables them to control quality, as well as to innovate (e.g. 2 x 1 Gbps in Singapore).

- They all operate in highly competitive markets.

The fastest access providers recorded by Steam in November 2017 can be ranked with the top 25 shown in Table 2. As might be expected, those countries with a higher proportion in the top 25 were also those with the highest national average. Korea, for example, had 5 ISPs in the top 10, while Sweden (5) and Japan (4) were also well represented in the leading 25 .

In addition, the top 25 include some of the largest ISPs in some countries. In Korea and the Netherlands, for example, the largest ISPs are KT and Ziggo, respectively. In Switzerland, the two UPC operators represent the second and third largest. In Sweden, Com Hem represents the second largest. 
Table 2. The fastest 25 networks recorded by Steam for ISPs in OECD member countries*

The rank indicates the size of the ISP in the country by the number of bytes delivered to the user.

\begin{tabular}{|c|c|c|c|}
\hline Country & ISP & Speed (Mbps) & Rank $^{* *}$ \\
\hline France & Blade SAS & 347.3 & 10 \\
\hline Switzerland & Init7 (Switzerland) Ltd. & 176.8 & 7 \\
\hline Korea & Korea Telecom (KT) & 105.7 & 1 \\
\hline Sweden & Telenor AB & 102.4 & 7 \\
\hline Korea & SK Broadband & 102.0 & 2 \\
\hline Japan & Sony Network Communications & 94.0 & 4 \\
\hline Korea & LGU+ (DACOM Corp. $)^{7}$ & 92.0 & 6 \\
\hline Korea & LGU+ (LG Powercomm) & 91.3 & 3 \\
\hline Netherlands & CAIW Diensten B.V. & 89.5 & 4 \\
\hline Korea & LGU+ (LG DACOM Corporation) & 88.2 & 4 \\
\hline Sweden & Ownit $A B$ & 83.8 & 9 \\
\hline Spain & Ibercom Telecom & 82.9 & 9 \\
\hline Sweden & Com Hem AB & 81.4 & 2 \\
\hline Norway & UNINETT AS & 80.4 & 9 \\
\hline Japan & ARTERIA Networks Corporation & 74.0 & 9 \\
\hline Japan & K-Opticom Corporation & 73.1 & 5 \\
\hline Japan & TOKAI & 69.5 & 10 \\
\hline Switzerland & UPC Schweiz GmbH & 67.1 & 2 \\
\hline Sweden & Bredbandsbolaget $A B$ & 65.5 & 3 \\
\hline Netherlands & Ziggo & 64.7 & 1 \\
\hline Sweden & Bahnhof Internet $A B$ & 63.9 & 4 \\
\hline Switzerland & Quickline & 63 & 9 \\
\hline Denmark & EnergiMidt Fiberbredband A/S & 62.5 & 4 \\
\hline Sweden & Bredband2 AB & 62.3 & 5 \\
\hline Korea & Cj-hellovision & 62.2 & 5 \\
\hline Singapore & MyRepublic & $138.1\left(76.1^{\star \star \star}\right)$ & 4 \\
\hline New Zealand & MyRepublic & $58.6\left(24.8^{\star \star \star}\right)$ & 5 \\
\hline Australia & MyRepublic & $36.1\left(12.5^{\star \star \star}\right)$ & 7 \\
\hline Indonesia & MyRepublic & $23.1\left(8^{\star \star \star}\right)$ & 3 \\
\hline
\end{tabular}

Note: *The ways companies are listed corresponds to how they appear for Steam. Some of the companies have been merged or have the same owner, which is indicated in further endnotes in the table.

**Ranks in the Steam statistics are established by the amount of IP traffic downloaded by ISP users during a seven-day window.

*** Average download speed in Mbps for the other nine fastest providers in that country.

Source: Data extracted from the Steam website, 10 November 2017. https://store.steampowered.com/stats/content/

Two players stand out in terms of the speeds recorded by Steam: Blade in France and Init7 in Switzerland. From countries outside the OECD area, only Singapore stood out. Nine of the ten operators scored a level that would have them added to this list. One operator from Hong Kong, People's Republic of China, also had a high score.

Of the Singapore ISPs, the standout was MyRepublic with a recorded speed of $138.1 \mathrm{Mbps}$. Some of the listed broadband players come originally from the cable television industry. In that sense, they could be considered historical incumbents. Only Korea Telecom (KT) is the only historical incumbent from the telecommunication industry.

Remarkably, the ISPs with the fastest speed all operate in countries with different market structures and degrees of network ownership. Indeed, some may wish to exclude Blade, a 
new service that relies to the greatest amount on the cloud. However, this would defeat the purpose of envisioning the future form of operators. Moreover, Steam has identified Blade as a provider that meets its requirements. Placing this issue to one side, it means the ISPs are located in France, Switzerland, Korea, Sweden, Japan and Singapore.

\section{So-net (Japan)}

Taking the leading operators, starting with the lower speeds, enables an examination of a few of the key factors that may contribute to their ranking. Thus, a first look is taken at Sony Networks (So-net). IIn 2013, So-net, a Sony-backed Japanese ISP, launched a fibrebased Internet service that reached download speeds advertised at 2 Gbps per second. At that moment, this speed was said to be the fastest commercial residential offer in the world.

Initially, So-net launched the service in Tokyo and six surrounding prefectures. It provided subscribers equipment in their homes to take advantage of the gigabit speeds (Alabaster, $\left.2013_{[12]}\right)$. Today, the service is offered with up to $10 \mathrm{Gbps}$.

In March 2017, So-net was the third largest ISP in Japan with 2.7 million subscriptions. It used FTTP provided by NTT, which uses regulated access to NTT's fibre. So-net can thus choose the technology used in the customer's premises. In this respect, So-net uses a technology called G-PON or XG-PON. This is different from GE-PON, which NTT has adopted to provide FTTP. G-PON can apparently provide up to $2.5 \mathrm{Gbps}$ downlink, while GE-PON can provide up to $1.2 \mathrm{Gbps}^{8}{ }^{8}$ In 2019 , So-net provided the Nuro FTTP service for its 10 Gbps offers in Tokyo, Osaka and Nagoya (Sony Network Communications, $2018_{[13]) \text {. }}$

In November 2017, So-net was recorded with the fourth largest amount of data downloaded by its subscribers. It accessed Steam with among the highest speeds around the world at an average of $94 \mathrm{Mbps}$. So-net's flexibility to choose technology likely contributed to recording much higher speeds than other players in Japan.

At the same time, So-net operates in areas of higher population densities than, for example, NTT's broader national coverage. So-net also likely attracts customers keen to maximise network performance. It offers PlayStation 4 and PlayStation Network Credit as an enticement for new customers, for example. It also provides a discount to its subscribers at the PlayStation network store for games, music and so forth.

Sony Networks took advantage of Japan's changes to encourage mobile virtual network operators (MVNOs) in recent years. The company has been one of the more innovative players. It offers a SIM-only service that includes $500 \mathrm{MB}$ of data at no charge (i.e. excluding the universal service fee).

\section{KT and SK (Korea)}

Taking the Korean ISPs together, KT at $105.7 \mathrm{Mbps}$ and SK at $102 \mathrm{Mbps}$ provide a different model to Japan. Both companies use their own end-to-end infrastructure without regulated access over a third-party network. Initially, Korea had regulated access in the early days of the broadband era via unbundled local loops. However, strong infrastructure competition altered this approach. Given Korea's high population density, three networks often compete to place their own equipment in the basements of apartment buildings. This has, in turn, led to more competitive prices and higher quality. This takes the form of faster speeds on offer, as reflected in the performance recorded by Steam.

Telenor (Sweden) 
In Sweden, Telenor $\mathrm{AB}$ recorded among the highest average speeds for global peers of 102.4 Mbps. In the third quarter of 2017, Telenor was reportedly the third largest provider of fixed network infrastructure in Sweden, as well as having 2.68 million mobile subscriptions (Telenor Sweden, 2018 $\left.{ }_{[14]}\right)$. In addition to the Telenor brand, the company has a number of consumer-oriented ISPs for large customers such as businesses. These include Ownit, the second fastest recorded network at $83.8 \mathrm{Mbps}$, and Bredbandsbolaget at 65.4 Mbps.

According to Steam, Telenor is likely a mix of Telenor corporate customers (a minor proportion), Ownit's customers and possibly some of Bredbandsbolaget's customers. These customers have higher speeds in Steam's measurements because they are relative newcomers who get their services delivered through fibre infrastructure. They also have the most modern equipment and more access to gigabit rates than the average customer base across all the company's brands.

Sweden's market is characterised by a mix of regulated access, municipal networks and end-to-end infrastructure competition. In the latter case, Com Hem, a cable broadband company, had the third highest speed with 81.4 Mbps. Telenor uses its own local access facilities, as well as open access networks.

\section{MyRepublic (Singapore)}

The ISP with the next highest recorded performance is Singapore's MyRepublic with 138.1 Mbps. It is included for two reasons. First, it operates in another market structure than the ones previously considered. Second, MyRepublic has taken its business model to other countries in the region where it is also the fastest ISP.

Singapore has a national broadband network. A structurally separated entity provides the wholesale dark fibre. ISPs such as MyRepublic provide the active electronics and manage services to their customers.

Just as in Japan, Korea and Sweden, Singapore benefits from the freedom to choose technologies. Companies can either own end-to-end infrastructure or select how to use wholesale fibre. This flexibility has been at the forefront of MyRepublic's approach in Singapore. It has enabled the firm to offer multiple $1 \mathrm{Gbps}$ connections to the same premises $\left(\mathrm{OECD}, 2017_{[2]}\right)$. For example, a family may choose to take a $1 \mathrm{Gbps}$ connection for a home office or study, while providing a second standalone 1 Gbps connection for games. The second line is at a marginal cost to the first line. In addition, MyRepublic offers a service tailored to gamers to attract them as subscribers.

In early 2018, MyRepublic's 1 Gbps service was priced at USD 38 per month (SGD 49.99). It offered a second 1 Gbps connection at an additional USD 7.60 (SGD 10) per month; a plan for gamers had the same price. These options could be combined with the following tiers: 1 Gbps, $2 \times 1$ Gbps, 1 Gbps + Game Plan, and $2 \times 1$ Gbps with game plans. For the gamer plan, customers are promised the following features or benefits (MyRepublic, 2018 $\left.{ }_{[15]}\right)$ :

- custom network routing that is constantly optimised with custom routes to overseas game servers

- low and stable latency for the most popular games and the ability to track in real time

- faster game downloads

- a dedicated hotline for game support 
- equipment choice to entice subscribers (e.g. PlayStation 4; Razor Keyboard and Mouse, etc.).

Additional options appear to be effective in boosting the experience of MyRepublic's customers with Steam. In Japan and Sweden, So-net and Telenor cover selected areas compared to the national coverage of incumbents. However, MyRepublic starts from the same national broadband network as other Singaporean ISPs. In other words, MyRepublic's average speed is nearly twice the performance of the average for its largest rivals. MyRepublic has replicated this performance in Australia and New Zealand, where the ISP is also a reseller of national broadband networks.

\section{Init7 (Switzerland)}

In November 2017, a relatively small ISP in Switzerland called Init7 distinguished itself with the remarkable speed of $176.8 \mathrm{Mbps}$. For USD 69 (CHF 64.75), Init7 offers an advertised symmetrical speed of 1 Gbps (Init7, 2018 $\left.8_{[16]}\right)$. The Swiss market is similar to the other countries covered here. It combines end-to-end infrastructure competition and regulated access, though not for fibre networks (Box 2). Init7 has its own backbone network. Notably, it has around 8000 bilateral peering sessions to ensure efficient traffic exchange. For the "final mile", it uses the fibre access network of Swiss Fibre Net (SFN), a joint venture of local energy providers.

SFN connects the local fibre optic networks of its shareholders and partners to the open "Swiss Fiber Net". Based on this arrangement, it offers high-quality transport services (Layer 1 and 2) for nationally active service providers and companies. This makes SFN one of the leading broadband providers in Switzerland and a strong infrastructure competitor in the telecommunication market. SFN also serves its shareholders by trying to achieve synergies in operations and sales

Inet7 has been using SFN's access network since May 2014. It operates its own international connectivity between cities such as Los Angeles to Warsaw and from Copenhagen to Miami (SFN, 2014 $\left.{ }_{[17]}\right)$. At the time of launching the agreement, Inet7 said its transported data volume exceeded 1 Tbps (terabits per second).

As of January 2017, Inet7 had set up around 75 Fiber7 points of presence (PoPs). From these PoPs, Inet7 actuated around $65 \%$ of the Swiss fibre optic ports. It also reported construction of new PoPs. The company also peers at PoPs established in Europe and in the United States. As an ISP, Inet7 ensures quality by managing its facilities as much as possible itself. The key component of the initial agreement was access to SFN's Layer 1 FTTP access. 


\section{Box 2. Swiss fibre access models}

In 2018, the Swiss Parliament began discussing revisions to the country's telecommunication law. Switzerland did not apply access regulation to optical fibre networks. Only the Swisscom copper network is subject to unbundling obligations for access seekers. The Federal Council had advised the Swiss Parliament to introduce technologically neutral access regulation. This would empower the regulatory authority to intervene in a case of dominance in next-generation access networks. In September 2017, the Federal Council proposed a partial revision of the telecommunication law. The telecommunication law was then amended on 22 March 2019. The provisions are expected to enter into force in the last quarter of 2020. The Swiss Parliament opted against imposing an obligation on dominant providers to guarantee access to subscriber connections that are based on optical fibre. However, the provisions grant telecommunication service providers the right to access buildings and to co-use existing domestic networks.

Switzerland has a history of trying to promote shared fibre infrastructure. In 2008, Swisscom launched a multi-fibre model to promote co-operation in the construction and operation of networks. Broadly, it wanted each network operator to deploy multi-fibre, a number of which would be available for competition for a fee. The same year, ComCom, the Swiss regulator, organised a roundtable to discuss co-operation and standardisation. Ultimately, it held nine roundtables between 2008-12 on the issue. Within this framework, several actors came together in September 2011 to adopt "Fibreoptique Suisse", a multi-fibre platform. Fibreoptique Suisse shares some of the same members as Swiss Fiber Net, but not Swisscom. Data are not available on the proportion of FTTP connections under the multi-fibre model or the wholesale approach used by Swiss Fiber Net.

\section{Blade: An operator in the cloud}

In November 2017, Blade in France achieved the highest recorded speeds recorded by Steam (347.4 Mbps). Its business model and technological approach are the most different from the previously considered operators. Therefore, it is discussed here separately.

Since 2017, Blade has offered a service called "Shadow" in France. In 2018, it expanded commercial services into Germany, the United Kingdom and to 19 states in the United States. It aimed to offer its services to all states by October 2018. To that end, it has raised a considerable amount of venture capital. Indeed, during a mid-2017 round, it added USD 57 million to previous commitments (Dillet, 2017 $[18]$ ).

In 2017, the service had around 3000 subscribers in France using Orange's FTTP service. It does not provide its own last mile infrastructure. In other respects, it shares attributes with some retail ISPs. For example, Blade had its own network, autonomous system number, peering and transit relationships. At the same time, the service relies heavily on its own data centres. In that respect, its infrastructure is far more extensive than would be the case for many ISPs. The company also only serves customers that are close enough to its own data centres (i.e. initially California instead of the entire United States). 
The service works in the following manner. Blade customers purchase their own Internet access from an ISP. Initially, Blade required this to be an FTTP service. However, it now recommends that a user has at least a 15 Mbps connection. In France, depending on the provider, a fixed broadband connection with a bundle of services would typically cost between USD 37 (EUR 30) to USD 50 (EUR 40) per month. The Blade service costs USD 37 (Euro 29.95) per month with a 12-month contract. The customer can also buy an optional Shadow Box for USD 149 (EUR 119.95) or pay USD 10 (EUR 7.95) per month for the Box.

In return for the monthly subscription, Blade users receive access to a high-end personal computer located at the Blade data centre, as well as $250 \mathrm{~GB}$ of storage. They can access that computer via devices such as another computer, tablet and smartphone. If users purchase a Shadow Box, they can also view the computer on a monitor such as a television. In addition, users' own devices can use the operating system of their choice (IOS, Android, Linux and so forth).

This approach offers two advantages for gamers. First, they do not need to purchase their own state-of-the-art computer. Second, Blade maintains the computer at the data centre at the leading edge of service performance. The company hopes that users will be attracted by higher service speeds, as well as the cost savings. The service is also accessible from any device with an Internet connection such that a gamer could use a fixed or mobile service.

Can Blade compare to a traditional ISP? It does not provide the last mile, but nor do many ISPs that use third-party networks through regulated access or by commercial agreement. On the one hand, by delivering services via the cloud, Blade is like an OTT provider such as Netflix. On the other, the Blade service provides a customer interface more like an ISP. For example, Shadow can be used for games and applications such as email, web access and Netflix.

How does the service compare in terms of speed to Inet7, its closest peer? Both companies use the last mile of a third party. Both have autonomous system numbers, and their own peering and transit arrangements. And both have a total comparable monthly cost over several years. Finally, from the perspective of another network, Blade's users appear as its customers and not those of Orange.

The Blade model provides one potential direction for operators in terms of both last mile providers and access seekers. By early 2018, Blade had risen from the tenth largest provider to the sixth for Steam in France and on 12 April 2018, the speed recorded for Blade was $330 \mathrm{Mbps}$. The company also plans to expand its target customer base beyond games. It wants to attract other user communities that have high demand for information and communication technologies (e.g. graphic designers).

The latency for the Blade is reported to be low over broadband connections with the recommended baseline speed. However, if users wish to stream their games to a service such as Twitch, they would need sufficient upstream capabilities for connecting a webcam (Preston, 2018 $\left.{ }_{[19]}\right)$. Meanwhile, users have the equivalent of a high-end computer in the cloud. They can use it for any function of a home computer except mining for bitcoins, which is precluded by Blade's terms of service.

Of course, other players beside Blade use the cloud to improve the experience of games over broadband networks. NVIDIA Corporation, for example, has an experimental cloud project. It aims to transform any Apple Mac or Windows personal computer (PC) into a high-end device by increased cloud usage (NVIDIA, 2018[20]). GeForce NOW, launched 
as a free trial service in January 2018, uses the latest high-performance NVIDIA graphic processing unit. This enables streaming at higher settings and frame rates than are possible on the personal equipment of most users. Its approach also enables further capabilities. The owner of a Mac, for example, can play a game designed for PCs. Users can download their games into the cloud and sign into services such as Steam or Uplay PC from where they purchased the game.

NVIDIA's service enables a user to access high performance equipment in the cloud from any computer (Hardawar, 2018 $8_{[21]}$ ). When users launch GeForce NOW, they watch a video streamed to their Mac or PC with little latency between their input over a keyboard or mouse and NVIDIA's servers. However, this is via a high-speed Internet connection. Just like Netflix, NVIDIA adjusts the streaming speed to a user's connectivity. Several servers at once may use a user's broadband connection. Therefore, NVIDIA offers the following guidance depending on the quality of screen resolution (i.e. high definition or HD) a user

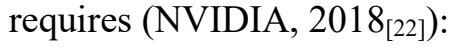

- $10 \mathrm{Mbps}$ - required broadband connection speed

- 20 Mbps - recommended for 720p 60 FPS quality (i.e. HD Ready or Standard HD)

- $50 \mathrm{Mbps}$ - recommended for 1080p 60 FPS quality (i.e. Full HD).

The approach by companies such as Blade, NVIDIA or Sony's PlayStation Now, has been tested unsuccessfully in the past. Between 2010 and 2015, for example, OnLive offered a cloud-based gaming service that streamed to users for USD 15 per month (Grunin, $\left.2018_{[23]}\right)$. There may be multiple reasons why a firm pioneering a new approach fails. However, broadband networks may not have been sufficiently developed to support this model. In 2013, for example, an OnLive reviewer found that a $5 \mathrm{Mbps}$ connection was insufficient to ensure the required quality. A $12 \mathrm{Mbps}$ connection improved performance, but a 60 Mbps fibre connection ensured excellent service (Morgan, 2013 [24]).

One gaming industry observer says that within a decade:

...100 Mbps-plus connectivity is likely to be ubiquitous, and it's at that point that cloud-based gaming-as-a-service and computing-as-a-service offerings will really start to catch on. ... Over the 10 years, when that turns into ubiquitous, anywhere access to high-speed connectivity, streaming services will move from being interesting tech demos to being the new normal. (Lal, 2018 [25])

\section{Different types of operators}

This section categorises different operator models. First, it highlights the core characteristics of each type. Second, it documents how different types have changed and adapted their business models to compete in a changing market environment. Third, it shows how they are further transforming their businesses to meet future demand. Overall, the section takes a broader definition of the term "operator". It analyses different models that provide access to fixed and mobile communication services in one or more ways.

\section{Traditional (vertically integrated) mobile and fixed broadband providers}

The historical business model of telecommunication operators is well known. This section will instead examine how traditional vertically integrated operators are addressing changes in communication markets. It will also explore how they are further developing their businesses. AT\&T, Elisa, Jio, Orange, Telefónica and Verizon will provide examples. 
Traditional vertically integrated telecommunication operators have faced pressure in recent years. Growth rates for some access products have declined, while new business lines have sometimes had lower margins. In part, this has been related to technological change (e.g. people giving up fixed telephone connections). However, it is also related to substitution for services that were once tied to the infrastructure they provided. In an IPbased environment, these services are no longer in demand.

In a positive change for the communication industry, the overall revenue pie has grown, more than doubling between 2002 and 2016 (Annex A). However, growth flattened in the second half of this period compared to the steep rise in the first half. This is related to the take up of fixed and mobile broadband connections that subsequently reached higher penetration rates.

Vertically integrated operators are striving to further drive costs down and increase profitability. At the same time, they are changing their business and operating models to increase revenues. While all operators strive for more efficiency and fewer operational costs, some have taken this a step further.

\section{Elisa (Finland)}

The Finnish company Elisa has capped its cost-to-revenue ratio. As a consequence, it has decoupled the costs from traffic increase (Jungermann, 2018[26]). Elisa's success is remarkable as it was the first Finnish company to offer unlimited data plans back in 2007. Currently, all of its mobile plans come with unlimited data for the home markets (Elisa, $2017_{[27]}$. They are differentiated by speed with tiers ranging from $1 \mathrm{Mbps}$ up to $300 \mathrm{Mbps}$. As a consequence of these offers, the data volume of the company has grown more than $700 \%$ over five years. Meanwhile, the number of mobile subscriptions has remained constant between 2013 and 2017 (roughly 4.7 million).

Its share of non-voice revenues in mobile communications rose from $44 \%$ to nearly $66 \%$ of mobile revenues during the five years between 2013-17. This highlights the role of data and the increase of data-voice substitution (Figure 9). In November 2016, the average data volume per Elisa SIM card exceeded 15 GB. Total subscriptions are relatively low in size compared to some other European operators. However, the company says it is the fifthbiggest mobile data network in Europe (Mattila, 2018 ${ }_{[28]}$ ). 
Figure 9. Elisa: Mobile service developments

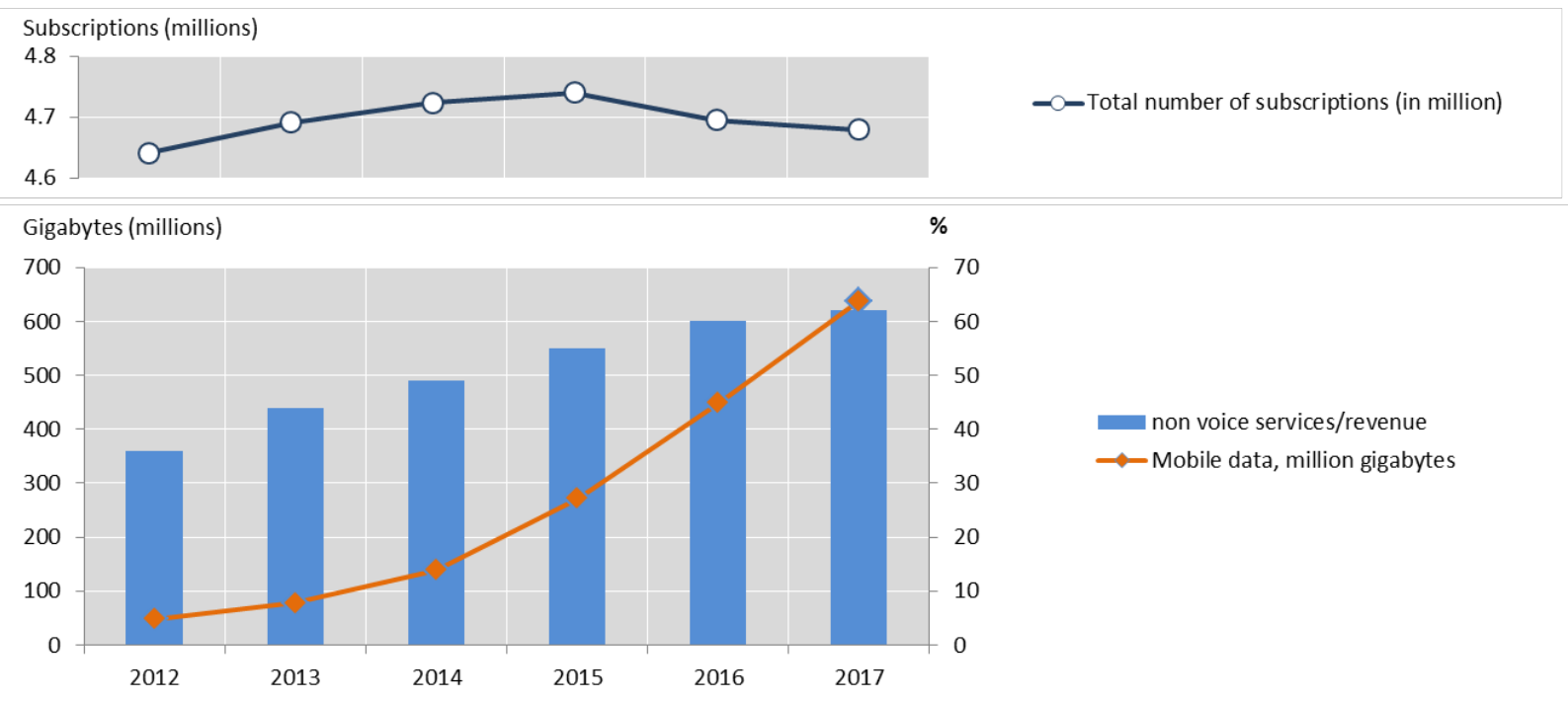

Source: Elisa operational data, Q4 2017, http://corporate.elisa.com/attachment/content/Elisa-Operational-DataQ4-2017.xlsx (Elisa, 2018[29]).

By the end of 2016, during a period of rapid data growth, Elisa expanded its $4 \mathrm{G}$ networks. It offered coverage of 99\% in Finland and 98\% in Estonia (Moody's, 2017 $[30]$ ). Notwithstanding these demands, the company managed to show a stable and impressive financial performance.

Between the last quarters of 2016 and 2017, Elisa's revenues increased from EUR 434 million (USD 537 million) to EUR 473 million (USD 585 million). The growth in revenues was paralleled by a steady and high level of profitability. Over the past five years, the company had stable EBITDA margins at an average of 34\% (Figure 10). Capital expenditure - the second most important expenditures category - has been kept at stable and low levels. It averaged EUR 55 million per year over the past five years, an equivalent of $14 \%$ of revenues (Elisa, 2018 $[31]$ ).

Figure 10. Elisa: Key financials

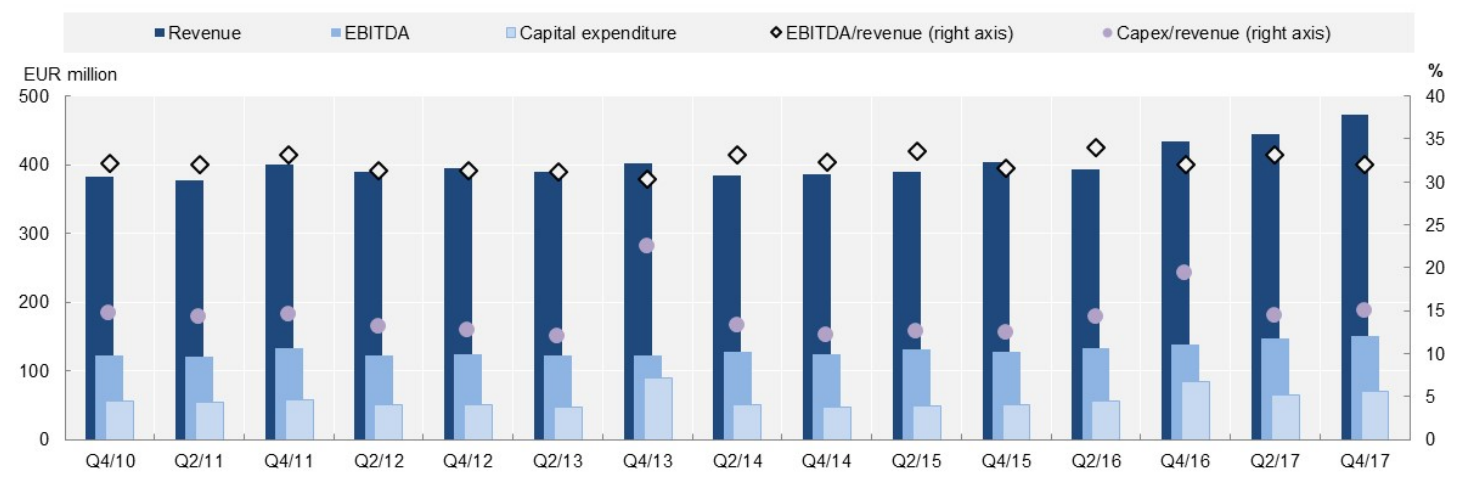

Source: Elisa Investors: Key Figures (Elisa, 2018[32]).

To attain this financial performance, Elisa has consistently worked on its strategy over a decade. It focused on cost control, improved processes, modernised IT systems and 
replacement of a legacy IT-system. In the search for innovative solutions, the company focused on maximising automation of network tasks. In a step beyond internal optimisation, the company has now started to sell network automation services to other telecommunication operators (Box 3).

\section{Box 3. Network optimisation and full automation at Elisa}

One cornerstone of Elisa's strategy has been to maximise the automation of its operations. In 2010, it began with fully automating its network operation centres that now run without human intervention (Jungermann, 2018 $8_{[26]}$ ). Elisa SON (self-organising networks) performs dynamic network optimisation, runs over 2 million tests and makes about 2000 daily changes in the network (Mobile Europe, 2018 [33] $_{\text {] }}$. Elisa has started to license its network automation solution to other telecommunication operators. It claims that it reduces both operating expenses and capital expenditure. Elisa decided to sell its internal network automation solution as a new source of revenue. Within Elisa's network, SON is one form of automation. Other approaches include base station integration, configuration and testing; radio access network operations; and predictive maintenance (Mobile Europe, 2018[33]).

Elisa's efforts to improve the quality of its network have reduced costs for the Help desk. Customers are primarily guided to address their issues over the web.

Sources: Jungermann, 2018[24], Mobile Europe, 2018[31].

\section{Reliance Jio (India)}

Reliance Jio in India is another integrated operator seeking to deal with rapidly increasing data use on an unprecedented scale. Following its launch in 2016, the company added 170 million subscriptions in 18 months. Over that time, the use of data surged. Jio is now considered to be the largest mobile data carrier in the world (Box 4).

Jio has leveraged the Indian digital transformation to significantly drive down costs of acquiring customers from USD 25.00 to about USD 1.00 per customer. Through the socalled India Stack (Box 4), Jio acquires customers in a paperless manner via mobile phones. This is a critical element for considering how traditional operators may evolve, particularly in countries leapfrogging towards digital economies. The Indian government has introduced reforms in areas other than telecommunication services that have also spurred Jio's remarkable progress. 


\section{Box 4. Jio and the digital transformation in India}

\section{A new entrant to the Indian market: The rapid rise of Jio}

Since its entry into the Indian mobile communication market in 2016, Reliance Jio has attracted over 170 million subscriptions. By way of comparison, from the first telephone call by Bell in 1876, it took until 1994 for countries outside the OECD area to reach 170 million fixed and mobile subscriptions. In other words, it took Jio less than 18 months to accomplish what a group of countries could only do in 118 years. This growth has required investments in Jio's network of USD 32 billion. This included the deployment of an extensive fibre backbone network connecting towers that could be rapidly upgraded to $5 \mathrm{G}$. Jio also used IPv6 as much as possible, which helped roll out its network at a lower cost and to scale the service.

When entering the market, the company eliminated charges for national roaming. It also offered voice calls for free. In addition, customers were not initially charged for data consumption. Not charging customers aimed to attract users from a previously voicecentric market. However, Jio was also the first operator in India with a 4G-only network. As such, it needed people to upgrade their devices to support $4 \mathrm{G}$.

When the promotional period ended, all Jio offers continued to include free voice calls (or the data used to make $4 \mathrm{G}$ voice calls). Its influence has reoriented the Indian market so that competition is focused on low data charges. The company proposes a wide range of prepaid and postpaid offers for different budgets associated with inexpensive smartphones. For instance, it offers daily prepaid data packages for USD 0.29 (INR 19) for $0.15 \mathrm{~GB}$ of data or USD 0.80 (INR 52) for $1.05 \mathrm{~GB}$. Prepaid offers go up to yearly plans with the most expensive plan costing USD 153.69 (INR 9 999). This plan includes $750 \mathrm{~GB}$ of data equalling USD 0.20 per GB.

On the post-paid side, Jio offers five different plans. A medium-sized post-paid plan, for example, includes $60 \mathrm{~GB}$ of data. It amounts to USD 7.83 (INR 509), or USD 0.13 per GB. In the December quarter, the data traffic per subscriber per month amounted to 9.6 GB. This placed Jio at the same level as the leading OECD countries in terms of monthly data consumption.

Many voices in the market claimed this data pricing strategy could not generate profits. However, Reliance Jio reported that it broke even in the 2017 December quarter with a net profit of USD 77.5 million (INR 504 crore). Revenues from operations reportedly amounted to USD 1.06 billion (INR 6879 crore). The changes introduced by Jio also make it well placed to take advantage of the shift in India to a "bill and keep" system for termination rates.

\section{India's digital transformation}

In recent years, remarkable technological and policy innovations have spurred the digital transformation of India. The foundation for this transformation is the so-called India Stack. The term originates from the software world where a "stack refers to multiple, interdependent layers of software services that are built on top of one another" (Gupta and Auerswald, 2017[34]). In the Indian case, these layers consist of four different categories of government services. The presenceness layer, launched in 2009, provides a universal biometric digital identity (called Adhaar) to people. To date, 1.064 billion Adhaars have been issued (IndiaStack, 2018 ${ }_{[35]}$ ) in a total population of 1.34 billion 
(United Nations, 2017 ${ }_{[36]}$ ). This system is "both the only non-US technical system globally to have broken the 1-billion-user threshold and the only such system to have been developed by the public sector" (Gupta and Auerswald, 2017[34]).

Three layers sit atop the presenceness layer. A paperless layer allows digital records to move with digital identity. A cashless layer provides a single identity to all bank accounts and wallets. Finally, a consent layer provides for secure data flows and for consumers to give access to specific parts of their personal information (IndiaStack, $\left.2018_{[35]}\right)$.

Several government initiatives encouraged the use of these layers. In 2014, for example, the Indian government launched a financial inclusion programme, Jan Dhan. This created low-cost bank accounts using the digital Aadhaar IDs and brought customer acquisition costs down significantly (Gupta and Auerswald, 2017 [34]). Since then, 339 million Aadhaar-linked bank accounts have been opened (IndiaStack, 2018 [35]). The bank accounts, together with the digital ID, enabled people to undertake mobile payments. "(T)he hundreds of millions of people eligible for the receipt of government services in India suddenly had a way to access those services digitally, from beginning to end" (Gupta and Auerswald, 2017 $[34]$ ). The demonetisation of India further spurred the transition to a digital economy. For example, before demonetisation, a government payment system processed about 100000 transactions per month in October of 2016. This number increased to 76 million transactions per month one year later (Gupta and Auerswald, 2017[34]).

Sources: Gupta and Auerswald, 2017[32]; Khan, 2018 [103]; Reliance Jio, 2018 ${ }_{[102]}$; RIL, 2018 ${ }_{[101]}$; Mundy, 2018 [10].

Aside from striving to reduce costs and increase efficiency, vertically integrated fixed and mobile operators are rethinking their business models to expand opportunities for revenue. As always, some operators are striving to extract higher rents from the networks they connect with to exchange traffic. In an environment where IP transit costs continue to fall, this is unlikely to be a successful long-term strategy. This is why most operators are instead seeking to move into other parts of their value chains. They are either creating new services or leveraging on the data they can access for analytical services (i.e. big data). Still others are moving into new industries such as banking, insurance, advertising and many others.

As one consideration, operators must choose to integrate services as extensions of vertical operations or as apps. Either way, they want to provide services across all geographical locations, not simply in their own areas of network coverage. These types of offers are for services that were largely the domains of others, such as cable television networks that provided video services. Taking the app approach, some operators have developed their own video streaming services to compete with OTTs. These operators include América Móvil (ClaroVideo), au (Video pass), NTT DoCoMo (dTV) and Verizon (go90). Others have developed their own chat services, such as Turkcell (BiP) or VEON (VEON app).

With respect to the production and distribution of content, some traditional telecommunication operators have gone a step further. Some have acquired content or Internet service companies to extend their value chains. In January 2011, for example, Comcast acquired a $51 \%$ majority stake in NBC Universal to increase its role in content production and distribution. In 2013, Comcast acquired the remaining 49\%. In July 2015, AT\&T completed its acquisition of the satellite-TV provider DIRECTV. This transformed the company into the largest service provider of Pay TV in the United States (AT\&T, 
$\left.2015_{[37]}\right)$. The acquisition of DIRECTV allowed AT\&T to expand its offers in audio-visual content. It now includes premier content such as sports programming and additional options such as video streaming. A year after its launch in 2016, the DIRECTV NOW streaming service had 1.2 million customers (AT\&T, 2018[38]). AT\&T further invested in Otter Media, a joint venture with the Chernin Group. The company invests in and develops OTT digital content services such as Crunchyroll and Fullscreen Media.

In June 2018, AT\&T acquired Time Warner, enabling the company to engage intensively in content production. It now has ready access to a vast array of video content, including CNN, HBO and Warner Brothers. The US Department of Justice has appealed a trial court decision that rejected blocking the merger on antitrust grounds.

Engaging in content production may reduce content acquisition costs, while offering broader revenue opportunities. In addition, AT\&T wants to leverage the merger to enter the digital advertising market.

"In particular, we have a sizable opportunity to transform targeted
advertising around premium video content, and do so with greater
transparency and accountability for advertisers. And this isn't just about
creating more effective ads and improved ROI for marketers. It's about
using insights from customer data to improve the viewing experience by
delivering more relevant ads and potentially reducing the number of ads
shown." (AT\&T, $2018_{[38]}$ )

Verizon

Verizon is another example of a vertically integrated operator that is expanding its value chain through acquisitions. The company recently acquired two online service companies with a view of growing its revenues in the digital advertising business. It aims to compete with companies such as Facebook and Google.

In 2015, Verizon acquired AOL. Aside from a portfolio of sports and entertainment sites, AOL owned a widely-known group of content and media sites. These included Engadget, The Huffington Post and TechCrunch. AOL also brought with it a set of advertising technologies, for traditional and digital media. Its acquisition opened the possibility for Verizon to become an important player in video advertising.

To complement the AOL acquisition, Verizon took over more companies. In 2017, for example, Verizon bought Yahoo's core Internet business. While Yahoo's search function had become less popular, its finance, sports and news channels aggregate an important number of visitors. Yahoo Finance, for example, is the most popular investment and finance website in the United States. As of July 2017, it attracted approximately 70 million unique monthly visitors. It thus ranks as one of the most popular websites in that country. Verizon has combined Yahoo with AOL into a subsidiary called Oath, which includes more than 50 media brands. Verizon states in its 2017 Annual Report:

\footnotetext{
We combined Yahoo's operating business with our existing media business to create Oath, a company that includes diverse media and technology brands which engage approximately one billion global content consumers. Oath generated about USD 6 billion in revenues in 2017. This scale enables us to attract high-value content partners, as we saw in our recent agreements with the National Football League and the National Basketball Association to stream live games and other content to users on our mobile and digital properties. Such partnerships will create tremendous possibilities as our
} 
customer base continues to expand and our networks continue to achieve new breakthroughs in speed and quality. Expanding our digital-media presence is not only exciting, it's deeply important to our company's future. (Verizon, 2018 ${ }_{[39]}$ )

Verizon has gained a large position in the online industry to complement its traditional communication business. The company can combine the data from its media business with communication user data, which it could leverage for its online advertising business.

Finally, like many other integrated operators, Verizon is striving to better market the benefits of Verizon Fios, its FTTP network. Steam consistently records Verizon Fios as the fastest ISP among the top ten players in the United States (61.7 Mbps on 16 April 2018). The company has an offer aimed at gamers through a partnership with Microsoft Xbox. It bundles a one-year subscription with its standalone 1 Gbps FTTP service for USD 79.99 per month. This aims to attract more customers as it reaches higher penetration of Fios.

At the launch of this offer, Verizon noted how a high-speed connection could improve the gaming experience by reducing latency and bandwidth issues. According to a company spokesperson: "More and more, gamers recognise that a strong high-speed Internet connection is one of the most, if not the most, important factors in online gameplay" (Buckley, 2018[40]). During the fourth quarter of 2017, Fios added 47000 Internet subscriptions. At the same time, it had a net loss of 29000 Fios video connections, possibly due to "cord cutting".

\section{Data analytics services and beyond}

While the above-mentioned companies have acquired online service companies, others are leveraging their communication businesses to provide services centred on data analytics. Telefónica is a case in point. Through Telefónica NEXT, a spin-off of Telefónica Deutschland, the company provides advanced data analytics services through anonymised mobile network motion data. It offers analyses of movement flows for cities such as Munich and Berlin to optimise traffic and public transportation (Telefónica, 2017 ${ }_{[41]}$ ). Telefónica NEXT plans to extend these data analytics services to other customers such as shopping malls or airports (Lindler, 1 August 2017 $[42]$ ).

Traditional players take another approach, venturing into areas outside communication services. Orange provides a leading example. The company offers mobile payment and mobile money services through smartphones and tablets to over 37 million subscribers in Africa and the Middle East (Richard and Fernandez, 2018 ${ }_{[43]}$ ). However, in 2016, it acquired its own bank (Groupama Banque). As such, the company now offers traditional banking services in France through its "Orange Bank". It plans to launch these services in other countries (Box 5). In another example, Rogers Communications, a Canadian media company, launched the Rogers Bank in 2013. The bank, fully owned by the company, offers a range of credit cards, but does not hold deposit accounts.

Canada offers other examples of operators venturing outside their traditional area of communications. TELUS, for instance, provides health services through TELUS Health. It is a significant health IT provider for both health organisations and consumer products, with annual revenues of more than CAD 600 million. The company also won the bid to provide the technical solution for the national e-prescribing service 'PrescribeIT' (TELUS, 2017 [44]). In 2017, the company invested CAD 130 million in its fixed broadband infrastructure. This supports the growth in demand for faster speeds, and also helps to "extend the reach and functionality of [its] business and healthcare solutions" (TELUS, $\left.2017_{[44]}\right)($ p. 70). 
In Canada and other countries, several telecommunication companies have entered the home monitoring and home security market. Increasingly, they offer services comprising smart connected devices. These include different types of sensors (e.g. smoke and carbon monoxide sensors), smart thermostats and security systems (e.g. alarms and smart door locks). Deutsche Telekom, for example, has developed the Smart Home Platform. It sells its services to other operators such as the Norwegian company Hitch, as well as to other companies such as utility providers (Engerati, 2018 ${ }_{[45]}$ ). In Canada, Rogers Communications began marketing its Smart Home Monitoring service in 2011. Bell and TELUS entered the home monitoring market in 2018. This took place after Bell acquired the home security and monitoring company AlarmForce.

\section{Box 5. The Orange Bank}

In 2017, Orange launched an online banking offer in its home market of France. Orange already had a substantial presence in the mobile payment market in Africa, the Middle East and Poland with a client base of about 37 million. The launch of the Orange Bank can be seen as an additional step to increase the diversification of Orange's revenues. It allows the company to gain a stronger presence in online and mobile financial services.

Orange Bank offers all its services through a digital platform optimised for smartphone screens. Most of its online banking services are free. These include opening the account, use of a credit card, cash withdrawals in France and Europe, ${ }^{9}$ bank transfers and a savings account. This puts the offer of Orange Bank among the lowest-priced in France. In addition, and in contrast to some competitors, anyone can open an Orange Bank account and there are no revenue requirements. In March 2018, Orange Bank also started to offer consumer credit from EUR 500 to EUR 75000 (USD 618 to USD 92 746). Repayment terms ranged from one to six years.

In the six months following its launch, the bank acquired around 100000 customers. This is above the numbers for two of its competitors in France. In 2017, Hello Bank (BNP Paribas) and BforBank (Crédit Agricole) had acquired 66000 and 25000 customers, respectively (Bondain, 2018 ${ }_{[46]}$ ).

In 2018, Orange Bank planned to launch its services in Africa, beginning in Mali and Madagascar. Subsequently, it planned to offer services in Senegal and Côte d'Ivoire. The company considers these banking services to be an evolution of mobile money services it has offered in Africa since 2008. Pure mobile money licences impede Orange to offer more traditional banking products such as credit or insurance. Orange, however, sees rising demand for these products in Africa. To offer such services through its Orange Bank, the company was reportedly considering co-operation with banks in some African countries or obtaining a full bank licence through acquisitions in other countries (Agence Ecofin, 2018 $\left.{ }_{[47]}\right)$.

Some vertically integrated operators are facing challenges in the traditional communication business. In response, they have expanded to diversify their revenue streams. In addition, they have a number of attributes that will be critical for future developments. Aside from having the financial capability to make large investments and run large organisations, telecommunication operators are known as trusted and reliable brands. This asset could be critical in an environment where concerns over privacy and security increase. This means that control of network infrastructure could be a competitive advantage. It would allow operators to facilitate the provision of trusted services, as well as to capitalise on developments around the Internet of Things (IoT). 


\section{(Vertically integrated) cable operators}

Following the liberalisation of telecommunication markets and the emergence of the broadband era, cable network operators began to provide triple play services (telephony, cable television and Internet access). From a market share peak of $48.3 \%$ in 2001 , they provided $32.9 \%$ of all fixed broadband subscriptions in OECD member countries by mid2017. In part, this reflected the expansion of broadband over telecommunication networks, especially in countries without traditional cable television networks. Changes in technology also helped them increase their market share.

The early years of the broadband era had much slower average speeds than today. As a result, it was initially easier for cable operators to compete for the traditional markets of telecommunication operators (i.e. telephony and Internet access). For their part, telecommunication operators had more difficulties competing over the first xDSL offers with cable's traditional service. This was because video required higher amounts of bandwidth. There were also far fewer OTT services to attract users.

Incumbent telecommunication operators responded to the new environment in various ways. Some operators in Australia and Portugal laid their own coaxial cable networks alongside their traditional copper lines. Others in Japan and Korea built FTTP networks. Still others in Germany and the United Kingdom deployed fibre deeper into their networks to support more advanced xDSL services. As a result, telecommunication operators are well placed to compete over triple play services against cable operators. Some have even started to leverage capabilities to provide quad-play services (i.e. adding mobile services to the bundle).

Cable broadband networks have responded by continuing to invest in infrastructure. They have embarked on upgrades using DOCSIS over their coaxial networks. After falling to a low of just $28.4 \%$ in 2009 , they have stabilised their market share. In recent years, they have just under $33 \%$ of all broadband subscriptions in the OECD area. In some countries, such as the United States, cable broadband operators have continued to increase their market share. Meanwhile, aware of the threat of quad-play bundles, cable operators have begun to create MNOs and MVNOs. They have also been taken over by MNOs, such as Vodafone, which would have otherwise faced the same challenge in offering quad-play services (Box 6).

At present, the highest standard used by cable operators is DOCSIS 3.1 Full Duplex. It has a theoretical maximum speed of $10 \mathrm{Gbps}$ (upstream and downstream), the same as the highest commercial offers of FTTP. This suggests cable networks can continue to compete robustly for Internet access services. However, they are likely to face increased pressure on their traditional business lines around television.

Fixed telecommunication operators lost their unique ability to provide telephony to a myriad of other players (e.g. mobile operators, cable networks, OTTs). In the same way, the traditional market of cable companies is no longer a fortress. These companies can no longer depend on their role as a key distributor of linear television and video from which they could enter other markets. In other words, content owners are challenging traditional cable bundles. These content owners are using the Internet to go direct to end users or with other players (fixed telecommunication providers, mobile operators, OTTs). Increasingly, they offer "skinny bundles" or à la carte services.

In 2018, in the United States, there were around 820 million video connected devices or roughly 2.5 of such devices per inhabitant. Meanwhile, the number of OTT-only households increased from just over 5\% to just under 15\% between 2013-17 (VAB, 
$\left.2018_{[48]}\right)$. Often, consumers that rely solely on OTT services hold multiple subscriptions such as Amazon, Netflix, YouTube and so forth. At the same time, the set top box, once the sole domain of cable broadband providers, is increasingly challenged by other players. A range of devices is available such as Android TV, Apple TV and Roko. They separate the broadband connectivity providers from the user interface in the same way smartphones did with MNOs.

In practice, this separation can make the cable broadband company's services appear the same as those of OTT providers. At the same time, new players like Amazon, Netflix and Apple have entered, or are set to enter, the video production market. This, in turn, increases competition against the production units of cable broadband companies. Moreover, traditional cable television channels, such as HBO and ESPN or sporting codes, have created OTT applications to go direct to customers. They also continue to make content available under traditional bundles.

Just as telecommunication operators are diversifying their businesses, cable companies are also pursuing new areas. In Canada, in addition to offering services in smart home applications and banking, Rogers has ventured into sports franchises. Since September 2000, it has been the majority owner of the Toronto Blue Jays, a professional baseball team (Major League Baseball). It has been the sole owner since January 2004. In addition, Rogers and Bell hold 37.5\% and 28\% interest, respectively, in Maple Leafs Sports \& Entertainment. This entity owns the Toronto Maple Leafs of the National Hockey League, the Toronto Raptors of the National Basketball Association and the Toronto FC of Major League Soccer, among other franchises.

Finally, as in other communication markets, blockchain technology may disrupt the video distribution models of cable broadband providers and today's leading OTTs. Numerous start-ups enable decentralised video streaming services based on blockchain technology. Others offer different business models to reward content producers (Virk, 2018 [49] $_{\text {). Viewly }}$ or Livepeer, for example, enable any content producer to distribute videos. Meanwhile, start-ups such as LBRY and Theta Labs are building protocols to support distributed apps. For their part, Stream Token and YouNow's PROPS use blockchain to organise payments for content producers. Spectiv VR aims to provide content producers with a larger share of advertising revenue. ${ }^{10}$

Proponents say the use of blockchain could reduce costs by moving from centralised distribution to a peer-to-peer model. They also believe that removing intermediaries between content producers and consumers could reduce costs, while ensuring producers control distribution.

While the cable broadband industry is changing tremendously, its players are still robust competitors as future infrastructure operators. To date, an increasing number of users are "cord cutting" or "cord shaving" the traditional television bundles. Yet cable broadband providers are largely holding their own in terms of Internet access. This is especially the case where users do not have multiple alternative infrastructure or service providers.

Technological developments such as fixed wireless over 5G networks could win a share of such markets. However, cable networks may well continue to evolve in ways that can meet such competition with an integrated end-to-end service model. Alternatively, in a country such as Sweden, some housing companies are replacing coaxial networks with fibre networks. This means the cable network loses its monopoly, as it becomes a wholesale provider. At the same time, a new "Netflix" or "YouTube" may emerge from the use of blockchain technology. While any of today's players may also adopt such an approach, 
cable broadband operators may well continue to provide infrastructure as their primary focus.

\section{Box 6. Where do standalone cellular wireless operators fit?}

For the most part, cellular wireless operators are now owned or aligned with fixed network operators. Network operators that were once standalone have sought to obtain a fixed or wireless component to offer a full range of services. These operators include BT as a fixed network in the United Kingdom or Vodafone as a cellular-only network in many countries. These changes recognise that fixed and wireless networks have evolved in ways that provide competition and complementarity.

The two technologies are also converging. Wireless networks need deeper deployment of fibre backhaul, while Wi-Fi has enabled competitive bypass and the necessary offloading of traffic. Unless they plan to be wholesale-only networks, fixed operators (telecommunication or cable) and wireless operators will likely continue towards offering a full range of services.

Will the next generation of wireless networks $(5 \mathrm{G})$ allow mobile providers to offer connectivity that competes more effectively with fixed networks? In other words, will mobile operators move beyond the services they have already substituted in many cases (e.g. video as well as voice)? In the United Kingdom, for example, Three appears to be pursuing this strategy. It is primarily a mobile operator. However, it is moving to offer fixed wireless through its subsidiary "UK Broadband", which is branded as Relish (Williams, 2017[50]).

\section{Wholesale-only operators (utility)}

For the most part, wireline communication operators, whether originally telecommunication or cable television companies, are vertically integrated. In other words, they control all the network resources needed to offer broadband communication services. In addition, most of these operators and especially telecommunication incumbents have established wholesale business units for regulatory or commercial reasons. They sell access to their backbone, backhaul and local access infrastructure.

Access to wholesale wireline facilities enables challengers to provide communication services and compete in the retail market against incumbents. This is especially the case where insufficient alternative infrastructure has created bottlenecks. OECD member countries have regulations that require some operators to provide such access depending on assessments of current or potential competition.

Wireless networks have had less regulatory intervention to ensure wholesale access. This is largely because there are more MNOs with infrastructure offering services in the same geographical regions (i.e. for the most part nationally). That said, MNOs also offer MVNOs wholesale access to their networks. Again, this is either because it makes commercial sense or because regulations require providing consumers with more choice. In addition, and again largely for commercial reasons, MNOs in many countries access towers. They also sometimes access the backhaul infrastructure connecting these towers from dedicated wholesale tower companies. Indeed, some traditional network operators have sold their wireless mast and towers to these players. MNOs then lease these facilities 
to which they have deployed active equipment and provide their own services. Meanwhile, Mexico and Rwanda have established their first wholesale-only mobile networks. The respective operators offer services to retail providers (MNOs and MVNOs), but not to endusers.

Recent developments in wholesale markets in both wireline and wireless may be one guide to how some operators may look in the future. Network operators, to one extent or another, all use facilities that are either their own or leased from other providers. However, for multiple reasons, some are changing their business models. Sometimes network operators have separated functions or structure to seek relief from regulations. In other cases, they have changed infrastructures for commercial and financial interests (e.g. divesting wireless towers).

In the future, there will still likely be a mix of business models depending upon financial and market conditions. Historically, many incumbents performed many more activities required to offer communication services in-house than they do today. For example, some were once wholly integrated equipment manufacturers and network companies that offered all services and devices under a monopoly. Alternatively, the government-owned monopoly operators sometimes had close ties with manufacturers. They often purchased the bulk of their equipment from leading national manufacturers.

Liberalisation, privatisation, the establishment of independent regulators of communication markets and a range of other factors have meant tremendous changes to market structures and business models. Today, for example, MNOs outsource much of the construction and establishment of networks to companies such as Ericson or Nokia. They also increasingly lease masts and towers and backhaul from companies such as American Tower or Cellnex. And they often share facilities with competitors and offer wholesale services to MVNOs and MNOs (i.e. the latter through roaming agreements). This is fundamentally different from the models of the past.

Today's integrated and wholesale-only operators are continuously changing aspects of their business models in light of meeting policy or commercial objectives. While the degree in the use of what might be thought of as wholesale models will continue to range extensively across different providers, it is worth examining some of the operators that have recently changed their approaches. One model may not necessarily supersede others, but an analysis could reveal why changes have occurred and provide better understanding of drivers.

The following two sections consider selected developments in both fixed and wireless wholesale-only market operators. They assume that operators may take different directions and may not be engaged in all markets.

\section{Wireline wholesale-only providers}

Historically, structural separation in telecommunication infrastructure and service provision has generally been compelled by regulatory intervention, even via consent agreements. The best-known case was the breakup of the "Bell System" in the United States. After 1982, AT\&T provided long distance and international telecommunication services. Meanwhile, the "Regional Bell Operating Companies" provided regional and local telecommunication services.

In subsequent years, further regulatory reform generally led to more integration of service providers rather than separation. In the United States, changes in the Telecommunications Act of 1996 meant that players in different market segments could go into each other's 
markets. Meanwhile, countries such as Australia, Canada, Finland and Japan liberalised formerly separate markets (e.g. domestic and international). This led to mergers between previously separate incumbents. It also allowed formerly distinct actors to compete in each other's markets. However, it took several decades after liberalisation until the first privately-owned incumbent operators voluntarily chose structural separation.

The next subsection highlights examples of the Czech Republic and New Zealand, among others. The trend following liberalisation was almost always towards integration and privatisation. More recently, however, local, regional or national authorities have established wholesale networks (either publicly or privately owned).

\section{Czech Republic}

In 2015, the incumbent fixed and wireless telecommunication operator in the Czech Republic became among the first operators to voluntarily structurally separate its operations. This move surprised many observers around the world. The operator was not compelled by a change in sector regulation or court action by antitrust authorities. Nor did it have to meet requirements to participate in a sponsored broadband network.

To be sure, regulatory relief was part of the rationale. Nonetheless, the operator concluded the new structure could better meet different business requirements in areas such as providing long-term infrastructure. At the same time, it felt the new retail company could serve customers more flexibly and quickly. The company also believed it would unlock considerable value not previously recognised by the market given the assessment of risk and reward associated with both parts of the business.

Following the separation, the incumbent was split into two players. CETIN (Ceska telekomunikacni infrastruktura a.s) became the wholesale-only provider. Meanwhile, the previous brand (O2 Czech Republic), a publicly listed company, maintained the retail service. Today, the PPF Group N.V. wholly owns CETIN and holds a $65.9 \%$ share of O2 Czech Republic.

For the operator, a wholesale-only business had three benefits. It streamlined its business with a focus on network infrastructure. It provided a long-term investment horizon. And it avoided the conflict of interest from regulatory obligations. This potential conflict arose as, by then, an open network enabled all operators to acquire wholesale access on equal terms (CETIN Finance, 2016 $\left.{ }_{[51]}\right)$. In addition, CETIN could expand its customer base and increase use of the network (e.g. joint sharing of mobile network infrastructure by MNOs). Moreover, CETIN says, the separated infrastructure business facilitates a higher level of external debt. This is due to the focus on long-term contracts with a stable cash flow. By contrast, they view the consumer business as more potentially volatile.

Capital markets appear to have welcomed the decision to split the company. In 2017, the value of $\mathrm{O} 2$ Czech Republic equalled that of the entire company before the division. In its 2017 Annual Report, O2 Czech Republic remained stable in mobile services. But it recorded higher revenue even as its customer base fell in fixed line services.

The decline was perhaps due to equal access for competitors (O2 Czech Republic, 2017 $7_{[52]}$ ). At the same time, the company expanded into areas not traditionally associated with telecommunication operators. These included financial services, hardware and travel insurance.

New Zealand 
The former Telecom New Zealand (TNZ) also decided to separate into a wholesale-only company and a retail company. In 2008, the company was functionally separated into three business units: Telecom Retail, Telecom Wholesale and Chorus. It created Chorus to bid for contracts under the government's programme to build FTTP networks covering $87 \%$ of the population by the end of 2022 .

In 2011, Chorus was split off from its parent as a condition of winning most of the contracts for the fixed broadband network. It was listed on stock exchanges as a separate company from TNZ; TNZ subsequently changed its name to Spark. Under the new structure, Chorus cannot provide retail services by law. However, Spark retained its wireless network, as well as its role as a retailer of fixed services.

In recent years, both companies have recorded solid financial performance. Successive New Zealand governments have reported satisfaction with the roll-out to meet their national broadband targets. As in the Czech Republic, the retail company in New Zealand witnessed a reduction in overall wireline connections. Again, equal access for competitors possibly accounted for the decline in connections. Meanwhile, it more than held its own with respect to mobile subscription levels.

There was one major difference between the Czech Republic and New Zealand models. In the case of New Zealand, the government specified that the successful bidder for broadband contracts would need to be a wholesale-only company. In other words, both companies envisioned financial benefits from the regulatory relief that would follow structural separation. In New Zealand, winning contracts under the government's broadband plan was expected to generate the most benefits. In the Czech Republic, an overall improvement in operating conditions was expected to generate the most benefits.

Other differences were also apparent. In the Czech Republic, the wholesale-only company kept both wireline and wireless infrastructure. Meanwhile, in New Zealand, Chorus inherited the fixed network and Spark the wireless network. Finally, while all four companies are privately owned, the two in New Zealand are publicly listed; only one is publicly listed in the Czech Republic. In contrast, CETIN is not a listed company. While they are distinct companies, there is substantial common ownership between O2 Czech Republic and CETIN.

\section{Denmark}

In addition to the two cases mentioned above, TDC, the incumbent telecommunication operator in Denmark, announced plans to establish two new business units in June 2018. One unit, NetCo, would focus on network infrastructure. Another unit, OpCo, would focus on digital services and customer experiences (TDC Group, 2018 ${ }_{\text {[53] }}$ ).

The change in direction followed the purchase of TDC by the Macquarie Group, a diversified financial company headquartered in Australia with substantial investments in infrastructure. Its investments include entities providing wholesale services on communication towers and three Danish pension funds (Jacobsen and Hellstrom, 2018 [54]). TDC was delisted from the Danish stock exchange in May 2018; the new business structure took effect from August 2018.

At the time of purchase, the new owners said they wanted TDC's entire fixed and mobile networks to become open for use by all telecommunication brands and retailers in Denmark (NetCo). Meanwhile, the existing business would concentrate solely on customer service, product development and content $(\mathrm{OpCo})$. The new owners said the separately managed NetCo would seek to reduce duplication in infrastructure. To that end, NetCo would invest 
in fibre networks jointly with Denmark's utility companies, while acting as a platform for increased retail competition.

A growing number of other wholesale-only networks in various countries reflects a large mix of different ownership and market structures. Some are publicly sponsored national or regional networks, including those evolving from public and private utilities. In those cases, policy makers determined that a non-interventionist approach had not sufficiently increased broadband penetration or service levels. This was especially the case in rural and remote areas, though also in Singapore.

Authorities in these countries expected negative consequences if broadband rollouts were left to commercial operators. Specifically, they believed these companies would concentrate in areas of higher population densities and not update infrastructure quickly enough to meet policy objectives. To avoid this, some governments invest in national network infrastructure that will provide wholesale-only services to existing and new retail service providers. Other countries have primarily supported market-driven infrastructure, while providing finance to areas considered unattractive to the marketplace.

\section{Australia}

Australia established the National Broadband Network Co (NBN) in 2009 as a national, wholesale-only next generation broadband platform. It would operate on an open access and non-discriminatory basis to support fair and effective retail-level competition. The establishment of NBN also addressed concerns about Telstra's dominance in the broadband market. Essentially, structural separation of Telstra enabled the progressive migration of its customers to the NBN. The national network uses a combination of fibre, hybrid fibre coaxial cable (HFC), copper, fixed wireless and satellite technologies.

An agreement between the companies gives NBN access to Telstra's infrastructure over a 35 -year period. Moreover, their agreement stipulates a period of 18 months between the availability of NBN services in a region and the migration of all households and businesses from the copper and cable networks to NBN. As part of the agreement, Telstra receives compensation from NBN in a payment per subscriber. ${ }^{11}$

Telstra is one of NBN's largest customers, as well as one of its biggest suppliers. In addition to copper access networks, it also provides HFC, as well as planning and design services to support the NBN roll-out. NBN also has an agreement to provide access to the HFC of Optus, historically the second largest network operator in Australia.

By April 2019, NBN said that around 8.9 million premises were ready to connect. In other words, around $75 \%$ of homes and businesses across Australia could order a service over the company's access network (NBN Co, 2019 [55]). Unlike in the Czech Republic and New Zealand, the Australian model required its national platform (NBN) to be publicly owned until completion of the network. In addition, NBN represented the creation of a new company. Conversely, CETIN and Chorus were new entities after structural separation, but carried over more than just the physical network assets from the original incumbent.

\section{Singapore}

The case of Singapore represents a further example of a national, sponsored wholesaleonly operator. In 2007, the Singapore government announced plans for a state-funded national broadband network to enhance competitiveness of the country's economy. After an open tender process, the roll-out of the new fibre network commenced in 2009 through the creation of OpenNet. Singtel, the incumbent telecommunication carrier, was a part owner. For its part, Singtel committed to transfer infrastructure to OpenNet. At the time, 
its chief executive officer said, “... passive network assets like ducts and manholes will no longer be a telco's competitive advantage as every service provider has equal access to the infrastructure" (Chin, 2017 $\left.{ }_{[56]}\right)$.

In 2011, Singtel established NetLink Trust to hold the passive non-fibre infrastructure assets used to support OpenNet's deployment of the national fibre network. NetLink Trust subsequently acquired OpenNet, in November 2013, and integrated its operations. The network connects all residential homes and non-residential premises in Singapore. The wholesale-only operator provides dark fibre to retail service providers. They, in turn, provide retail broadband services to end-users, consisting of residential and business customers. NetLink Trust was floated on the Singapore stock exchange in 2017; the regulator had required Singtel to divest its majority stake in NetLink Trust.

\section{France}

France, Ireland, Italy, Switzerland and Argentina have also developed or proposed wholesale-only wireline networks that are owned or sponsored by national governments or fully owned by the private sector. Some of these networks are aimed at suppliers of service to business users. Others target retail operators servicing both the enterprise and consumer markets. KOSC Telecom, for example, is a private sector start-up in France that has set up a dedicated wholesale-only network (KOSC Telecom, 2018 [57] ).

KOSC has made substantial investments to update its network. Initially, its infrastructure was made up of two different networks bought in March 2016 from OVH and Completel. OVH, Europe's leading cloud computing specialist and web host provider, has backed the company. KOSC aims to provide wholesale infrastructure, as well as back office management tools for retail companies servicing business users.

KOSC calls this a "Connectivity as a Service" model. An Extranet platform and API in line with the latest technology standards give customers full control over their back-office administration. With one interface on one system, customers can validate addresses; check eligibility; receive instant quotations; place, follow and modify their orders; check indicators; carry out tests and register maintenance tickets. They then use the interface to serve their own customers such as businesses and universities.

The company has $20000 \mathrm{~km}$ of fibre optic cables across France connecting more than 180 towns and cities. It also uses a mix of local access technologies. While competing with Orange in the wholesale market, KOSC has also signed a long-term agreement with Orange to co-invest on a nationwide fibre infrastructure. Finally, KOSC has also started to connect to the different subsidised fibre networks in France to extend its national coverage (KOSC Telecom, 2017 $\left.{ }_{[58]}\right)$. This effectively adds the active connections each region has on offer to KOSC's own passive connections.

Beyond national wholesale-only networks, many private sector players have variations of the concept internationally. These offer combinations of dark fibre and cloud services to other wholesale providers and B2B service providers. Superloop, for example, provides connection in cities such as Singapore and Sydney with city fibre networks. These are closely linked to data centres, Internet exchange points and international undersea cables (Superloop, 2018 [59]). Ufinet, a neutral fibre optic operator headquartered in Madrid, has $58200 \mathrm{~km}$ of fibre spread across Europe and Latin America (ufinet, 2018 $8_{[60]}$ ). Ufinet offers dark fibre, either through rental of threads or long-term transfer of right-to-use via commercial agreements (Indefeasible Right of Use). The company provides the fibre thread, while the customer illuminates it according to its needs and with its own equipment over short or long distances (ufinet, 2018 [61]). 
Ireland

Aside from entirely private sector wholesale-only providers servicing operators aimed at the business community, there are players with government stakes. Ireland, for example, has a wholesale-only operator called Enet. It operates a fibre optic network known as the Metropolitan Area Networks on behalf of the Irish government. The open network connects 94 towns and cities throughout Ireland. It is used by over 60 carriers, which acquire a wide range of products and services from Enet. The company also has a wireless network to complement its fibre network. In 2017, the Irish Infrastructure Fund, a private equity fund, acquired $78 \%$ of Enet. ${ }^{12}$

Meanwhile Enet and SSE, a large energy provider operating in Ireland and Scotland, are jointly bidding for the next stage of Ireland's national broadband plan. This involves providing FTTP to roughly 540000 premises in rural Ireland (Kennedy, 2018 ${ }_{[62]}$ ). Companies such as Enet or Eir, the incumbent telecommunication operator, have certain obligations. Winning bids to provide infrastructure under the programme must provide wholesale-only networks on an open access basis for retailers. The retailers, in turn, sell services to the public (DCCAE, 2018[63]).

Many energy utilities have entered the telecommunication market as wholesale-only providers in OECD member countries. In Ireland, SIRO is a joint venture between Electricity Supply Board (ESB) and Vodafone. Together they deliver a wholesale-only FTTP broadband network, with speeds of up to $1 \mathrm{Gbps}$. ESB is a state-owned electricity company in Ireland (SIRO, 2018[64]). Notably, using the existing ESB network, SIRO is delivered through fibre optic cables. These run alongside existing electricity connections, all the way to the premises of business and consumers (i.e. FTTP). SIRO is offered on an open-access basis to all telecom retailers in Ireland. Launched in mid-2015, SIRO had passed 40000 premises by the end of 2016 and 160000 by the close of 2017 .

\section{Switzerland}

Another example of utility companies providing wholesale-only broadband is Swiss Fibre Net AG, a joint venture of local energy providers in Switzerland. Swiss Fibre Net and similar Swiss players have attracted traditional operators such as Sunrise. The largest challenger brand in the country, Sunrise has co-invested in its "layer 1" fibre. It has signed long-term leases of 20 years and offers retail 1 Gbps FTTP services (Sunrise, 2018[65]). Sunrise's MNO also has an agreement with Swiss Fibre Net to offer wireless sites and the fibre connecting these towers (Sunrise, 2015 $5_{[66]}$ ).

In March 2018, Salt - an MNO in Switzerland - announced the launch of a 10 Gbps service to consumers using Swiss Fibre Net (Salt, 2018 $8_{[67]}$ ). By using a wholesale network, Salt evolved from a standalone mobile service provider to one offering a fixed line triple play service (Internet access, television and telephony). It also offered this service at substantially lower prices than 1 Gbps services in Switzerland or than the small number of 10 Gbps service in other countries. The monthly price of USD 52 per month (CHF 49.95) was reduced to USD 41 (CHF 39.95) for Salt's mobile customers. Salt's "Fiber Box" delivers symmetrical $10 \mathrm{Gbit} / \mathrm{s}$ technology by means of a $10 \mathrm{Gbit}$ LAN port, which the company claims as the world's first.

\section{Italy}

In Italy, Open Fiber is establishing a wholesale-only network based on FTTP with two joint owners. One owner is Enel S.p.A, a multinational power company and integrated operator in the electricity and gas sector. The other is the government-backed investment 
bank Cassa Depositi e Prestiti. By the close of 2017, the network passed some 2 million households with its fibre networks. It is rolling out infrastructure in 20 Italian cities, with plans to work in another 80 urban areas. Furthermore, it has won public tenders to deploy broadband networks in rural areas, covering around 7000 communities.

Telecom Italia, the integrated incumbent telecommunication operator, is also in transition. In March 2018, it announced a plan to voluntarily separate its functions into two companies. Telecom Italia plans to create a separate unit for the network, but to continue full ownership. It has said the spin-off plan would grant competitors "absolute equality" of access to the network (Lepido, 2018 $[68]$ ).

\section{Argentina}

In 2016, Argentina's state-owned satellite operator ARSAT was tasked with bringing lowcost broadband access to 1200 localities throughout the country. This included 100 communities that had never been connected to the Internet (TeleGeography, 2016 $6_{[69]}$ ). At the time, the cost was projected to be USD 308 million. The funds were to be used to connect the rural localities to the country's in-deployment Federal Fibre-Optic Network (Red Federal de Fibra Optica, REFEFO). The REFEFO is composed of a federal backbone network. It is divided into 13 geographic regions and several provincial networks that are interconnected to the backbone.

REFEFO aims to span $58000 \mathrm{~km}$ and connect around 2600 localities, equivalent to $90 \%$ of the total population. Around $35000 \mathrm{~km}$ of the network is said to be complete. Although it is primarily designed as a wholesale operation, ARSAT will serve end users in regions where there is no other operator. Moreover, ARSAT is deploying a wholesale-only mobile network for LTE using spectrum in the 850-MHz and $1900-\mathrm{MHz}$ bands.

\section{Sweden}

National governments, the private sector or some combination of the two are creating wholesale-only networks, there are also many provincial or municipal networks (OECD, $\left.2015_{[70]}\right)$. Since pioneered in Stockholm, at the dawn of the broadband era, some municipal networks have been successful and others, for a variety of reasons, have fallen well short of expectations. For its part, Stokab continues to be viewed as one of the most successful wholesale-only municipal networks. Its model of only selling dark fibre in Sweden's capital has avoided classic pitfalls. Sometimes municipal networks selling integrated services or creating platforms constrain retail providers from fully leveraging the benefits of such networks.

\section{Wireless wholesale-only providers}

While providing wholesale services to MVNOs is common in the wireless sector, most MNOs provide their own retail services direct to users in competition to these MVNOs. The number of wireless wholesale-only providers is more limited. This is also influenced by that fact that most MNOs share some kind of infrastructure.

In the Czech Republic, CETIN provides wholesale wireless infrastructure without providing retail mobile services. Meanwhile, Rwanda and Mexico have established wireless wholesale-only network providers that also do not sell services directly to the public.

In 2013, Rwanda signed an agreement with KT Corporation, Korea's incumbent telecommunication carrier. The company is deploying a wholesale-only high-speed (4G LTE) broadband network to cover $95 \%$ of the population. Korea Telecom Rwanda 
(KTR) committed USD 140 million over a number of years. For its part, the government contributed access to its $3000 \mathrm{~km}$ of fibre optic network and spectrum. It also provided a licence to create the only $4 \mathrm{G}$ network in the country.

KTR reached its coverage target by the close of 2017, the highest level in sub-Saharan Africa for 4G. Three MNOs and 14 other retail providers now use the network to sell mobile and fixed wireless services. While the three original MNOs continue to use their own facilities (Edge/GPRS and 3G), they also resell KTR's network. By the close of the third quarter of 2017 , MNOs had $86.4 \%$ of the $4 \mathrm{G}$ resale market and the other resellers $13.4 \%$. The difference is partially due to the distinct advantage of the original MNOs; they enjoy sole access to numbering for calls over $4 \mathrm{G}$ (although the other $4 \mathrm{G}$ operators can use VoIP).

In Mexico, the Red Compartida, a wholesale-only 4G network, commenced operations in March 2018. It had surpassed an initial roll-out target for that date of more than $30 \%$ of the population. As in Rwanda, part of the rationale for creating the Red Compartida was to improve communication services in underserved areas. It had a final target of $92.2 \%$ within five years of commencing operations. However, Red Compartida also sought to improve the level of competition, particularly in underserved areas.

There are several differences between the market structures in the Czech Republic, Mexico and Rwanda. For example, CETIN inherited a wireless network over which it has built 4G. For their part, KTR and the Red Compartida are start-up 4G-only networks. At the same time, CETIN and the Red Compartida compete, at least at the wholesale level, against other 4G MNO networks. Conversely, KTR is the sole such network in Rwanda. Finally, the resellers in the Czech Republic and Mexico do not face any disadvantage compared to the MNOs in terms of numbering.

\section{The rise of wholesale-only wireless tower providers}

In recent years, MNOs such as AT\&T, Bouygues Telecom, KPN, Verizon and many others have sold wireless towers outright or as long-term leases. Buyers and renters included firms such as American Tower, Cellnex, Crown Castle and SBA Communications (Annex A). In 2017, by one account, more than 120 independent tower and Distributed Antenna System (DAS) providers operated in the United States (Bazelon and Seth, 2017 $7_{[71]}$ ). It also noted that independent providers rather than MNOs now own most of the over 100000 towers of the more than 300000 transmission sites (i.e. including antennas on buildings) in the United States. Finally, the report said the largest of these companies are organised as real estate investment trusts; the industry terms MNOs or others locating equipment on the towers as tenants. ${ }^{13}$

Alternatively, some MNOs (e.g. Telefónica and Telxius) have set up infrastructure divisions of which a share is sold. Others (Telecom Italia and INWIT, America Móvil and Telesites) have created separate listed companies, where common ownership still occurs. Some telecommunication operators have also created entities that provide towers for television broadcasting, and which can then be divested. Telecom Italia, for example, has considered the sale of its division called Persidera (Telecompaper, 2018[72]). Meanwhile, players that once specialised in broadcasting (e.g. Arqiva in the United Kingdom) have entered the wireless telecommunication tower market.

Other major players that have entered into the tower market are investment funds. These include those run by Brookfield, the Macquarie Group, KKR and the Canada Pension Plan Investment Board. Some companies have created their own tower operators. Others have taken major ownership stakes in tower players created by MNOs. Still others have become 
among the largest shareholders in the listed companies in the sector. In addition, investment funds owned by some traditional telecommunication companies invest independently from the companies' MNO operations. For example, Deutsche Telekom Capital Partners was part of a consortium that invested in Sunrise's towers in Switzerland, a country in which T-Mobile does not have an MNO.

DAS represents a market segment for another group of wholesale-only players, including specialised companies such as Boingo. It also includes companies with a mix of towers and indoor small cell provision such as the Wireless Infrastructure Group, which operates 2000 sites in the United Kingdom (Wireless Infrastructure Group, 2015 [73]]).

Large companies best known for tower provision, such as American Tower, have also entered this market along with new players such as Tillman Infrastructure. The latter, in partnership with JCDecaux, which is a leading advertising services company, which sells advertising on, for example, street furniture, billboards and posters on buses, trains and subways. Meanwhile, entities such as edotco, the wholesale-only unit of Malaysia's Axiata, have begun installing street lamps that can host multiple MNOs (edotco, 2017[74]).

All these players are focused on providing wholesale connectivity to MNOs in locations such as shopping malls, airports and, increasingly, on street furniture. They all see opportunities to provide an increasing portfolio of wholesale-only services to MNOs gearing up for the small cells required by $5 \mathrm{G}$.

There is no single business model for the wholesale-only wireless players, whether offering neutral wireless towers or DAS. Essentially, however, they provide a portfolio of passive infrastructure and related services to MNOs. These include roles such as site identification and acquisition through to tower or DAS construction and maintenance. Unless they have spectrum, such as CETIN in the Czech Republic, or use unlicensed spectrum, they do not operate active infrastructure. Some of the players have extensive fibre backhaul networks, which they offer to MNOs.

These developments raise the questions of why some MNOs have sold wireless towers, why other players have entered this space and what it may mean for operators. New entrants, investors and tower operators enter the tower or DAS markets reportedly for several reasons. These include stable revenues backed by long-term customer contracts, predictable cash flows, strong operating margins and growing customer demand.

In addition, high barriers to entry have historically been a feature of the telecommunication sector, limiting the potential for disruption. Typically, leases to MNOs average about ten years, with annual escalations linked to inflation. Meanwhile, growth in demand for wireless services has been spectacular for more than two decades. Demand for facilities is also expected to increase with $5 \mathrm{G}$.

The case made by tower and DAS providers to MNOs can be exemplified by the words of GTL: "Our business model of infrastructure sharing enables the Telecom Operators to convert their capital expenditure to a fixed and predictable operational expenditure, allowing them to divert precious capital towards core activities." 14

Nonetheless, there are a number of possible reasons why some MNOs have sold towers or created new entities to attract investors or new businesses. Those that have sold towers outright or over long-term leases can use the influx of money in many ways. They may fund acquisitions, retire debt, return value to investors through stock buy-backs, purchase spectrum and upgrade their networks with new generations of wireless technology. Some MNOs, depending on the country of operation, may also seek relief from regulation. In 
addition, they may wish to increase network sharing through the introduction of an independent or arms-length player.

A transaction between an $\mathrm{MNO}$ and a tower company illustrates the mutual benefits. In 2015, Verizon agreed to lease the rights to 11324 of its towers and sell 165 additional towers outright to American Tower for USD 5 billion (Marek, 2015 ${ }_{[75]}$ ). The deal gave American Tower exclusive right to lease and operate Verizon's towers for 28 years. In addition, American Tower purchased the right to acquire the towers at the end of the lease term. American Tower estimated, at the time, that the towers would generate about USD 410 million in rental revenue and around USD 235 million in gross margin. For its part, Verizon agreed to lease tower space back for a minimum of ten years at a monthly rate of USD 1900 per site and with an annual increase of 2\%. Verizon also retained the option to use additional space in the future.

The leading independent and listed tower and DAS providers have performed well in recent years. American Tower, for example, has performed well in relation to the S\&P Index 500 (Table 3).

Table 3. Cumulative total return for American Tower (AMT) versus other indexes

\begin{tabular}{rrccccc}
\hline & 2012 & 2013 & 2014 & 2015 & 2016 & 2017 \\
\hline American Tower Corporation & 100 & 101.79 & 104.78 & 131.78 & 146.59 & 201.79 \\
S\&P 500 Index & 100 & 132.39 & 150.51 & 152.59 & 170.78 & 208.14 \\
Dow Jones US Telecommunications Equipment Index & 100 & 121.43 & 139.90 & 124.79 & 148.67 & 182.98 \\
FTSE Nareit All Equity REITs Index & 100 & 102.84 & 131.68 & 135.40 & 147.09 & 159.85 \\
\hline
\end{tabular}

Source: American Tower, Annual Report, February 2018.

Tower and DAS providers have been attracted in part because of a record of stable earnings, underpinned by long-term leases in a market with burgeoning demand. In its 2017 annual report, for example, Crown Castle reported that non-renewals had averaged approximately $2.5 \%$ of site rental revenues over the previous five years; this included a number of small MNOs acquired by larger MNOs in the United States (Crown Castle International, $\left.2017_{[76]}\right)$. That being said, tower providers recognise industry consolidation as a risk. It can result in MNOs eliminating duplicative facilities or not expanding in areas for which they may have otherwise signed new leases due to the inherited facilities. This has been evident in lower valuation for tower providers in India following industry consolidation in 2017.

How will developments over recent years play out for operators in the future? The Chair of Bharti Airtel, the third largest MNO in the world by subscriptions and also Chairman of the GSMA, provides one perspective. In February 2018, his company planned to follow the lead of other MNOs by seeking to sell towers to players that specialise in their operation and management. In his view, "...towers are steel and concrete. They are not the domain of mobile companies" (Busvine, 2018[77]). Certainly, the attractiveness of the model appears to be strong for many MNOs, some tower providers and segments of the investment community as well.

Costs can certainly be reduced and capital invested in infrastructure could be released through a wholesale approach using independent providers. However, this relies on competitive discipline in the market. Recent contracts point to MNOs continuing to look for cost reductions, but also participating strategically in new site development. In November 2017, for example, AT\&T and Verizon entered into an agreement with Tillman 
Infrastructure to build hundreds of towers in the United States. In addition to assuming the role of anchor clients, they would also investigate shifting facilities to these sites as leases came up for renewal.

The two MNOs said choosing Tillman Infrastructure, rather than one of the three largest suppliers in the United States, considered the benefits of diversifying supply. Verizon's Chief Network Officer had said "...we are excited to develop new vendor partners to diversify our infrastructure providers... We need more alternatives to the traditional tower leasing model with the large incumbents. It's not cost-effective or sustainable" (Verizon, $\left.2017_{[78]}\right)$.

While MNOs seek to diversify supply, policy makers and regulators may also benefit from the uptake of the wholesale-only model for wireless towers, which is largely driven by market forces. A case in point is for ensuring new market entry. In India, for example, Reliance Jio uses wholesale towers in addition to building its own infrastructure. In March 2018, the Reliance Chair noted it had taken three years for Jio to roll out a 4G network that could be rapidly updated to $5 \mathrm{G}$ (Cantoni, 2018[79]). He contrasted this to the 25 years it had taken for all MNOs to reach that coverage level with $2 \mathrm{G}$.

Today, when a new entrant enters a market for the first time, it can negotiate for access to wholesale-only infrastructure. In February 2018, ahead of the launch of its MNO in Italy, Iliad was reportedly negotiating with Cellnex to use its 7766 towers in that country (Telecompaper, 2018 $8_{[72]}$ ). The extent to which independent tower providers connect their facilities to extensive backhaul and extend their DAS coverage may pave the way for new fixed wireless and cellular wireless entrants. It may also enable existing MNOs to compete more effectively against rivals with larger coverage.

\section{Wholesale-only networks: Benefits and challenges}

Wholesale-only provision is playing an increasing role in communication markets. It is driven by the demand to reduce costs, the rationale to optimise capex and to improve services through shared infrastructure. Sometimes regulations also drive wholesale-only provision in areas that lack competition among facilities or underserved locations; the regulations would ensure greater choice for users. All markets use wholesale-only provisions, to one degree or another, at some level of the value chains that enable fixed and wireless communication services. That said, with such market structures, all models for the delivery of communication services offer potential benefits and challenges.

Wholesale-only operations that have emerged from a restructuring of the businesses of traditional integrated service providers is one potential model. At one end of the scale are CETIN in the Czech Republic and Chorus in New Zealand. At the other end are players created by the divestiture of towers by MNOs. Meanwhile, newly created players have entered as wholesale-only providers. These include Australia's NBN, Ireland's Enet or SIRO, Italy's Open Fiber, Mexico's Red Compartida and Singapore's OpenNet. There are also municipal wholesale-only networks in many parts of the world such as Stokab in Stockholm.

A key challenge for all these networks is obtaining the necessary investment and support from prospective clients. This is perhaps easier for players such as CETIN and Chorus, which already own and operate existing networks. In other words, they have access to rights of way, skilled staff, existing customers and revenue streams.

New entrants such as Australia's NBN and the Red Compartida would have more challenges. They are entering established markets with vertically integrated competitors in 
strong positions. In such cases, they need to buy existing assets of these players (Australia). They also need to persuade those operators to use their wholesale networks (Australia and Mexico).

Incumbents will often respond in ways they believe will allow them to compete more effectively with the wholesale-only players. Telecom Italia's proposed functional separation, for example, aimed to offer neutral facilities to compete with Open Fiber. As another example, Ireland's incumbent Eir was sold to Iliad, a company that emerged as a challenger in France.

Meanwhile, wholesale-only providers need to consider how technological change may open opportunities for alternative broadband pathways. In New Zealand, for example, Spark reportedly emphasises its own wireless infrastructure, which has higher returns than its retail services on the fixed wholesale network offered by Chorus (Bennett, 2018 ${ }_{[80]}$ ).

The challenge for a green fields operation is exemplified in Stockholm. This is true even though, as a municipal network, Stokab started with advantages such as established rights of way. At inception in $1994^{15}$, in association with the liberalisation of the telecommunication market in Sweden, Stokab did not own fibre networks and had no customers. With no revenue streams, it still needed long-term and heavy investment to build fibre networks. Cash flow, therefore, was critical. As a result, Stokab had negative free cash flow, calculated as EBITDA minus capital expenditures, for the first nine years of its operations.

The need for additional capital was resolved through a group contribution by the owner, the City of Stockholm. For the first four years, the city rolled out its initial network and achieved sufficient sales. The group contribution was subsequently repaid. Today, the city receives a healthy dividend, as well as the benefits from the extensive dark fibre network for all service providers. The high demand for access to operator-neutral dark fibre in Stockholm was, however, not guaranteed at the outset. Furthermore, it has exceeded the city's expectations.

Once a wholesale-only network is operational and returning a profit, other areas may present challenges. One issue is whether the market structure provides the correct incentives for further investment. This is especially the case if the wholesale-only player lacks competition or, if required, regulatory oversight.

In addition, depending on the model used, wholesale-only operators may influence the pace of network upgrades and innovation in a variety of ways. Stokab, for example, provides only dark fibre. This means private sector customers can introduce new technologies and innovations at a pace dictated by a competitive market. On the other hand, some wholesale networks in Sweden offer services at higher network layers than Stokab.

As a result, some have raised the question as to whether the lower introduction of equipment capable of offering IPv6 in Sweden is an outcome of not following the Stokab model. At the other end of the scale, some believe the Red Compartida's higher layers of services to MNOs and MVNOs will enable it to move quickly from $4 \mathrm{G}$ to $5 \mathrm{G}$, particularly when face by integrated competitors.

But what happens when wholesale-only networks face insufficient competition? Longer term, what incentives do wholesale-only operators have to continue investing in infrastructure?

In the case of Stokab and OpenNet, ubiquitous coverage has been achieved with dark fibre networks in their areas of operation, though in locations with high population densities. In 
the Czech Republic, CETIN has sought to attract and reassure its key customers (O2 and T-Mobile). To that end, it has agreements of specified amounts of capital for upgrading and expanding fixed and mobile networks (USD 900 million or CZK 21 billion for 2016-22).

Various forms of wholesale-only operators are present within OECD member countries. These wholesale access networks may significantly change the dynamics of communication markets. If they can attract others to use their infrastructure, they could be a more cost-effective model for investment in broadband networks. For future operators, the various wholesale-only models could help save money, increase use of networks and perhaps orient risks more towards retail businesses. At the same time, wholesale-only players require service providers to use the network. The key features required for successful wholesale-only businesses are stable financial performance, long investment horizons and strong free cash flows.

\section{(Terminal) equipment and online service providers}

The Internet has enabled increasingly different parts of a value chain to enter into each other's market, or potentially to do so. Consider telephony or cable television. Once the sole domains of specific types of communication companies, telephony and cable are now offered by players best known for equipment (e.g. Apple's FaceTime), search (e.g. Google Hangouts), social networks (e.g. Facebook's WhatsApp) or books (Amazon's Alexa). Many others from Twitter to Microsoft offer voice, video or other services once tied to specific infrastructures. For convenience, these companies are here called terminal equipment and online service providers.

By 2017, as measured by market capitalisation, these companies had become the largest enterprises in the world. In that year, the top four firms by this measure were Apple, Alphabet, Microsoft and Amazon, joined by Facebook (6th), Tencent (11th) and Alibaba (12th) (PwC, 2017 [81]).

Other familiar digital economy players in the top 20 were Samsung (14th) and two traditional operators AT\&T (15th) and China Mobile (20th). Market capitalisation represents investors' views of forward earnings. It translates into something that has given these companies the scale to profoundly influence the future of communication infrastructures and services.

This is nowhere more evident than in the expenditure attributed to online service companies for research and development (R\&D). According to Bloomberg terminal data and company reports, Amazon (USD 22.6 billion) ${ }^{16}$ and Alphabet (USD 16.6 billion) were the leaders in R\&D expenditure in 2017. They were followed by Samsung Electronics (USD 14.9 billion), Volkswagen (USD 14.8 billion), Microsoft (USD 13.9 billion), Huawei (USD 13.3 billion), Intel (USD 13.1 billion) and Apple (USD 12.1 billion) (Fox, $\left.2018_{[82]}\right)$.

Facebook (USD 7.8 billion) is also among the firms with the highest recorded R\&D for 2017. With a rate of $19 \%$ of R\&D expenditures to sales, Facebook is the leading online service company by this measure. It is followed by Google (15\%) and Microsoft (13.5\%) for the 2017 financial year. This was in stark contrast to the R\&D expenditure shares to sales of selected traditional telecommunication operators over the past year. These ranged between $0.08 \%$ (Deutsche Telekom) and $2.7 \%$ (BT).

Aside from the devices and services for which they are best known, these companies have been expanding their own communication infrastructures and creating new sources of 
content. They are now among the largest providers of backbone fibre networks. This includes undersea cables, an area once primarily the domain of telecommunication network operators. At the same time, they now commission an increasing amount of first run video entertainment. This was once primarily the domain of players more closely related to cinemas, broadcasting and cable television operations.

In recent years, companies in this category have driven the growth in submarine cables. Over 2013-17, the international capacity deployed by online service companies rose tenfold to 339 Tbps. Meanwhile, the capacity deployed by other operators has only increased three-fold to 350 (Mauldin, 2017 ${ }_{[83]}$ ). Companies such as Google (Box 7), Microsoft (AEC1, Hibernia Express, MAREA, NPC Cable system), Amazon (Hawaiki, JUPITER) and Facebook (AEC-1, APG, Havfrue, HKA, JUPITER, Marea, PLCN, SJC2) are all invested in submarine fibre cables.

Three factors drive demand in these companies. First, there are the needs of their own data centres. Second, there is the demand between the data centres in different regions. Third, there is the need for traffic routing optimisation between these centres and their customers (Mauldin, 2017[83]). In addition, companies have invested in fibre backbones.

Google offers FTTP and fixed wireless services in some American cities, and now has an MVNO offer in the United States, Project Fi. It uses Sprint and T-Mobile networks, as well as Wi-Fi networks. International mobile roaming is included for 170 countries. In April 2018, a data-only plan was priced at USD 10 per GB per month (Google, 2018 ${ }_{[84]}$ ).

Terminal equipment and online service providers have also entered another area of traditional operator markets. Specifically, they offer voice and chat services such as FaceTime, Line, Viber, Skype, Telegram, WeChat or WhatsApp. Many consumers use these services instead of, or in addition to, the traditional telecommunication voice and SMS offers. In this way, they benefit from the convergence of communication services over IP networks.

Beyond messaging and voice, a number of these companies are now important video content producers. Besides Netflix, companies such as Amazon, Apple, Facebook and Google all produce their own content and shows. Some of this output follows traditional models, while other content is a fusion between social media and video content.

Facebook, Twitter and YouTube, for example, have all secured the rights to transmit major sporting codes. These were once the sole domain of broadcast, cable television and telecommunication networks. They have also introduced new content or remakes of successful shows previously aired by traditional players. Some examples are Facebook's "Tasty", a cooking show that has attracted 92 million followers in that community. Facebook also commissioned a remake of "Skam", a successful show originally made and webcast/broadcast by NRK, Norway's national broadcaster (Tiffany, 2017 ${ }_{[85]}$ ) (Goodfellow, 2018 ${ }_{[86]}$ ). Skam, a drama aimed at teenagers, has scripted dialogue that can take place at any time of the day or location, as well as weekly summaries. This approach lends itself to interaction over social media. As one commentator noted:

In its approach to storytelling, Skam is a proper pioneer, spanning formats of Instagram, webisodes and traditional broadcast in a way that's never been done before, and which has helped foster its ravenous fan community. Each episode tells the story of one week, but consists of several scenes that drop in real time online: say a classroom scene happens at $2 \mathrm{pm}$ on a Wednesday - that scene will drop online at 2 pm on Wednesday ( (Vartleet, 2017 $[87])$ " 
Moreover, terminal equipment and online service providers have also launched subscription services, with integrated linear television and on-demand shows. These include Amazon "Prime Video" and "YouTube TV", which were once solely the domain of broadcasters and cable television companies. In addition, online service companies, depending on their business models, are some of the largest players in the advertising market. They draw much of that revenue away from traditional players.

\section{Box 7. Google's submarine fibre cable investments}

Over the past three years, Google has invested USD 30 billion to expand its infrastructure, including submarine fibre cables and data centres. In early 2018, Google announced its investment in three new submarine cables for launch in 2019. They will serve five new regions. The Havfrue cable will connect the United States with Ireland and Denmark. The HK-G cable will connect Hong Kong, the People's Republic of China with Guam. Together with other cables in the Pacific, the HK-G cable will provide an additional connection to Australia. The Curie cable, connecting the United States with Chile, is the first private cable built by a non-telecommunication company. In April 2018, work started on the Japan-Guam-Australia cable (JGA), a 6000 -mile cable $(9600 \mathrm{~km})$. It has a capacity of around $36 \mathrm{Tbps}$ (Sawers, 2018 $\left.8_{[88]}\right)$. Taken together, Google is participating in 12 undersea cables (Table 4).

Table 4. Overview of Google's investment in submarine fibre cables

\begin{tabular}{lrr}
\hline \multicolumn{1}{c}{ Cable } & Year in service & \multicolumn{1}{c}{ Landings } \\
\cline { 2 - 3 } JGA & 2019 & JPA, GUM, AUS \\
Curie & 2019 & USA, CHL \\
Havfrue & 2019 & USA, IRL, DNK \\
HK-G & 2019 & HK/CHN, GUM \\
Indigo & 2019 & SGP, IDN, AUS \\
PLCN & 2019 & HK/CHN, USA \\
Tannat & 2018 & BRA, URY \\
Junior & 2018 & BRA: Rio de Janeiro to Santos \\
Monet & 2017 & USA, BRA \\
FASTER & 2016 & USA, JPN, TWN \\
SJC & 2013 & JPN, HK/CHN, SGP \\
UNITY & 2010 & USA, JPN \\
\hline
\end{tabular}

Source: (Traynor Sloss, 16 January 2018[89]).

The investments enable Google to extend its network and provide more direct links between its data centres, cloud platforms and their users. In addition, Google's engineering vice president has highlighted that owning the cable has some important benefits: "Since we control the design and construction process, we can fully define the cable's technical specifications, streamline deployment, and deliver service to users and customers faster. Also, once the cable is deployed, we can make routing decisions that optimise for latency and availability" (Pearce, 2018 $\left.{ }_{[90]}\right)$.

Who will lead the field in terms of the IoT and machine-to-machine, as well as services for industrial sectors, business, consumers and smart city applications? It could be terminal equipment and online service providers or traditional operators, but more likely will be a 
mix of both. As discussed in the next section, for example, terminal equipment and online service companies have become leading players for voice assistant systems in IoT and artificial intelligence. An illustration that user behaviour can rapidly change is that in May 2016, mobile queries to Google in the United States concerning voice had already reached 20\% (Sterling, 2016 [91]).

At the same time, Amazon's virtual assistant, Alexa, is now built into more than 4000 types of smart home devices from 1200 brands. Adoption among device makers is said to be growing. At the 2018 Consumer Electronics Show, for example, "brands announced new AVS products [...] including: new integrations for Alexa on PCs from HP, Acer, ASUS and Lenovo; a new automotive integration with Toyota; and new devices from Polk Audio, Anker, Jabra and more" (Amazon.com, 2018 ${ }_{[92]}$ ).

In sum, terminal equipment and online service providers will be key players in the evolution of communication infrastructure and services. They have the financial strength and $R \& D$ capabilities to enter adjacent markets and contribute to substantial innovation in these sectors. To date, however, with a few notable exceptions such as Alphabet and Sony, they have largely not become ISPs. Furthermore, with the exception of Google Fibre, they have not provided last mile facilities. They are extremely effective competitors for OTT services. Likely, they will continue to drive change in these markets that reflect their R\&D commitments. However, traditional and new access operators maintain advantages in this field.

\section{Examples of technologies that may influence the operators and providers}

The layered model for providing communication infrastructure and services lends itself to substantial dynamism. Some of the largest shifts in communication markets in the previous three decades have been around the use of fixed and mobile broadband access and the Internet. These technologies have progressed from handfuls of users to many billions. For the most part, however, the operators that provided the infrastructure and services in the days of monopolies for telecommunication and cable television services are still among the market leaders. However, the range of their services has often been transformed. Many newcomers from different industries or parts of different value chains have joined them. At the same time, some players that pioneered new business models, services or technologies did not become future operators. Companies such as AOL, Altavista, Broadcast.com, Netscape and VocalTec were all, at one time, among the leaders in dialup, search, webcasts, browsers and VoIP.

These companies all influenced the direction of the sector, but for various reasons were overtaken by other developments. Today, companies such as Alphabet, Amazon, Apple, Facebook and Microsoft all offer a combination of services that include at least one element pioneered by others. Alphabet, for example, offers access through Google Fibre, Fi and Webpass, Google Search, YouTube, Chrome and Google Hangouts.

In the face of these developments, network operators have transformed their business models, portfolios of offered services and technologies. They have also entered each other's markets. Voice and video, while still important, are often no longer the core businesses of telecommunication and cable providers. They have been replaced by a combination of access and data transmission in response to changing demand.

Cord cutters may give up the traditional all-encompassing bundles of cable television in favour of services such as Netflix, SlingTV and Prime. However, they are purchasing more access from cable broadband providers. Consumers may make fewer telephone calls or 
send fewer text messages, but these are increasingly replaced by substitutes such as Skype, FaceTime and WhatsApp. All these services contribute to the burgeoning demand for communication access networks and data use.

Some technologies on the horizon such as blockchain, pCells, artificial intelligence, virtual reality and others may augment or disrupt operators in the future. In respect to blockchain technology, IBM has identified a number of applications for communication operators, including enhancing

...trust, security, transparency and control across the participating ecosystem for all points in a transaction process. This results in the potential for lower costs, faster throughput and improved experiences for all players ... including the IoT $\ldots$ billing, roaming, wholesale, NFV management and supply chain management. In the context of roaming, blockchain's benefits include faster identification of visiting subscribers, prevention of fraudulent traffic and claims reduction. In addition, the elimination of clearing houses could lead to significant cost reduction. (Van den Dam, 3 January 2018 [93])

In March 2018, for example, Colt Technology Services and PCCW Global, announced a collaboration with Clear, a blockchain start-up company. They sought to demonstrate that blockchain technology could reduce inter-carrier settlement times from hours to minutes (Colt Technology, 2018 ${ }_{[94]}$ ). The promise of this technology is to make inter-carrier settlements more efficient, reliable and scalable. The trial analysed and settled tens of thousands of call records in a few minutes. A manual process would have taken hundreds of hours of work. Furthermore, the companies noted "... blockchain technology adds an extra layer of security and trust to transactions in an industry where sensitive and proprietary information is frequently exchanged, fraud is rife, and dispute resolution can be lengthy and complex (Colt Technology, 2018[94])."

Telegram is another player seeking to expand its communication service through blockchain technology. The company is best known for its cloud-based encrypted instant messaging service. It reportedly has 200 million users who can exchange voice, audio, photos, videos, etc. In early 2018 , it was raising several billion dollars to create a new cryptocurrency (Al Ali and Khrennikov, 2018 ${ }_{[95]}$ ). The company says it wants to build its own blockchain network, with the currency built-in. In this way, it aims to enable faster transactions than rival cryptocurrencies. The funds raised are reportedly earmarked to build the network, rent servers and pay operating expenses. Ultimately, it wants to make ease of use, security and transaction speed selling points to encourage widespread adoption.

While blockchain could benefit future operators in several ways, it may also lead to disruption. One example is Ammbr Network, a wireless mesh network that aims at extending connectivity through a shared Wi-Fi approach (Ammbr, 2017 $[96]$ ). It is not owned or controlled by any single company, but rather by a community of users and infrastructure owners. It is based on three building blocks:

i) self-sovereign digital identity, which enables people and businesses to store their identity data on their own devices, and provide it efficiently to those who need to validate it

ii) blockchain technology, which is a digitised, decentralised public ledger of all cryptocurrency transactions

iii) mesh networking, which allows all parts of the community to share connectivity with each other. 
The Ammbr device provides the functionality of a Wi-Fi base station, an IoT module for ZigBee and a point to multipoint (LTE-U). It may allow users to trade connectivity, subject to approval by the infrastructure provider.

Another company using a mesh network approach is Common Networks (Networks, $2019_{[97]}$ ). It started service as an ISP in Alameda, a city in the United States, in 2017. Common Networks uses FCC-approved antennas that transmit data using $5 \mathrm{GHz}$ signals. A small antenna is installed on the rooftop of a customer's residence. Meanwhile, the inside wiring is completed with an Ethernet cable to a wireless router. The ISP charges USD 50 per month for a minimum symmetrical speed of $75 \mathrm{Mbps}$ and unlimited data usage.

The antennas are then used to interconnect locations in an Alameda neighbourhood. This creates a wireless mesh network between homes, the company's relay locations and their fibre Internet lines (Radich, 2018 ${ }_{[98]}$ ). As soon as some residences are connected, others can also purchase Internet access, as only a few of the antennas need to be connected to the source. The company says this mesh approach increases reliability by ensuring every home has multiple points of connectivity in a neighbourhood. If one radio fails or network traffic is particularly heavy in one area, they can route accordingly without the service being interrupted.

Another example of a product that may change the borders between operators and users is Artemis Network's Wireless Antenna. It provides short-range pCells over a $15 \mathrm{~mm}$-wide cable or small antenna. Webpass, an operator in the United States, is testing the pCell and provides broadband over wireless to multi-dwelling units. The pCells could also turn each fixed network user location into a network. In this way, it would provide nomadic connectivity to others in such a community.

Aside from connectivity, network access provides traditionally controlled customer interfaces (e.g. on set-top cable boxes and telephones). In recent years, these interfaces have largely been separated from the provision of access services. However, this is still much more common in telecommunication services than in cable television. In the area of smartphones, for example, Apple is the gatekeeper for default applications on its mobile smartphones. Historically, the MNO was the gatekeeper. Apple has exclusive control on both the hardware and software layer on its terminal devices. Moreover, Apple and Google dominate the market in mobile operating systems (ARCEP, 2018[99]).

In the future, two technologies may once again redefine such interfaces: artificial intelligence and virtual or augmented reality.

A range of devices available for "smart homes", automobiles and so forth, increasingly uses artificial intelligence to interact with users. Amazon's Echo device, for example, enables users to command communication capabilities, such as telephony and video calls, through voice. It can be used in combination with Alexa, an intelligent personal assistant developed by Amazon, enabling hands-free communication. Meanwhile, rivals such as Apple are integrating voice-activated assistants and artificial intelligence into a range of software and devices to enable users to manage functionality in televisions, automobiles and so forth. On an Apple TV, for example, "Siri" (the company's assistant) and the TV app combine to interact with a television. Conventionally, a set-top box provided by an ISP with a bundled Pay TV service would be used. A further example is Apple's HomePod, an audio speaker and home assistant.

Network operators such as Telefónica have also recently launched voice-activated assistants to interact with customers (Telefónica, 2018 $\left.{ }_{[100]}\right)$. The company is initially offering its assistant ("Aura") in selected countries. For example, Aura will operate as a 
smartphone app in Argentina, Brazil and the United Kingdom. It will also operate on Telefónica's Pay TV platform (Movistar Home) in Spain, and via Facebook Messenger in Chile and Germany. Telefónica plans to make the service available through Google Assistant and Microsoft Cortana.

In Spain, Telefónica planned to launch Movistar Home in the second half of 2018. The service integrates Aura's artificial intelligence capabilities with edge computing features to process and analyse data. Telefónica wants the service to become a hub for users to connect and manage all their devices at home, including their router and to control televisions. Users will be able to make voice-activated video calls on the television, as well as interact with entertainment features.

The range of devices and software enabling users to interact with other equipment and services is burgeoning. Some, like Telefónica's Aura platform, are agnostic. Others, such as Apple's HomePod and Siri, rely on an IOS device such as an iPhone. Meanwhile, services such as Telegram are said to be using artificial intelligence and machine learning to raise the quality of their peer-to-peer voice services (Telegram, 30 March 2017 ${ }_{[101]}$ ). For their part, operators increasingly offer devices such as Apple TV as a set-top box for their customers (e.g. AT\&T, Salt) rather than using their own equipment. Some, like Telefónica, make their intelligent assistant as widely available as possible via an application.

How will augmented and virtual reality influence how people interact with communication services? Smartphones have become the interfaces most used for communication services. However, companies such as Avegant, Microsoft, Magic Leap, Reality Reflection and others are working to place interactive images before viewers. Augmented reality aims for technology to detect and respond to the environment, creating a seamless blend of the real and the digital. Under such a scenario, the screens of devices such as smartphones or televisions may begin to cede part of their functionality to other forms of viewing and interacting with data. In other words, a future era of spatial computing will likely create new directions for all players beyond tethered devices and services (Agulhon, 2016 ${ }_{[102]}$ ).

For their part, network operators are experimenting with augmented and virtual reality. In August 2017, for example, KT and Verizon undertook what is reportedly the first international hologram-call using 5G networks (Song, 2017 ${ }_{[103]}$ ). Meanwhile, SK Telecom has an evolving service called Oksusu. It lets Koreans interact while watching videos, games and sport events together (Horwitz, 2018 ${ }_{[104]}$ ). The company has also presented the "holobox", a cylindrical device with a virtual assistant. Its image can appear on the device or on a smartphone (Boxall, 2 February $\left.2018_{[105]}\right)$. Finally, in the United Kingdom in March 2018, BT announced it would create more than 1300 apprenticeship and graduate jobs in areas such as television production, engineering, customer service and cyber security (BT, $\left.2018_{[106]}\right)$. Candidates will use virtual reality technology to complete a series of "Crystal Maze" style tasks.

\section{Comparing different types of operator models against policy objectives}

This section focuses on the implications of the different models on competition, innovation and investment. They relate these considerations to the different categories of market structures and evolving business models for network providers. Ultimately, it aims to help operators understand likely trends. Factors such as inherited networks, geography, population density and so forth mean that conclusions will always depend on local conditions. 
It takes an identifiable user group and at the leading edge of demand (game players), for all the reasons previously set out, to see how demand may shape outcomes over five to ten years. ISPs providing the highest levels of performance come from different market structures, use different technologies and often have different business models. In some countries, ISPs from traditional telecommunication operators with integrated business models are among the leaders. In other countries, the leaders are ISPs that provide retail services but not the "last mile" facilities. Some come from traditional telecommunication or cable broadband networks. Others are new entrants emerging from a variety of different parts of the communication value chain.

Policy makers have similar objectives for expanding and improving broadband networks. Their tools to achieve these goals include fostering competition, innovation and investment in communication markets. In addition, they have put certain social obligations related to accessibility and/or deployment in specific areas on traditional communication operators. How will policy makers adapt these obligations to the rise of alternative operator models described previously?

In terms of technology, operators of all these networks overwhelmingly believe in the need to deploy fibre deeper into networks. This belief is irrespective of their current last mile choices and underscored by the quality of service experience by Steam users. Today's leading-edge fixed broadband offers at $10 \mathrm{Gbps}$ (i.e. the outliers) for consumers will likely be replicated in other locations over the coming five to ten years. Meanwhile, depending on network configurations, the Steam data sometimes identify the increasing use of wireless networks by game players. There is also a widespread view that fibre optic networks will need to be deployed more deeply to support the smaller cells expected with $5 \mathrm{G}$.

Overall, given the right circumstances, all the different operator models can meet policy objectives. Successful cases can be found for each operator category. For example, all the models can be found among the leading companies in the Steam statistics. A full assessment of the different models' effects on competition, innovation and investment must be undertaken. It needs to examine carefully any market under analysis. This would include the number of players, whether different operator models co-exist, the historical developments in a market and so forth. The following provides some general thoughts on issues and challenges.

\section{Competition}

Since the liberalisation of communication markets, end-to-end infrastructure competition of traditional vertically integrated operators and cable operators has been considered the most valuable model to foster competition. If enough operators compete on an end-to-end basis, consumers can typically benefit in several ways. They would enjoy a range of different technologies; a wide variety of prices and offers in a market; and technological and service innovation.

Integrated telecommunication and cable broadband operators typically compete with bundles on price, capacity and differentiated data volumes in combination with their brands. Sometimes they also combine fixed and mobile services. Cable operators have often benefited from their experience in the production and distribution of content when offering bundles that contain television services. Sometimes they include premium content.

Vertically integrated operators typically face retail competition. This will likely increase in the future, especially given the large outlays of competitors in areas such as media 
content production and R\&D. Following the growth of providers of terminal equipment and online service, incumbent communication operators face two kinds of competition. They compete in traditional services, but also in areas such as voice assistants. This competition comes from OTT service providers and device manufacturers alike. They both benefit from IP networks enabling open markets where services are no longer tied to equipment or access provision. Some vertically integrated companies have responded by partnering with terminal equipment and online service providers. They want to make their offer more attractive for consumers or tackle OTTs head on in their own markets (e.g. by offering advertising).

Telecommunication and cable operators remain strong competitors in OECD member countries. The size of the overall market has increased as measured by indicators such as subscriptions or total revenue. Some areas, however, lack infrastructure competition, which demands ongoing regulatory intervention or oversight. As a result, vertically integrated incumbents were, and in many cases remain, subject to regulation following liberalisation.

In the OECD area, regulations stipulate that some operators must provide wholesale facilities or services to access seekers, depending on assessments of the level of competition. Providing such access to parts of incumbent infrastructure has spurred competition in the retail market. Such regulatory intervention has ensured that countries such as Japan and Sweden are among the leaders in broadband networks. At the same time, the experience of Korea highlights the need to lift some access requirements due to fierce infrastructure competition.

In these landscapes, regulators should monitor the conditions placed by traditional operators on their offers. In addition, they should assess if alternatives for end-customers are restricted in any way and if different layers of a market have enough competition. While discussions will continue around issues such as network neutrality, access networks must ensure competitive service choices for users. Meanwhile, even if retail competition mitigates such concerns, issues can arise with wholesale monopoly power.

In recent years, different wholesale models have arisen in several OECD member countries. Some have been driven by the private sector. Other models have received public funding or are publicly owned. This is the case, for example, with some regional or national broadband networks. Policy makers should be aware of the effects of wholesale networks on competition. Does the wholesale model cover a more extensive part of the communication value chain or only parts of it, such as wholesale access to dark fibre or towers?

All such networks in this category are keen to highlight a split between wholesale and retail operations. However, there are implications for regulation, especially if monopoly power is involved. The more passive a wholesale infrastructure is, the more likely it will encourage new market entry and differentiation in retail competition. The experience of locations such as Stockholm demonstrate that passive infrastructure can help attract new private sector players to create a more vibrant market. These players do not have to build up the entire infrastructure based on their own resources.

In cases of a strong incumbent, a wholesale company can facilitate competition by challenger companies. These companies can compete more easily with the incumbent because the wholesaler typically lowers the challengers' capital expenditures. On the other hand, wholesale models can, even if they only cover part of the value chain, lead to collusion in a market. This is especially the case if it reduces the number of players. These 
concerns increase at higher points of the value chain if the wholesale player has a monopoly. In these cases, the wholesale company has more say over dictating the choices for retail providers and, therefore, end users.

Several observations can be made about the effects for competition of wholesale models that span larger parts of a value chain. First, the expansion of these types of wholesale models could decrease competition as they may reduce the number of parallel networks. In addition, they could dictate communication technologies used in a market. If the number of networks is reduced in a market, regulators must provide strong oversight to avoid regressing into a monopoly situation. However, wholesale-only operators can facilitate competition in a retail market if they provide access on a non-discriminatory basis and at competitive prices.

In addition, wholesale offers must allow retailers to innovate and compete against each other. In this case, some view access to networks as a commodity. This makes wholesaleonly operators more of a utility type of operator, potentially influencing the dynamics of a market. Indeed, some contend this is one of the challenges for such models. They note telecommunication infrastructures can incorporate digital innovation. As such, they should not be referred to as "utilities".

Innovation can occur within telecommunication infrastructures. Proponents of integrated models believe this is better to ensure networks will be upgraded to meet competition and evolving demand. This is why they believe integrated models will better serve emerging developments, such as $5 \mathrm{G}$. This view, however, is at odds with proponents of structural separation for fixed and wireless networks. For the wholesale company, the competitive edge depends on several issues. These include the stage at which the company enters a market, the level of access it offers, market structure and the presence of competitive constraints.

\section{Innovation}

The widely different models used by operators demonstrate and reinforce that innovation can occur at any level of the communication value chain. In markets with end-to-end competition, vertically integrated operators have a strong incentive to innovate to stay competitive. Operators such as Elisa in Finland innovate at network and operational layers to reduce costs and meet new demands. They are also striving to enter new markets such as in banking, advertising, security and insurance. Success in these markets requires bringing their capabilities and skills from providing connectivity, as well as new features.

In addition, traditional communication operators have begun to expand their data analytics businesses to compete with online service providers. Operators will likely continue to increase their presence in this area. As a result, there are likely to be fewer "pure operators". In other words, they will continue to enter new business lines, unless they decide to be wholesale-only players. In the first round of this expansion, operators that were only fixed or wireless networks tended to build or buy a presence in adjacent and converging markets. These presences can be actual or virtual networks. In all cases, the new and existing entrants need to bring innovation to add value to existing offerings.

To date, terminal equipment and online service providers have largely spurred innovation at the application layer. Increasingly, however, they are also becoming important innovators at the network layers. They continue to expand their network infrastructure, invest in content distribution networks, distribute video content more efficiently to allow for the streaming of content at different speeds, etc. 
Policy makers should consider several issues when assessing the role of wholesale operators and their effect on innovation. First, if wholesale providers reduce the number of operators in a market, this could hinder innovation. This is especially the case if the providers using the wholesale network do not have enough flexibility to innovate. If conditions are set efficiently, however, wholesale operators can facilitate new business models in the retail market. In Singapore, for example, a retail provider seemingly has the same ability to innovate as a fully integrated provider.

For innovation towards business customers, one model may not prove more effective than another. They both have potential strengths in an area such as the IoT. An integrated operator, for example, could bring co-ordinated changes to a network faster, to meet demand, than one with multiple parties deciding on factors such as technology and investment. On the other hand, a more disaggregated approach may provide flexibility to the business customer that wants to become its own virtual network.

Finally, compared to network sharing among integrated operators, a wholesale provider independent from other communication companies is arguably less prone to activities leading to collusion. This is because revenues increase with the number of customers and network services purchased by these customers. Against the opportunity to lower costs or generate other advantages, however, providers could lose some of the dynamism and innovation promoted by infrastructure competition. Consensus on the sharing of passive infrastructure is likely to prevail. However, as networks become more virtual, regulators should carefully study reliance on only shared active components.

\section{Investment}

Under any market structure or policy, communication networks have always had to face the question of investment. This will not change in the future. Networks are capitalintensive, and will require private or public sources of investment. Some believe communication infrastructure is a natural monopoly. This may be true in some cases, such as in areas with lower population densities. However, infrastructure competition is thriving in many areas of the OECD; it is still the dominant model for providing services.

Certainly, some types of technology, such as fibre optics, provide virtually unbounded capacity to serve multiple providers. Moreover, network virtualisation may increase options in this direction over a variety of technologies in the future. On the other hand, long experience with communication networks demonstrates that monopoly power does not lead to better policy outcomes. Without alternative networks, for example, there is no guarantee that a monopoly provider will expand, upgrade and innovate at the same pace as one facing competition.

There is also the challenge of ensuring an appropriate level of investment. In times past, regulators of private monopolies used tools such as rate of return regulation to address the absence of market disciplines. These tools were associated with well-known issues around the incentives to under-invest in some areas and to "gold plate" in others. Meanwhile, publicly owned networks historically suffered from under-investment, as they needed to compete against other priorities. These debates still characterise other sectors, where such approaches are used. These are often in markets with far less technological change than the communication industry.

There is no reason that one model will dominate in all countries. Certainly, there are obvious drivers for more infrastructure sharing. Some regions or countries have also found the right formula to make this work given their market conditions. Moreover, market 
players are often taking such decisions as they strive to reduce investment costs. In some areas, for example, they foresee changes to deliver the needed types of infrastructure. These changes could include micro cells for 5G and more fibre backhaul to support them. If they have not already provided such infrastructure for their own needs in the past, they will likely look to share such costs in the future.

Although revenue growth has levelled off in recent years, the size of the overall pie continues to increase. As a result, traditional telecommunication operators continue to invest extensively. They appear to have reasonable returns on these investments, although this has also declined over the years. Ultimately, these private operators need to continue to attract investment from capital markets or from other sources such as public investment. They will therefore need to structure business lines in ways that attract investors with different objectives and levels of risk. Some may opt to split their business into wholesale and retail operations. They will base their decision on the respective appetites of investors and their timelines. Others will continue to compete, in an integrated manner, in what again is a growing market.

For their part, cable broadband companies have frequently invested extensively to upgrade their networks to the latest DOCSIS standards. This has enabled them to remain competitive in some markets and offer the leading speeds in others. Telecommunication operators faced disruptive change with earlier generations of broadband. Similarly, the full weight of higher speeds is now bringing such change to video markets. On the positive side, the demand for their access services continues to increase due to this investment. This is occurring even at a time when their traditional business lines of video services face this disruptive change. In the long run, however, they will need to make similar choices as other broadband networks: will they remain a fully integrated competitor or adopt some other model?

Wholesale-only networks also face a range of choices. For example, they need to decide how much of the value chain to occupy. It must be enough to attract the investment needed by showing capital markets or the public purse that benefits outweigh costs. Some industry drivers seem to be in their favour, such as the need to reduce costs through use of more shared infrastructure. Yet they need flexibility to meet future demand, which has often been well served by integrated providers. As a result, there will be widespread interest in the first deployments of $5 \mathrm{G}$ that use shared infrastructure models that involve independent players. There will also be similar interest in projects such as the Red Compartida in Mexico.

A shared wholesale network potentially lowers the total capital and operating expenses in a market compared to parallel infrastructures. In this way, it reduces investment demands. This can be attractive in some market conditions, such as in an area of lower population densities. It could also appeal where no other competition is likely against an entrenched incumbent who does not have the required investment to meet policy objectives. Companies that connect to wholesale access networks are typically lighter on investment. However, they can generate competition between each other under certain conditions. Specifically, conditions to access the wholesale network would need to be flexible, letting the different retailers innovate. On the other hand, all models have strengths and weaknesses. Much depends on local conditions.

\section{Summing up}

Given that access to infrastructure is a prerequisite for digital transformations, network operators play a key role in this development. They have historically built, invested, 
operated and provided telecommunication services. The migration to all IP networks has decoupled services from transmission. This has fundamentally changed the market, making it possible for applications and content to flow seamlessly across networks.

The report analysed some of the most demanding high-speed users of the Internet - players of video games. This captured key characteristics of future operators as these outliers may provide indicators for more general industry trends. It is almost impossible to foresee what types of services the users of tomorrow will demand. However, countries with a high proportion of next generation networks have likely laid the foundation for the most demanding communities to leverage on the benefits of these networks. This provides an important pillar for digital economies.

This report highlights three overall trends, which influence the dynamics of the market.

i) A broader variety of services from telecommunication operators. Operators are acquiring media companies and Internet firms and moving into new industries. These industries include advertising, banking, health services, home monitoring systems, insurance and sports franchises.

ii) Increased specialisation. The move of wholesale-only operators to share infrastructure partially illustrates the trend towards specialisation. This development covers both fixed and wireless networks. Proponents say it is driven by financial, organisational, regulatory and market factors. It indicates the development towards what they see as a utility-like business model.

iii) Expanded role of terminal equipment and online service providers that now serve end-users. This role is facilitated by applications with a global reach and propelled by the leadership of such providers in $R \& D$ expenditure.

In terms of operators' financial performance, profit margins are relatively stable for the different operator sectors and investment levels are around $15-17 \%$ in relation to sales. Although levels of return had a tendency to decrease, 2017 halted that trend. Telecommunication carriers consistently invest more than cable and satellite operators and incumbents reported higher capex to sales compared to challengers. Overall, telecommunication operators have a number of attributes that will be critical for future developments. Aside from having the financial capabilities to undertake large investments and run large organisations, the reputation of telecommunication operators as trusted and reliable brands is an asset.

There is no single operator of the future, but rather a wide range of types of operators with different roles in providing services. It is critical for policy makers that the sector continues to invest to facilitate new generations of networks. Meanwhile, the available evidence indicates these actors continue to invest in a robust manner. Although profit margins have been under pressure over time, they seem to be relatively healthy across the different types of operators. Still, policy makers should closely monitor developments to facilitate digital transformations in their economies and societies. 


\section{Annex I.A. Selected wholesale-only wireless tower and distributed antenna systems (DAS) operators}

Table A.1. Overview of selected tower companies and DAS operators

\begin{tabular}{|c|c|c|}
\hline & Towers & Background and status \\
\hline $\begin{array}{l}\text { China Tower Co } \\
\text { www.china-tower.com }\end{array}$ & 1886454 & $\begin{array}{l}\text { Founded in 2014, this is a joint venture between the three MNOs in China, which seeded } \\
\text { the company with their towers. They remain shareholders. The company is reported to } \\
\text { control } 95 \% \text { of the towers in the country. The main rationale in creation was said to be } \\
\text { the cost reductions for the MNOs from shared infrastructure. The company was listed on } \\
\text { the Hong Kong, People's Republic of China stock exchange in August } 2018 \text {. The } \\
\text { number of towers shown is for } 31 \text { March } 2018 \text {. }\end{array}$ \\
\hline American Tower & 150000 & $\begin{array}{l}\text { With revenues of USD } 6.6 \text { billion in 2017, the company operates in France, Germany, } \\
\text { India, Ghana, Nigeria, South Africa, Uganda, Argentina, Brazil, Chile, Colombia, }\end{array}$ \\
\hline www.americantower.com & & $\begin{array}{l}\text { Costa Rica, Mexico, Paraguay, Peru and the United States. It is the largest listed tower } \\
\text { company in the world. In addition to towers, the company operates DAS in locations } \\
\text { such as shopping malls. It had more than } 800 \text { locations as at the close of 2017. In 2016, } \\
\text { American Tower purchased FPS Tower, which was at that stage the leading pure-play } \\
\text { telecom tower company in France. It then owned over } 2400 \text { towers, had access to } \\
20000 \text { rooftops across the country and commercialised over } 76500 \text { electricity pylons. } \\
\text { FPS had been created through the acquisition of approximately } 2000 \text { mobile telecom } \\
\text { tower assets from Bouygues Telecom, one of four MNOs in France, in 2012. Meanwhile, } \\
\text { in } 2015 \text {, in the United States, Verizon Wireless agreed to lease the rights to } 11324 \text { of its } \\
\text { towers for an average of } 28 \text { years and sell } 165 \text { additional towers to American Tower. }\end{array}$ \\
\hline www.industowers.com & 122962 & $\begin{array}{l}\text { Indus Towers is a privately owned company in India established in } 2007 \text { to share } \\
\text { infrastructure. It was founded by Bharti Infratel Limited (Airtel) and two MNOs that } \\
\text { currently propose to merge -- Vodafone India and Aditya Birla Telecom (Idea). }\end{array}$ \\
\hline TowerCom (RCom) & 43000 & $\begin{array}{l}\text { The towers and related assets of this Indian provider were purchased by Reliance Jio } \\
\text { towards the close of } 2017 \text {. Reliance Jio is an MNO and the purchase included } \\
122.4 \mathrm{MHz} \text { of } 4 \mathrm{G} \text { spectrum in the } 800,900,1800 \text { and } 2100 \mathrm{MHz} \text { bands, over } \\
43000 \text { towers, nearly } 178000 \text { route km of fibre with a pan India footprint and } 248 \text { media } \\
\text { convergence nodes. It covers } 5 \text { million square feet used for hosting telecom } \\
\text { infrastructure. }\end{array}$ \\
\hline Crown Castle & 40000 & $\begin{array}{l}\text { This company had revenue of USD } 4.3 \text { billion in } 2017 \text {. It sold its Australian towers to a } \\
\text { consortium led by Macquarie Infrastructure, part of an Australian investment bank, in }\end{array}$ \\
\hline www.crowncastle.com & & $\begin{array}{l}\text { 2015. It now operates solely in the United States. It also has approximately } 60000 \text { route } \\
\text { miles of fibre primarily supporting macro and small cell networks. In } 2012 \text {, Crown Castle } \\
\text { purchased } 12000 \text { towers from T-Mobile USA. The following year AT\&T sold and leased } \\
\text { back the rights to about } 9100 \text { of its wireless network towers, for an average length of } \\
28 \text { years, to Crown Castle. It sold another } 600 \text { towers to the tower operator. }\end{array}$ \\
\hline Bharti Infratel & 39009 & $\begin{array}{l}\text { Bharti Infratel, operating in India, also has a } 42 \% \text { stake in Indus Towers with those } \\
\text { towers reported separately here ( } 51547 \text { towers). In 2017, the company had revenue of }\end{array}$ \\
\hline www.bharti-infratel.com & & $\begin{array}{l}\text { USD } 2 \text { billion. In February 2018, the Chair of Bharti Enterprises said he was exploring } \\
\text { merger or sale options. He seeks to exit the tower and related infrastructure business } \\
\text { and focus on connectivity via Airtel, the group's MNO. In 2017, the Group sold a 10.3\% } \\
\text { stake in Bharti Infratel to KKR and the Canada Pension Plan Investment Board. }\end{array}$ \\
\hline Deutsche Funkturm & 28000 & $\begin{array}{l}\text { A member of the Deutsche Telekom (DT) Group, the subsidiary operates towers in } \\
\text { Germany for DT and in part for other companies, including Vodafone and Telefónica. In }\end{array}$ \\
\hline www.dfmg.de & & $\begin{array}{l}\text { 2017, there were reports DT investigated spinning off the company, but this has not } \\
\text { eventuated as yet. Meanwhile, in 2017, Deutsche Telekom Capital Partners (DTCP) } \\
\text { DT's investment management group with USD } 1.5 \text { billion assets under management and } \\
\text { advisory, invested as part of a consortium in buying Sunrise's towers in Switzerland. DT } \\
\text { is not an MNO in Switzerland. }\end{array}$ \\
\hline $\begin{array}{l}\text { GTL Infrastructure } \\
\text { www.gtlinfra.com }\end{array}$ & 28000 & This listed company, operating in India, had revenue of USD 353 million in 2017. \\
\hline SBA Communications & 27909 & $\begin{array}{l}\text { SBA reported USD } 1.7 \text { billion of revenue in } 2017 \text {. Its principal site-leasing business is in } \\
\text { the United States, but it owns and operates towers in South America, Central America, } \\
\text { and Canada. Apart from towers, the company also managed or leased approximately } \\
9000 \text { actual or potential sites, in } 2017 \text {. About } 500 \text { sites produced revenue. }\end{array}$ \\
\hline
\end{tabular}




\begin{tabular}{|c|c|c|}
\hline www.boingo.com & $\begin{array}{l}23500 \\
D A S \text { node }\end{array}$ & $\begin{array}{l}\text { Boingo Wireless, a DAS and Wi-Fi provider, serves carriers, consumers and advertisers } \\
\text { worldwide. As at the close of 2017, there were } 23500 \text { DAS nodes live with another } 11200 \\
\text { nodes in process. Revenue of USD } 204.4 \text { million in } 2017 \text { increased } 28.3 \% \text { compared to } \\
\text { USD } 159.3 \text { million in 2016. Growth was driven by strength in wholesale Wi-Fi, DAS and } \\
\text { the provision of service on military bases. Boingo specialises in the offloading of wireless } \\
\text { traffic in locations such as airports with most locations having at least two MNOs as } \\
\text { customers. }\end{array}$ \\
\hline http://www.ihstowers.com & 23000 & $\begin{array}{l}\text { IHS is the largest independent tower operator in Africa and EMEA. The company } \\
\text { operates in Cameroon, Côte d'Ivoire, Nigeria, Rwanda and Zambia. IHS acquired Helios } \\
\text { Towers, Nigeria in 2016, and announced an agreement in October } 2017 \text { to acquire } \\
\text { Zain's towers in Kuwait, subject to certain regulatory and statutory approvals. IHS is part- } \\
\text { owned by Johannesburg-based MTN, French investment firm Wendel SA and Goldman } \\
\text { Sachs \& Co. Millicom International Cellular SA, which has mobile-phone operations in } \\
\text { Latin America and African countries including Tanzania. Media reports say the company } \\
\text { plans to list on a stock market in } 2018 \text {. }\end{array}$ \\
\hline $\begin{array}{l}\text { Cellnex } \\
\text { www.cellnextelecom.com }\end{array}$ & 27000 & $\begin{array}{l}\text { With revenues of USD } 975 \text { (EUR 789) in 2017, the listed company provides services in } \\
\text { Italy, Netherlands, United Kingdom, France, Switzerland and Spain. }\end{array}$ \\
\hline edotcogroup.com/solutions/towers/ & 26000 & $\begin{array}{l}\text { Founded in 2012, edotco operates towers in Malaysia, Sri Lanka, Bangladesh, } \\
\text { Cambodia, Pakistan and Myanmar. It is a subsidiary of Axiata, which has MNOs in } \\
\text { Malaysia, Indonesia, Sri Lanka, Bangladesh, Cambodia and Nepal, as well as interests } \\
\text { in "Idea" in India and "M1" in Singapore. In early 2018, Bloomberg reported that Axiata } \\
\text { was considering floating the company on the Malaysian stock exchange. }\end{array}$ \\
\hline telxius.com & 16000 & $\begin{array}{l}\text { Majority owned by Telefónica, a } 40 \% \text { stake was sold to KKR, the private equity firm in } \\
2016 \text {. Apart from owning towers in Spain and Latin America, Telxius has approximately } \\
65000 \mathrm{~km} \text { of submarine fibre optic cables. It plans a new undersea cable between Brazil } \\
\text { and the United States, and Europe and the United States. }\end{array}$ \\
\hline www.telesites.com.mx & $\begin{array}{l}14974 \\
\text { (end } \\
2016)\end{array}$ & $\begin{array}{l}\text { Telesites is a listed company, which was spun off from America Móvil. It operates towers } \\
\text { and related businesses in Costa Rica and Mexico. In Mexico, Telesites added } \\
1882 \text { tower sites in 2016, its first year as a separate entity. It provides services to Telcel, } \\
\text { Telefónica and AT\&T, while signing an agreement to offer Altán facilities for the Red } \\
\text { Compartida. In 2016, Telesites also entered the market in Costa Rica, building } 218 \text { new } \\
\text { towers. The Slim family holds } 61 \% \text { of Telesites' capital stock, making them effectively } \\
\text { the principal shareholders. Regarding the preponderance resolution, in Mexico, a } \\
\text { number of measures are applicable to Telesites. These include, but are not limited to, } \\
\text { infrastructure sharing. In } 2016 \text {, Telesites owned } 50 \% \text { of the towers in Mexico. The IFT } \\
\text { had concluded that up until then only half of these sites could support more than one } \\
\text { operator. }\end{array}$ \\
\hline www.ptsmn.co.id & 14500 & $\begin{array}{l}\text { SMN was established in June } 2008 \text { with a primary focus to invest in operating } \\
\text { companies that specialise in owning and operating telecommunication towers for } \\
\text { wireless operators. SMN's activities are conducted through its subsidiary, PT Profesional } \\
\text { Telekomunikasi Indonesia ("Protelindo"). Protelindo, established in 2003, has become } \\
\text { the largest-independent owner and operator of towers for wireless operators in } \\
\text { Indonesia. Protelindo's primary business is leasing space at its multi-tenant tower for all } \\
\text { major wireless operators in Indonesia under long-term lease agreements. The company } \\
\text { was listed on the Indonesian stock exchange in } 2010 \text {. }\end{array}$ \\
\hline www.inwit.it & 11500 & $\begin{array}{l}\text { Infrastrutture Wireless Italiane S.p.A. (INWIT) is the tower unit of Telecom Italia. } \\
\text { Established as a subsidiary in } 2015 \text { and listed on the Italian stock exchange, Telecom } \\
\text { Italia retains a } 60 \% \text { share. }\end{array}$ \\
\hline www.globaltower.com.tr & 10000 & $\begin{array}{l}\text { Global Tower was founded in } 2006 \text { as a subsidiary of Turkcell. It provides site services } \\
\text { to GSM and fixed-based operators, TV \& radio broadcasters, public institutions and } \\
\text { service providers. Global Tower provides services with service points, which includes } \\
\text { tower sites, rooftop and in-building systems. In addition to these sites, Global Tower } \\
\text { provides mobile towers. }\end{array}$ \\
\hline Tillman Infrastructure & 10000 & $\begin{array}{l}\text { Tillman Global Holdings is a US-based global investment firm. Tillman, its portfolio } \\
\text { companies, and associated businesses span five continents and over a dozen countries. } \\
\text { They work in telecommunication infrastructure, owning and managing over } 10000 \\
\text { macro towers, and } 1 \text { million urban locations for small cells, renewable energy and digital } \\
\text { cities. Portfolio companies include Apollo Towers Myanmar and Tillman Infrastructure. In } \\
\text { addition to Tillman Infrastructure, Ahuja's holding company owns JCDecaux-Link, a joint } \\
\text { venture with outdoor advertising company JCDecaux. Together, they provide small cell } \\
\text { sites to carriers. In 2017, AT\&T and Verizon jointly agreed to build hundreds of new cell } \\
\text { towers with Tillman Infrastructure. }\end{array}$ \\
\hline
\end{tabular}




\begin{tabular}{|c|c|c|}
\hline www.arqiva.com & 8000 & $\begin{array}{l}\text { Arqiva is an independent provider of telecommunication towers, with around } 8000 \text { active } \\
\text { licensed sites. The company is the only national provider of terrestrial television and } \\
\text { radio broadcasting in the United Kingdom. It provides services to mobile companies } \\
\text { such as BT-EE, Vodafone, O2 and Three... to independent radio groups and major } \\
\text { broadcasters, such as the BBC, ITV, Sky, Turner and CANAL+... and to utility } \\
\text { companies such as Thames Water. Arqiva is owned by a consortium of investors led by } \\
\text { the Canada Pension Plan Investment Board and Australia's Macquarie Bank. In 2017, it } \\
\text { had revenue of USD } 1.3 \text { billion. }\end{array}$ \\
\hline www.brookfield.com & 7000 & $\begin{array}{l}\text { Brookfield is one of the world's largest investors, owners and operators of infrastructure } \\
\text { assets globally across the utilities, transport, energy, communications infrastructure and } \\
\text { sustainable resources sectors. It owns and operates a portfolio in France that consists of } \\
7000 \text { multi-purpose towers and active rooftop sites, as well as } 5000 \mathrm{~km} \text { of fibre } \\
\text { backbone. }\end{array}$ \\
\hline hwww.heliostowers.com & 6600 & $\begin{array}{l}\text { Formed in 2009, Helious Towers owns about } 6600 \text { telecoms towers in Ghana, } \\
\text { Tanzania, Congo Brazzaville and the Democratic Republic of Congo. It is owned by } \\
\text { telecommunication companies Millicom and Bharti Airtel and hedge funds including } \\
\text { Soros Fund Management and Rothschild Investment Trust Capital Partners. In } 2017 \text {, it } \\
\text { reported revenue of USD } 345 \text { million. Helious has announced plans to launch on the } \\
\text { London Stock Exchange in } 2018 \text {. }\end{array}$ \\
\hline www.cetin.cz & 6000 & $\begin{array}{l}\text { CETIN is the principal mobile service supplier and mobile network provider for } 02 \text { Czech } \\
\text { Republic. It operates the mobile network for T-Mobile Czech Republic in the eastern part } \\
\text { of the Czech Republic. Meanwhile, T-Mobile Czech Republic operates its own mobile } \\
\text { infrastructure in the western part of the country. Mobile network services comprise active } \\
\text { radio access network technology, passive infrastructure, backhaul and IP core. CETIN } \\
\text { provides backhaul services for mobile sites operated by all three major operators, i.e. } \\
\text { O2 Czech Republic, T-Mobile Czech Republic and Vodafone Czech Republic. CETIN's } \\
\text { nationwide network is being consolidated into a network shared with T-Mobile Czech } \\
\text { Republic, which is an MNO. }\end{array}$ \\
\hline $\begin{array}{l}\text { www.capitalgroup.com/pe/portfolio/cipef- } \\
\text { vi/eaton-towers.html }\end{array}$ & 5000 & $\begin{array}{l}\text { Eaton Towers is a pan-African telecommunication tower management company. It } \\
\text { provides shared site and tower services for telecom network operators by building, } \\
\text { acquiring and maintaining passive telecommunication infrastructure assets. The } \\
\text { company has approximately } 5000 \text { towers across five countries. Eaton Towers is also } \\
\text { said by media reports to be considering a float in } 2018 \text {. }\end{array}$ \\
\hline www.verticalbridge.com & 3198 & $\begin{array}{l}\text { After American Tower, Crown Castle and SBA Communications, Vertical Bridge is the } \\
\text { largest tower operator that is not an MNO. A list of other United States tower providers } \\
\text { can be found here: http://wirelessestimator.com/top-100-us-tower-companies-list/ }\end{array}$ \\
\hline http://en.rtowers.ru & 3000 & $\begin{array}{l}\text { Formed in } 2009 \text {, the Russian Towers Group invests in construction and acquisition of } \\
\text { tower structures of different designs in the Russian Federation and ensures their } \\
\text { maintenance and operation. In 2017, it was reportedly purchasing Vimplecom's } 12000 \\
\text { to } 13000 \text { towers. However, the deal does not appear to have been concluded. }\end{array}$ \\
\hline ALTÁN Redes & 2500 & $\begin{array}{l}\text { ALTÁN Redes is the company rolling out the wholesale-only shared network in Mexico } \\
\text { for use by MNOs and MVNOs (Red Compartida). By early 2018, the company reported } \\
2500 \text { towers ready for activation with the assistance of Telefónica, Mexico. }\end{array}$ \\
\hline Axicom & 2000 & $\begin{array}{l}\text { Axicom operates and manages a portfolio of approximately around } 2000 \text { towers in } \\
\text { Australia. }\end{array}$ \\
\hline \multicolumn{3}{|l|}{ www.axicom.com.au } \\
\hline Macquarie Infrastructure and Real Asset & $\begin{array}{l}1700 \\
(2015)\end{array}$ & $\begin{array}{l}\text { The Macquarie Group has co-ownership or investments in tower companies around the } \\
\text { world. It also purchased } 1700 \text { towers serving the then three MNOs in Australia. }\end{array}$ \\
\hline \multicolumn{3}{|l|}{ www.mirafunds.com } \\
\hline Mexico Tower Partners (MTP) & 1700 & $\begin{array}{l}\text { MTP builds, owns, manages and leases telecommunication towers in Mexico. The } \\
\text { infrastructure is installed on rooftops, offices, hotels, industrial warehouses, storage } \\
\text { facilities and shopping centres. It is leased to telecommunication carriers and other } \\
\text { wireless technology users. Established in 2014, MTP is a joint venture between Digital } \\
\text { Bridge LLC and Fondo de Infraestructura Macquarie México (MMIF). }\end{array}$ \\
\hline
\end{tabular}




\section{References}

Agence Ecofin (2018), "Orange prévoit de lancer sa banque en Afrique, d'ici la fin de l'année 2018”, 29 March 2018, https://www.agenceecofin.com/operateur/2903-55654-orangeprevoit-de-lancer-sa-banque-en-afrique-d-ici-la-fin-de-l-annee-2018.

Agulhon, V. (2016), “What is spatial computing?", Medium, 14 July 2016, https://medium.com/@victoragulhon/what-is-spatial-computing-777fae84a499.

Al Ali, N. and I. Khrennikov (2018), "Telegram on track to push its cryptocurrency sale to $\$ 1.7$ billion", Bloomberg, 3 March 2018, https://www.bloomberg.com/news/articles/2018-0323/telegram-seen-successful-in-boosting-crypto-sale-to-1-7-billion.

Alabaster, J. (2013), "Sony ISP launches world's fastest home Internet, 2Gbps", Computerworld, 15 April 2013, https://www.computerworld.com/article/2496671/wireless-carriers/sony-isplaunches-world-s-fastest-home-internet-2gbps.html\#39;s\%20fastest \%20for\%20home\%20use.

Amazon.com (2018), “Amazon.com announces fourth quarter sales up 38\% to \$60.5 billion”, 1 February 2018, Press Release, Amazon.com, Seattle, https://www.businesswire.com/news/home/20180201006454/en/Amazon.com-AnnouncesFourth-Quarter-Sales-3860.5\#targetText=Common\%20shares\%20outstanding\%20plus\%20shares,497\%20million \%20 one $\% 20$ year\%20ago.\&targetText $=$ Net $\% 20$ sales $\% 20$ increased $\% 2038 \% 25 \% 20$ to,billion $\% 2$.

Ammbr (2017), "Share WiFi with Neighbours and the Community. Get Paid", webpage (accessed 4 April 2018), https://www.ammbr.com/.

ARCEP (2018), Devices, the Weak Link in Achieving an Open Internet, ARCEP, Paris, https://www.arcep.fr/uploads/tx_gspublication/rapport-terminaux-fev2018-ENG.pdf.

AT\&T (2018), 2017 Annual Report, AT\&T, Dallas, https://investors.att.com/ /media/Files/A/ATT-IR/financial-reports/annualreports/2017/complete-2017-annual-report.pdf.

AT\&T (2015), “AT\&T completes acquisition of DIRECTV”, 24 July 2015, Press Release, AT\&T, Dallas, http://about.att.com/story/att completes acquisition of directv.html.

Bazelon, C. and P. Seth (2017), "Brattle report discusses the impact of the wirelees infrastructure industry on the US economy", Brattle News, 11 July 2017.

Bennett, B. (2018), "Spark doubles down on wireless broadband", Bill Bennett, 24 January 2018, https://billbennett.co.nz/spark-wireless-broadband-strategy/.

Bondain, A. (2018), “Orange Bank, une offre à prendre au sérieux, selon UBS”, Boursier.com, https://www.boursier.com/actions/actualites/news/orange-bank-une-offre-a-prendre-auserieux-selon-ubs-761123.html. 
Boxall, A. (2 February 2018), “Take a hike, Alexa: Wendy's a digital human ready to be your friend", Digital Trends blog, https://www.digitaltrends.com/mobile/sk-telecom-realityreflections-holobox/.

BT (2018), BT to invest in tech talent with creation of over 1,300 graduates and apprenticeship jobs, http://home.bt.com/tech-gadgets/tech-news/bt-recruit-1300-graduates-and-apprentices11364259426267 (accessed on 4 April 2018).

Buckley, S. (2018), "Verizon Fios, Microsoft Xbox lure gamers with $\$ 79$ gigabit broadband offer", FierceTelecom, 6 April 2018, https://www.fiercetelecom.com/telecom/verizon-fiosxbox-lures-gamers-79-gig-broadband-offer.

Busvine, D. (2018), "Airtel wants to get out of telecom towers, plans Africa unit IPO”, livemint, 28 February 2018, https://www.livemint.com/Companies/a5ucZXsjLqG8qLI6qsev5M/Airtelwants-to-get-out-of-telecom-towers-plans-Africa-unit.html.

Cantoni, N. (2018), Kids thought of Jio in 2011: Mukesh Ambani, Times of India, https://timesofindia.indiatimes.com/business/india-business/kids-thought-of-jio-in-2011mukesh-ambani/articleshow/63339575.cms (accessed on 4 April 2018).

CETIN Finance (2016), Base Prospectus for a 2 billion Euro Medium Term Note Programme, https://www.cetin.cz/documents/10182/53953/20161117+CETIN+Finance+B.V.+prospectus. pdf/6c04f24e-9858-4af1-a0e9-80a672670e6d.

Chin, H. (2017), "NetLink NBN Trust's IPO: A brief walk through history", The Motley Fool, 30 June 2017, https://www.fool.sg/2017/06/30/netlink-nbn-trusts-ipo-a-brief-walk-throughhistory/.

Colt Technology (2018), "Colt and PCCW Global demonstrate speedy payment settlements using blockchain technology", Colt, 13 March 2018, https://www.colt.net/resources/colt-andpccw-global-demonstrate-speedy-payment-settlements-using-blockchain-technology/.

Crown Castle International (2017), Form 10-K Annual Report pursuant to Section 13 OR 15(d) of the Securities Exchange Act of 1934 for the fiscal year ended December 31, 2016, United States Securities and Exchange Commission, Washington, D.C.

DCCAE (2018), "NBP latest news", Department of Communications, Climate Action and Environment of Ireland, Department of Communications, Climate Action and Environment of Ireland, Dublin, https://www.dccae.gov.ie/en-ie/communications/topics/Broadband/nationalbroadband-plan/latest-news/Pages/Latest-News.aspx.

Dillet, R. (2017), "Shadow raises $\$ 57$ million for its cloud computing service for gamers", Techcrunch, 14 June 2017, https://techcrunch.com/2017/06/14/shadow-raises-57-million-forits-cloud-computing-service-for-gamers/.

edotco (2017), "edotco unveils 'smart lamp pole' initiative", edotco, 20 December 2017, http://edotcogroup.com/media/edotco-unveils-smart-lamp-pole-initiative/.

Elisa (2018), Elisa Operational Data 2017, database (accessed 20 March 2018), http://corporate.elisa.com/attachment/content/Elisa-Operational-Data-Q4-2017.xlsx. 
Elisa (2018), Financial Results 2017,

http://corporate.elisa.com/attachment/content/FINANCIAL-RESULTS-2017.pdf.

Elisa (2018), “Investors: Key Figures”, webpage (accessed 21 March 2018), http://corporate.elisa.com/investors/key-figures/.

Elisa (2017), "Saunalahti-puhelinliittymät (Saunalahti telephone connections)", webpage (accessed 3 April 2018), https://elisa.fi/kauppa/\#!/puhelinliittymat.

Engerati (2018), "Can telcos be the new contenders in the smart homes space?", Engerati, 27 June 2018, https://www.engerati.com/smart-infrastructure/article/smart-homes/can-telcos-benew-contenders-smart-homes-space.

Fox, J. (2018), “Amazon's great R\&D gift to the nation”, Bloomberg, 5 April 2018, https://www.bloomberg.com/opinion/articles/2018-04-05/amazon-s-technology-and-contentspending-a-huge-gift-to-economy.

Geek Wire (2017), Valve reveals Steam's monthly active user count and game sales by region, https://www.geekwire.com/2017/valve-reveals-steams-monthly-active-user-count-gamesales-region/.

Goodfellow, M. (2018), Facebook content chief hails rise of "social entertainment".

Google (2018), "Project Fi: Phone Plans and Prices", webpage (accessed 9 April 2018), https://fi.google.com/about/plan/.

Grunin, L. (2018), "Cloud Gaming Inches Forward but the Roadblocks Remain”, CNET, webpage (accessed 30 January 2018), https://www.cnet.com/news/cloud-gaming-inchesforward-but-the-roadblocks-remain/.

Gupta, A. and P. Auerswald (2017), "How India is moving toward a digital-first economy", Harvard Business Review, 8 November 2017, https://hbr.org/2017/11/how-india-is-movingtoward-a-digital-firsteconomy?utm_source $=$ twitter\&utm_medium $=$ social\&utm_campaign $=$ hbr.

Hardawar, D. (2018), "NVIDIA proves the cloud can replace a high-end gaming rig", Engadget, 31 January 2018, https://www.engadget.com/2018/01/31/nvidia-geforce-now-pc/.

Hardy, S. (2017), "BT tests superchannel, 100-Gbps broadband optical network technologies", Lightwave, 12 June 2017, http://www.lightwaveonline.com/articles/2017/06/bt-testssuperchannel-100-gbps-broadband-optical-network-technologies.html.

Horwitz, J. (2018), “MWC 2018: SK Telecom will demo 5G social VR”, Venturebeat, 27 February 2018, https://uploadvr.com/mwc-2018-sk-telecom-will-demo-5g-social-vr/.

IndiaStack (2018), “What is India Stack?”, webpage (accessed 25 March 2018), http://indiastack.org/about/. 
Init7 (2018), "Fiber7 - Gigabit-Glasfaser-Internet von Init7 zum konkurrenzlosen PreisLeistungs-Verhältnis (Fiber7 - Gigabit optical fibre at unrivaled value for money)", Init7, webpage (accessed 3 April 2018), https://www.init7.net/de/internet/fiber7/.

Jacobsen, S. and J. Hellstrom (2018), “TDC backs \$6.7 billion takeover offer from Macquarieled consortium", Reuters, 12 February 2018, https://www.reuters.com/article/us-tdc-m-a/tdcbacks-6-7-billion-takeover-offer-from-macquarie-led-consortium-idUSKBN1FW0ST.

Jungermann, F. (2018), “The secret behind Elisa's financials”, teficient, 4 February 2018, https://tefficient.com/the-secret-behind-elisas-financials/.

Kennedy, J. (2018), "Irish government vows to press ahead with national broadband plan", siliconrepublic, 31 January 2018, https:/www.siliconrepublic.com/comms/nationalbroadband-plan-naughten-eir-enet-sse.

KOSC Telecom (2018), "The New French Telecom Operator Dedicated to the Wholesale Business Connectivity", webpage (accessed 3 April 2018), http://www.kosctelecom.fr/en/home/.

KOSC Telecom (2017), "KOSC Telecom launches its B2B network", Press Release, 31 March 2017, https://www.kosc-telecom.fr/wp-content/uploads/2019/05/PR-31.03.2017-KOSCWholesale-Telecoms-Launch.pdf.

Lal, A. (2018), "Will the PS5 and next Xbox be the final physical consoles?", GamingBolt, 6 February 2018, https://gamingbolt.com/will-the-ps5-and-next-xbox-be-the-final-physicalconsoles\#43GVgmolGU0PF15j.99.

Lepido, D. (2018), "Telecom Italia board approves national landline network spinoff", Bloomberg, 6 March 2018, https://www.bloomberg.com/news/articles/2018-03-06/telecomitalia-board-approves-national-landline-network-spinoff.

Lindler, J. (1 August 2017), “Kooperation von Telefónica NEXT und Intraplan: Big-DataAnalysen für Verkehr in München (Cooperation of Telefónica Next and Intraplan: Big data analyses for traffic in Munich)", Telefónica Deutschland blog, https://blog.telefonica.de/2017/08/kooperation-von-telefonica-next-und-intraplan-big-dataanalysen-fuer-verkehr-in-muenchen/.

Marek, S. (2015), "Verizon offloads towers to American Tower for \$5B", FierceWireless, 5 February 2015, https://www.fiercewireless.com/wireless/verizon-offloads-towers-toamerican-tower-for-5b.

Mattila, V. (2018), "CEO's review: Excellent demand for Elisa's Premium subscriptions with unlimited data use in the Nordic and Baltic countries", Interim Report, Q1 2019, Elisa, http://corporate.elisa.com/investors/investor-facts/ceos-review/.

Mauldin, A. (2017), “A Complete List of Content Providers' Submarine Cable Holdings", TeleGeography, blog, https://blog.telegeography.com/telegeographys-content-providerssubmarine-cable-holdings-list. 
Microsoft (2017), Fourth Quarter Fiscal Year 2017 Results, Microsoft, https://view.officeapps.live.com/op/view.aspx?src=https://c.s-microsoft.com/enus/CMSFiles/SlidesFY17Q4.pptx?version=c9735c19-0baa-103d-2a4e-bacd46514428.

Mobile Europe (2018), "Operator turns vendor as Elisa offers new SON solution to rivals", Mobile Europe, 14 February 2018, https://www.mobileeurope.co.uk/news-analysis/operatorturns-vendor-as-elisa-offers-new-son-solution-to-rivals.

Moody's (2017), Elisa Corporation: Update to Discussion of Key Credit Factors, Moody's Investors Service, New York, http://corporate.elisa.fi/attachment/content/Elisa-COPublished-21-April-2017.pdf.

Morgan, T. (2013), “OnLive boosts quality: Is cloud gaming now viable?”, Eurogamer, 11 April 2013, https://www.eurogamer.net/articles/digitalfoundry-onlive-boosts-image-quality.

MyRepublic (2018), "GAMER Features”, webpage (accessed 3 April 2018), https://myrepublic.net/sg/gamer-features/.

NBN Co (2019), Weekly Progress Report, https://www.nbnco.com.au/corporateinformation/about-nbn-co/corporate-plan/weekly-progress-report.

Netflix (2018), “Internet Connection Speed Recommendations”, webpage (accessed 3 April 2018), https://help.netflix.com/en/node/306.

Netflix (2018), "Netflix ISP Speed Index”, webpage (accessed 3 April 2018), https://ispspeedindex.netflix.com/.

Netflix (2017), fourth quarter earnings 2017, https://www.netflixinvestor.com/financials/quarterly-earnings/default.aspx.

Networks, C. (2019), www.common.net.

NPR (2018), “The Science in Science Fiction”, Podcast, 22 October 2018, https://www.npr.org/templates/story/story.php?storyId=1067220.

NVIDIA (2018), "GeForce NOW Cloud Gaming for Mac", webpage (accessed 3 April 2018), https://www.nvidia.com/en-us/geforce/products/geforce-now/mac-pc/.

NVIDIA (2018), “GeForce NOW System Requirements”, webpage (accessed 3 April 2018), https://shield.nvidia.com/support/geforce-now/system-requirements/2.

O2 Czech Republic (2017), Annual Report 2017, O2 Czech Republic, Prague, https://www.o2.cz/file_conver/578992/VZ_2017_EN_20_2.pdf.

OECD (2017), OECD Digital Economy Outlook 2017, OECD Publishing, Paris, http://dx.doi.org/10.1787/9789264276284-en. 
OECD (2015), Development of High Speed Networks and the Role of Municipal Networks, OECD, Paris, http://www.oecd.org/officialdocuments/publicdisplaydocumentpdf/?cote=DSTI/ICCP/CISP $\%$ 282015\%291/FINAL\&docLanguage $=$ En.

OECD (2001), "The development of broadband access in the OECD countries", OECD Digital Economy Papers, No. 56, OECD Publishing, Paris, http://dx.doi.org/10.1787/233822327671.

Pearce, J. (2018), "Google unveils new regions and subsea investments as part of \$30bn infrastructure drive", Capacity, 16 January 2018, http://www.capacitymedia.com/Article/3780812/Google-unveils-new-regions-and-subseainvestments-as-part-of-30bn-infrastructure-drive.

Preston, D. (2018), "Shadow streaming service review: Hands-on", Tech Advisor, 26 January 2018, https://www.techadvisor.co.uk/review/gaming-pcs/shadow-streaming-service-reviewhands-on-3670984/.

PwC (2017), Global Top 100 Companies by Market Capitalisation.

Radich, K. (2018), "What Technology does Common Networks use?", webpage (accessed 30 August 2018), https://support.common.net/hc/en-us/articles/115001648008-What-technologydoes-Common-Networks-use-.

Richard, S. and R. Fernandez (2018), Résultats financiers d'Orange, Orange, https://www.orange.com/fr/content/download/46099/13574666/version/2/file/FY17\%20Presen tation $\% 20-\% 20 \mathrm{FR} \% 20-\% 20 \mathrm{vDef} . \mathrm{pdf}$.

Salt (2018), "Salt ready to conquer the Swiss fixed net market with its revolutionary Fiber Box", 20 March 2018, Press Release, https://www.salt.ch/media/press/files/2018/3/20/b3fec24bb191-4833-af09-eab49fa6d3ed/354/Salt_Salt\%20Fiber\%20Summary_EN.pdf.

Sawers, P. (2018), "Google invests in 6,000-mile subsea cable system connecting Japan to Australia", VentureBeat, 4 April 2018, https://venturebeat.com/2018/04/04/google-invests-in6000-mile-subsea-cable-system-connecting-japan-with-australia/.

SFN (2014), Init7 und SFN AG unterzeichnen Glasfaser-Zugangsvertrag, http://www.swissfibrenet.ch/en/medien/medienberichte/SFN_Init7 Medienmitteilung 19092 014 final.pdf (accessed on 3 April 2018).

SIRO (2018), "SIRO Powered Broadband", webpage (accessed 3 April 2018), https://siro.ie/.

Song, S. (2017), "KT, Verizon test world's first 5G live hologram call”, Korea Herald, 3 April 2017, http://www.koreaherald.com/view.php?ud=20170403000999.

Sony (2017), Corporate Strategy Meeting, Sony Corporation, Tokyo, https://www.sony.net/SonyInfo/IR/library/presen/strategy/2017/presen_E.pdf.

Sony Network Communications (2018), "NURO 10G”, webpage (accessed 3 April 2018), https://www.nuro.jp/10g/. 
Sterling, G. (2016), "Google says 20 percent of mobile queries are voice searches”, Search Engine Land, 18 May 2016, https://searchengineland.com/google-reveals-20-percent-queriesvoice-queries-249917.

Sunrise (2018), "Sunrise expands its fiber optics partnerships with SFN, IWB and SIG", 1 March 2018, Press Release, Sunrise, Zurich, https://www.sunrise.ch/en/corporatecommunications/medien/press-releases.html.

Sunrise (2015), "Sunrise expands the 4G network in key towns and cities", 15 February 2015, Press Release, Sunrise, Zurich, https://corporate.sunrise.ch/media/press-releases/prstory?storyId $=821 \quad 1060 \quad 1 \mathrm{cb} 0 \mathrm{z} 0$.

Superloop (2018), “About Superloop”, webpage (accessed 3 April 2018), https://www.superloop.com/company/.

TDC Group (2018), “TDC: TDC Group changes its organisation in Denmark”, 28 June 2018, Press Release, https://tdcgroup.com/en/investor-relations/announcement-list.

Telecompaper (2018), "Cellnex to rent out Italian towers to Iliad - report", Telecompaper, 19 February 2018, https://www.telecompaper.com/news/cellnex-to-rent-out-italian-towers-toiliad-report--1232518.

Telefónica (2018), “Telefónica launches Aura and leads the integration of artifical intelligence in its networks and customer care", 25 February 2018, Press Release, Telefónica, Madrid, https://www.telefonica.com/en/web/press-office/-/telefonica-launches-aura-and-leads-theintegration-of-artifical-intelligence-in-its-networks-and-customer-care.

Telefónica (2017), "DGAP-News: Telefónica Deutschland Holding AG: Preliminary results for January to September 2017”, Telefónica, 25 October 2017, Press Release, Telefónica, Madrid, https://www.telefonica.de/fixed/news/6076/dgap-news-telefonica-deutschlandholding-ag-preliminary-results-for-january-to-september-2017.html.

TeleGeography (2016), “ARSAT to helm USD 300 M rural fibre project”, TeleGeography CommsUpdate, 6 April 2016, https://www.telegeography.com/products/commsupdate/articles/2016/04/06/arsat-to-helmusd300m-rural-fibre-project/.

Telegram (30 March 2017), "Voice calls: Secure, crystal-clear, AI-powered", Telegram blog, https://telegram.org/blog/calls.

Telenor Sweden (2018), “About Us”, webpage (accessed 3 April 2018), https://www.telenor.com/about-us/global-presence/sweden/.

TELUS (2017), TELUS 2017 Annual Report, TELUS, Vancouver, https://assets.ctfassets.net/rz9m1rynx8pv/30cPueYwwUSuysoSSeE6oe/4bc06c10c67a516f4ff 77e2ef72bb0d7/TELUS 2017 annual_report-for_online.pdf.

Tiffany, K. (2017), Facebook is remaking the viral Norwegian teen drama Skam. 
Traficom (2018), "Market shares of fixed network broadband subscriptions", webpage (accessed 3 April 2018), https://www.viestintavirasto.fi/en/statisticsandreports/statistics/2013/marketsharesoffixednet workbroadbandsubscriptions.html.

Traynor Sloss, B. (16 January 2018), "Expanding our global infrastructure with new regions and subsea cables", Google blog, https://www.blog.google/topics/google-cloud/expanding-ourglobal-infrastructure-new-regions-and-subsea-cables/.

ufinet (2018), "Dark Fiber", webpage (accessed 3 April 2018), https://www.ufinet.com/index.php/services/?lang=en/\&lang=en/\#SectionDarkFiber.

ufinet (2018), "Ufinet - Our team of professionals in fiber optic", webpage (3 April 2018), https://www.ufinet.com/index.php/our-team/?lang=en/\#SectionOurLeadership.

United Nations (2017), World Population Prospects: The 2017 Revision, database, (accessed 25 March 2018), https://esa.un.org/unpd/wpp/DataQuery/.

VAB (2018), You Down With OTT? An Overview of the Competitive Video Ecosystem, Video Advertising Bureau, New York, http://www.thevab.com/wp-content/uploads/2018/03/OTTEcosystem-Overview-Final.pdf.

Van den Dam, R. (3 January 2018), "Blockchain in telecom: From concept to reality", IBM Telecom, Media and Entertainment blog, https://www.ibm.com/blogs/insights-onbusiness/telecom-media-entertainment/blockchain-telecom-concept-reality/.

Vartleet, L. (2017), Why you should be watching Skam, Tumblr's most talked about TV show of 2017.

Verizon (2018), "Giving people the ability to do more", Annual Report, Verizon, New York, http://www.verizon.com/about/sites/default/files/2017VerizonAnnualReport.pdf.

Verizon (2017), “AT\&T, Verizon and Tillman Infrastructure announce collaboration to build hundreds of cell towers", 13 November 2017, Press Release, Verizon, New York, https://www.verizon.com/about/news/att-verizon-and-tillman-infrastructure-announcecollaboration-build-hundreds-cell-towers.

Virk, R. (2018), How blockchain could kill both cable and Netflix, VentureBeat, https://venturebeat.com/2018/01/28/how-blockchain-could-kill-both-cable-and-netflix/ (accessed on 5 April 2018).

Williams, C. (2017), "Three plans to blanket cities with 5G network", The Telegraph, 1 May 2017, https:/www.telegraph.co.uk/business/2017/05/01/three-plans-blanket-cities-5gnetwork/.

Wireless Infrastructure Group (2015), Indoor Networks, http://www.wirelessinfrastructure.co.uk/indoor-networks/ (accessed on 4 April 2018). 


\section{Notes}

${ }^{1}$ Other measures include, for example, latency or assurance of error-free delivery (see also Box 1 of the report).

${ }^{2}$ Bloomberg is a company specialised in financial information and news media. Their classification system is called BICS, Bloomberg Industry Classification System.

${ }^{3}$ Sony does not break out the financial data for its Sony Networks business. This, however, does not significantly affect the results. The company represents only $3.6 \%$ of total operator revenues in the sample in 2017.

${ }^{4}$ Round trip time for information between two devices across the network - Latency.

${ }^{5}$ Data Packets lost on the providers and partners networks - Packet Loss.

${ }^{6}$ Akamai is a content delivery network and has over 240000 servers in more than 130 countries.

${ }^{7}$ Korea's three operators, DACOM Corp., LG Powercomm, and LG DACOM Corporation merged to become LG Telecom in 2010, which is now called "LGU+".

8 The technologies are described here: http://www.ad-net.com.tw/gpon-vs-gepon-whats-thedifference-advantages-of-gepon-over-gpon/

${ }^{9}$ The credit card and the mobile payment functions are free of charge if at least three payments are made per month.

10 The players mentioned can be found at: https://livepeer.org, https://view.ly, https://streamtoken.net, https://lbry.io, https://www.thetatoken.org and https://www.propsproject.com

${ }^{11}$ Amounted to AUS 76 million H1, FY 2015. Telstra half year 2015 results announcement.

12 Enet's website is at: http://www.enet.ie/carriers/wholesale-products/dark-fibre.html. The Irish Infrastructure Fund private equity fund. which is managed by Irish Life Investment Managers and Australian investor AMP Capital: http://www.ampcapital.com.au/article-detail?alias=\%2Fsiteassets $\% 2$ Farticles $\% 2$ Fmedia-releases $\% 2$ F2017\%2F2017-07\%2Firish-infrastructure-fund-acquiresmajority-stake

${ }^{13}$ A REIT is a company that owns, operates or finances income-producing real estate. Variations of the model are widely used around the world. See for example: https://en.wikipedia.org/wiki/Real_estate_investment_trust

${ }^{14}$ GTL Infrastructure Ltd. describes its business on its website: http://www.gtlinfra.com/about-us/

${ }^{15}$ Stokab was registered as a company in 1993.

16 Amazon does not report R\&D spending. In its earning statement, it has an item termed "technology and content" that has been accepted by many as a proxy, although it is not $100 \%$ the same. The definition of this item by Amazon: "Technology costs consist principally of research and development activities including payroll and related expenses for employees involved in application, production, maintenance, operation, and development of new and existing products and services, as well as AWS [Amazon Web Services] and other technology infrastructure costs. Content costs consist principally of payroll and related expenses for employees involved in category expansion, editorial content, buying, and merchandising selection." Spending on the movies and TV series streamed on Amazon Prime are not considered under this item. 